\title{
Single-cell profiling of healthy human kidney reveals features of sex-based transcriptional programs and tissue-specific immunity
}

Authors: Caitriona M. McEvoy ${ }^{\dagger 1,2,3}$, Julia M. Murphy ${ }^{\dagger 1,2,4}$, Lin Zhang $^{5}$, Sergi Clotet-Freixas ${ }^{\wedge 1,2}$, Jessica A. Mathews ${ }^{\wedge 1,2}$, James $\mathrm{An}^{1,2,4}$, Mehran Karimzadeh ${ }^{6}$, Delaram Pouyabahar ${ }^{7,8}$, Shenghui Su ${ }^{1,2}$, Olga Zaslaver $^{7,8}$, Hannes Röst ${ }^{7,8}$, Madhurangi Arambewela ${ }^{1,2}$, Lewis Y. Liu ${ }^{1,2,4}$, Sally Zhang ${ }^{12}$, Keith A. Lawson $^{12}$, Antonio Finelli ${ }^{12}$, Bo Wang $6,9,10,11$, Sonya A. MacParland ${ }^{1,2,4,10}$, Gary D. Bader ${ }^{7,8,12,13}$, Ana Konvalinka ${ }^{*}, 1,2,3,10,14$, Sarah Q. Crome ${ }^{*}, 1,2,4$

\section{Affiliations:}

${ }^{1}$ Toronto General Hospital Research Institute, University Health Network; Toronto, ON, Canada.

${ }^{2}$ Ajmera Transplant Centre, University Health Network; Toronto, ON, Canada.

${ }^{3}$ Department of Medicine, Division of Nephrology, University Health Network; Toronto, ON, Canada.

${ }^{4}$ Department of Immunology, University of Toronto; Toronto, ON, Canada.

${ }^{5}$ Department of Statistical Sciences, University of Toronto; Toronto, ON, Canada.

${ }^{6}$ Vector Institute; Toronto, ON, Canada.

${ }^{7}$ Department of Molecular Genetics, University of Toronto; Toronto, ON, Canada.

${ }^{8}$ The Donnelly Centre, University of Toronto; Toronto, ON, Canada.

${ }^{9}$ Department of Computer Science, University of Toronto; Toronto, ON, Canada.

${ }^{10}$ Department of Laboratory Medicine and Pathobiology, University of Toronto; Toronto, ON, Canada.

${ }^{11}$ Peter Munk Cardiac Centre, University Health Network; Toronto, ON, Canada.

${ }^{12}$ Princess Margaret Cancer Centre, University Health Network; Toronto, ON, Canada

${ }^{13}$ The Lunenfeld-Tanenbaum Research Institute, Mount Sinai Hospital; Toronto, ON, Canada

${ }^{14}$ Institute of Medical Science, University of Toronto; Toronto, ON, Canada.

+ co-first authorship

* co-corresponding authorship

$\wedge$ equal contribution

*co-corresponding authors:

Sarah Q. Crome (sarah.crome@utoronto.ca)

Ana Konvalinka (Ana.Konvalinka@uhn.ca)

ORCID identifiers:

CMM 0000-0002-3179-5542

JMM 0000-0002-0617-1666

SCF 0000-0002-6965-4403

JAM 0000-0003-2926-8222

MK 0000-0002-7324-6074

SAM 0000-0002-8036-1425

GDB 0000-0003-0185-8861

AK 0000-0001-6672-355X

SQC 0000-0001-5117-7453

Word Count: 3950 in Main Text + 4203 Methods 


\section{Abbreviations}

\begin{tabular}{ll} 
AUC & Area under the curve \\
CCD & Cortical collecting duct \\
CNT & Connecting tubule \\
CTAL & Cortical thick ascending limb of the loop of Henle \\
DC & Dendritic cell \\
DCT & Distal convoluted tubule \\
Endo & Endothelial \\
IC-A & Intercalated cells type A \\
IC-B & Intercalated cells type B \\
IRI & Ischemia-reperfusion injury \\
LogFC & Log Fold Change \\
MP & Mononuclear phagocyte \\
MHC & Major histocompatibility complex \\
NK cell & Natural killer cell \\
Non-PT & Non proximal tubular parenchymal cell \\
PBMCs & Peripheral blood mononuclear cells \\
PGE2 & Prostaglandin E2 \\
PT & Proximal tubule \\
RBC & Red blood cell \\
SCRNAseq & Single cell RNA sequencing \\
STC & Scattered tubular cell \\
TCA & Tricarboxylic Acid \\
TCR & T cell receptor \\
\hline
\end{tabular}




\section{Abstract}

2 Maintaining organ homeostasis requires complex functional synergy between distinct cell types, a

3 snapshot of which is glimpsed through the simultaneously broad and granular analysis provided by

4 single-cell atlases. Knowledge of the transcriptional programs underpinning the complex and

5 specialized functions of human kidney cell populations at homeostasis is limited by difficulty

6 accessing healthy, fresh tissue. Here, we present a single-cell perspective of healthy human kidney

7 from 19 living donors, with equal contribution from males and females, profiling the transcriptome

8 of 27677 high-quality cells to map healthy kidney at high resolution. Our sex-balanced dataset

9 revealed sex-based differences in gene expression within proximal tubular cells, specifically, increased anti-oxidant metallothionein genes in females and the predominance of aerobic

11 metabolism-related genes in males. Functional differences in metabolism were confirmed between male and female proximal tubular cells, with male cells exhibiting higher oxidative phosphorylation and higher levels of energy precursor metabolites. Within the immune niche, we identified kidneyspecific lymphocyte populations with unique transcriptional profiles indicative of kidney-adapted functions and validated findings by flow cytometry. We observed significant heterogeneity in resident myeloid populations and identified an $M R C 1^{+} L Y V E 1^{+} F O L R 2^{+} C 1 Q C^{+}$population as the 


\section{Introduction}

The complex functions of the kidney that maintain body homeostasis are executed by a diverse range of specialized parenchymal cells residing in distinct compartments. Within tissues, resident immune populations function in surveillance, maintenance of self-tolerance, response to infection and injury, and interface with parenchymal cells to maintain tissue homeostasis ${ }^{1-3}$. There is limited understanding of this network of kidney parenchymal and resident immune cells in humans due to lack of access to healthy, fresh tissue. Much of our knowledge is based on studies that used kidneys rejected for transplant or tumour-adjacent nephrectomy specimens, where parenchymal populations can have altered molecular programs, and immune populations and their signalling circuits may not be entirely reflective of the steady-state ${ }^{4,5}$. Further, sex-based dichotomy in gene expression within human kidney cell populations has not been thoroughly examined, but is of great significance to acute and chronic kidney disease, ischemia-reperfusion injury (IRI) and progression of diabetic kidney disease, which exhibit a male preponderance ${ }^{6-8}$.

Here we present a detailed atlas of healthy human kidney using single cell RNA sequencing (scRNAseq) of living donor kidney biopsies, capturing parenchymal and immune cell transcriptomes reflective of a healthy state. We explore sex-based dichotomy in gene expression among kidney populations, revealing altered transcriptional programs between male and female proximal tubular cells, and perform an in-depth characterization of the immune niche in healthy, non-inflamed kidney.

\section{Single-cell map of healthy human kidney}

We examined the cellular landscape of human kidney using pre-implantation kidney biopsies from 19 sex-matched living kidney donors (Fig. 1a, b). Our dissociation method was developed to maximize viability to preserve representation of rare and fragile cell populations, and we employed rigorous quality control. Minimal immune cell representation in healthy kidney ( $0.3 \%$ of cells captured) necessitated CD45-enrichment for immune cells in 10/19 biopsy samples ( 5 female, 5 male) (Fig. 1a). 
Of 27677 cells in our map, 6899 cells were from CD45-enriched samples, while 20778 cells were from non-CD45-enriched samples. Twenty-three clusters were identified including several distinct immune cell populations, alongside all anticipated parenchymal populations of the nephron (Fig. 1c, Supplementary Fig. 1a). Clusters were comprised of cells captured from multiple donors, there was no exceptional variability in cell cycle state across clusters, and most clusters had symmetrical distribution of donor sex (Figure 1b-e, Supplemental Figure 1).

As anticipated, Proximal Tubular (PT) cells comprised $75 \%$ of sequenced cells. Sub-clustering revealed 6 distinct clusters (PT1-PT6) (Fig. 1d, Supplementary Fig. 2a), with some heterogeneity between individuals, methods of sample preparation, and sexes noted (Supplementary Fig. 2b). PT segment-specific separation is evident; PT1, 4, and 6 are enriched for PT segment 1 (S1) marker SLC5A2 and S1/2-abundant genes (SLC7A7, ANK2, SLC4A4, SLC6A19, SLC22A8), while PT2 shows increased expression of S3-abundant genes (DCXR, AGXT, SLC22A7, SLC7A13) (Fig. 1e) $)^{9,10}$. PT3 highly expresses dissociation stress-associated genes ${ }^{3}$, together with general (LRP2, CUBN) and segmentspecific PT genes, indicating cell contributions from all PT segments (Fig. 1e, Supplementary Fig. 2c). PT5 $\left(\mathrm{VIM}^{+} S 100 A 6^{+} V C A M 1^{+} D C D C 2^{+} A N X A 4^{+}\right)$displays similarity to a putative regenerative PT population - termed 'scattered tubular cells' (STC) ${ }^{11,12}$. These genes also characterize a population which expands following IRI and is postulated to reflect failed PT repair, though expression was also observed in healthy kidney ${ }^{13}$. Some STC-associated genes were exclusively expressed by PT5 or PT3, while others were expressed in both populations (Supplementary Fig. 2d-f). This transcriptional overlap between the regenerative STC-like PT5 and stressed PT3 cells may indicate attempted initiation of repair in PT3 cells. Transcription factor analysis (Supplementary Fig. $\mathbf{2 g}$ ) of PT5 genes revealed potential upstream regulators directing cell differentiation and migration (SNAI2, ZNF217), and epithelial phenotype maintenance (ELF3), alongside NFE2L2 (NRF2), a key regulator of antioxidant and cytoprotective genes ${ }^{14}$. Predicted upstream regulators for PT3 (EGR1, FOS, and JUN) 
are associated with oxidative stress and fibrogenesis. Predicted regulator ATF3 (protective in renal $|\mathrm{R}|^{15}$ ) supports potential reparative processes in this cluster (Supplementary Fig. $\mathbf{2 g}$ ).

Fourteen non-PT parenchymal cell populations were identified ${ }^{9}$ (Fig. 1f-g) including rare but important glomerular populations such as podocytes, mesangial cells, and parietal epithelial cells. We detected notable heterogeneity in CTAL and endothelial populations. Two CTAL subpopulations expressing CLDN10 and CLDN16, respectively, identify cells with differing paracellular cationresorption preferences in CLDN10-dominant $\left(\mathrm{Na}^{+}\right)$versus CLDN16-dominant tight junctions (Ca ${ }^{2+}$, $\mathrm{Mg}^{2+}$ ) (Supplementary Fig. 3a-e) ${ }^{16}$. Among endothelial subpopulations (Endo1-4) (Fig. 1f), we identified two populations (Endo1, Endo3) of peritubular capillary cells ( $P L V A P^{+} T M E M 88^{+} D N A S E 1 L 3^{+}$) (Supplementary Fig. 3a, f, g). Endo1 expressed ESM1 - required for VEGF-related maintenance of the peritubular capillary network ${ }^{17}$, while Endo3 expressed motility and angiogenesis markers MARCKS, CLU, ACKR1, SEMA3D (Supplementary Fig. 3f). Endo2 (SOX17 SERPINE2 ${ }^{+} C L D N 5^{+} C X C L 12^{+}$) represents afferent arterioles and vasa recta, exhibiting reduced $K D R$ expression and increased expression of extracellular matrix-encoding genes (Supplementary Fig. 3g). Endo4 expresses the glomerular microvascular endothelial cell markers EDH3, SOST, and TBX3, a transcriptional regulator critical to fenestrated glomerular endothelial development (Supplementary Fig. 3f) ${ }^{18}$.

\section{Identification of sex-based transcriptomic differences in proximal tubular cells}

Leveraging the sex-balanced large sample size, we examined differences in gene expression in healthy human kidney between males and females. Using varimax-rotated principal component analysis, we examined individual kidney populations for separation due to donor sex, and observed a clear separation for the PT population (left panel in Fig. 2a, Supplementary Fig. 4a). Such separation was not evident in other cell populations, perhaps reflecting insufficient power with fewer cells. Consequently, subsequent analyses focused on PT cells. Using machine learning, we identified the most discriminant subset of genes in our dataset that could correctly classify cell sex. Model-1 (80 
genes) correctly classified cell sex with an area under the curve (AUC) of 0.98 (training dataset), and an accuracy of $84 \%$ (validation dataset) (middle panel in Fig. 2a, Supplementary Fig. 4b,c,f). As Xand Y-linked genes potentially drive sex-biased effects ${ }^{19}$, we removed all sex chromosome-encoded genes and derived Model-2 (15 genes), which correctly classified cell sex in the training dataset (AUC 0.85), but had reduced accuracy (68\%) in the validation set (Supplementary Fig. 4d-f). Using an independent single-cell kidney dataset for validation ${ }^{20}$, our gene signatures accurately classified cell sex in 79\% (Model-1) and 66\% (Model-2) of cells (Supplementary Fig. 4f). Next, we identified genes with significant differential expression between males and females ( $n=75$ genes, $p$-value $<0.05$, LogFC $>0.25$ ) (right panel in Fig. 2a). As our conservative analysis excluded genes expressed uniquely by one sex (e.g. Y-chromosome-encoded genes), these genes ( $n=12)$ were added for downstream analyses (Fig. 2b). Results from our three analyses were compared (Supplementary Table 1). In agreement with previous studies ${ }^{21,22}$, the majority of the sex-biased genes uncovered are located in autosomes, rather than in sex chromosomes. Several sex-biased genes are consistent with previous reports of genes upregulated in murine male (NAT8, FKBP5, KDM5D, DGKG) and female (MGST3, SLC3A1, CYP4A11, RPS29) PT cells, respectively ${ }^{21-23}$.

Twenty-two genes featured in all three analyses (Fig. 2c), including $9 \mathrm{Y}$ - and $3 \mathrm{X}$-chromosome encoded genes. An additional 18 genes featured in differential expression analysis (MAST+) and one other analysis (Fig. 2c). The X-chromosome genes reported are known to escape $\mathrm{X}$-chromosome inactivation, explaining their higher expression in females ${ }^{19}$. Many of the autosomal-encoded genes or their family members are associated with primary sex determination (SRSF5'24, GATM ${ }^{25}$, GADD45A), sex-biased expression (CISH, SRSF5, ACTG1, GATM, AOX1), or sex-specific effects $\left(S L C 2 A 9^{26}\right)$. Intriguingly, many of the genes have established links with kidney disease, including SLC27A2 (diabetic kidney disease)27, SLC3A1 (cystinuria), and GATM ${ }^{28}$; while others are associated with hypoxia (PHGD, CA12), inflammation (PPIA), and genotoxic stress (ASS1). Metallothionein gene family members (MT1F, MT1G, MT1H), which encode cysteine-rich antioxidant proteins ${ }^{29}$, were 
notably higher in females (Fig. 2a,c). Additional differentially expressed genes also relate to cysteineglutathione availability and metabolism, including $S L C 3 A 1^{30}, M G S T 3$, and HRASLS2.

We next aimed to validate sex-biased gene expression profiles using commercially-available human primary PT cells from 3 male and 3 female independent healthy donors (Supplementary Table 2, age range of donors 50-59 years old). As expected, Y-linked genes KDM5D, UTY, and EIF1AY were exclusively expressed in male PT cells (Fig. 2d). We also studied the X-linked genes EIF1AX and DDX3X. While proposed as 'X-inactivation escapees', the extent of $\mathrm{X}$-inactivation can be highly variable across genes, tissues, and individuals ${ }^{31}$. In agreement with our scRNAseq findings, primary female PT cells displayed increased transcript levels of EIF1AX and DDX3X, compared to male cells

(Fig. 2d). Female sex is linked to lower oxidative stress markers in the kidney in vivo ${ }^{6}$ but whether the sex of PT cells is a major contributor to this effect is unknown. Gene expression of MT1F, MT1G, MT1H was significantly increased in primary female PT cells, compared to male cells, as identified by scRNAseq and validated with qPCR in these independent donors (Fig. 2a,c,d). Of note, many of the transcripts exhibiting sex dimorphism in our scRNAseq analysis were absent when using matched single nucleus RNA sequencing, likely due to cytosolic or mitochondrial localization of the transcripts

\section{(Supplementary Fig. 5)}

We next investigated the biological processes enriched among the genes showing sex-biased expression in PT cells. Pathway analysis (Fig. 3a, Supplementary Table 3) revealed processes related to amino acid metabolism, PT transport, and regulation of the inflammatory response as increased in females. Among the pathways increased in males, processes related to mitochondrial aerobic metabolism ('oxidative phosphorylation', 'tricarboxylic acid (TCA) cycle' and 'electron transport chain') predominated. Two additional metabolic processes, namely 'generation of precursor metabolites' and 'nucleoside triphosphate metabolism', were also enriched in males. To validate these observations, we studied functional differences in mitochondrial metabolism and precursor metabolite generation in male and female PT cells. We exposed primary male and female PT cells to 
minimal media containing glucose and glutamine, which serve as mitochondrial substrates. We then

measured their oxygen consumption rate (OCR), as a marker of mitochondrial respiration ${ }^{32}$.

Supporting our pathway analysis, male PT cells showed a significant increase in OCR at baseline and and three additional nucleoside triphosphate metabolites - GTP, ITP, and UTP (Fig. 3d).

\section{Immune landscape of healthy human kidney}

Despite the relative paucity of immune cells in healthy human kidney, we examined kidney-resident immune cells to delineate their steady-state phenotypes and functions. Sub-clustering of immune

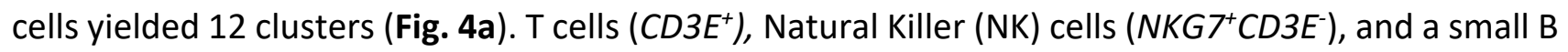
cell population $\left(C D 79 A^{+}\right)$mainly expressing the immunoglobulin chain IGHM were identified (Fig. 4b,

Supplementary Fig. 7a). Plasma cells $\left(C D 38^{+} X B P 1^{+}\right)$were scarce in healthy kidney tissue

(Supplementary Fig. 7b). Myeloid clusters $\left(C D 68^{+}\right)$(Fig. 4b) displayed enrichment of phagocyterelated pathways including "receptor-mediated endocytosis", "regulation of TLR signaling", and 

of "T-helper cell differentiation" and "Interleukin-7-mediated signaling" pathways (Fig. 4c,

Supplementary Fig. 7c). T1 also included $C C R 7^{+} S E L L^{+}$cells, suggesting central memory T cell identity

(Supplementary Fig. 8) ${ }^{36}$. T2 demonstrates expression of a cytotoxic program (GZMA, GZMB, GZMH,

GNLY, PRF1) alongside NK receptor genes (KLRD1, KLRG1), consistent with effector memory T cell or

NKT cell identity (Fig. 4c), T2 also contained some gamma-delta $(\gamma \delta)$ T cells, marked by co-expression of TCR chain components TRDV2 and TRDC (Fig. 4b). T3 had sparse expression of resident memory T

cell (Trm) markers (CXCR6, ITGA1), while T4 was marked by high GZMK expression, a marker of

circulating age-associated memory $\mathrm{T}$ cells $(\mathbf{F i g} . \mathbf{4 b}, \mathbf{c})^{37}$. FOXP3 ${ }^{+} \mathrm{CD} 4^{+}$regulatory $\mathrm{T}$ cells were notably absent from scRNAseq and flow cytometry analyses (Supplementary Fig. 9a), while being observed in kidney pathologies ${ }^{38,39}$, indicating they are likely recruited during inflammation. NK cell cluster NK1 displayed a cytotoxic gene program and broad FCGR3A(CD16) expression. Flow cytometry confirmed $\sim 95 \%$ of renal NK cells are CD56 $6^{\operatorname{dim}} \mathrm{CD} 16^{+}$(Supplementary Fig. 10a). Low abundance of ILC2s, ILC3s and CD56 bright NK cells was suggested by a predictive classifier and confirmed by flow cytometry

(Supplementary Fig. 10b, c). sources, we directly compared lymphocytes in living donor kidney with tumor-unaffected renal tissue. We confirmed the presence of many similar immune populations across tissue sources, yet also observed differences in abundance and transcriptional signatures. When T cell and NK cell clusters were compared between these different tissue sources, alterations in checkpoint molecule expression (i.e TIGIT, CTLA4, PDCD1) were noted, with some of these differences also being observed at the protein level. We also observed high donor heterogeneity in immune infiltration and generally be altered from healthy kidney. 
bioRxiv preprint doi: https://doi.org/10.1101/2021.12.09.471943; this version posted December 10,2021. The copyright holder for this preprint (which was not certified by peer review) is the author/funder, who has granted bioRxiv a license to display the preprint in perpetuity. It is made available under aCC-BY-NC-ND 4.0 International license. Mononuclear phagocytes (MP) acquire tissue-adapted phenotypes and functions ${ }^{40}$. Definitively attributing macrophage or DC identity to myeloid populations based on gene expression alone is particularly challenging within the kidney due to a lack of consensus on lineage defining markers $^{41}$ and here they are annotated more generally as five MP populations. Cluster MP1 highly expressed complement components $(C 1 Q A, C 1 Q B, C 1 Q C)$ and markers of alternative macrophage activation or anti-inflammatory function (CD163, LYVE1, STAB1, MRC1, VSIG4, FOLR2) (Fig. 4b-c, Supplementary Fig. 12). Efferocytosis receptor MERTK expression supports homeostasis or repair functions (Supplementary Fig. 12). MP3 contained cells expressing CDC2 markers (CLEC1OA, CD1C), alongside a subgroup of cells co-expressing lipid-associated genes (CD9, TREM2, APOE, APOC1) (Fig. 4b). Similar populations have been identified as kidney-resident macrophages and are expanded in fibrotic tissues ${ }^{42}$. MP2 and MP4 (FCGR3A $A^{+}$SIGLEC10 $\left.10^{+} F C N 1^{+}\right)$resemble CD16 ${ }^{+}$non-classical monocytes (Fig. 4b-c, Supplementary Fig. 12). MP4 had elevated expression of IL1B, MHC Class-II genes, and CX3CR1 while MP2 had higher expression of CXCR4 and FPR1 (Supplementary Fig. 7d). MP5 expressed markers of classical $\mathrm{CD}_{14}{ }^{+}$monocytes (S100A8, S100A9, CD14, VCAN), yet was predominantly from one individual with elevated hemoglobin transcripts, indicative of increased circulating cells in this particular sample (Fig. 4b, c, Supplementary Fig. 7e). Flow cytometry confirmed greater abundance of $\mathrm{CD}_{16} 6^{+}$cells in kidney relative to blood, as well as low proportions of $\mathrm{CD} 14^{+} \mathrm{CD} 16^{-} \mathrm{MPs}$ resembling MP5 and the presence of MRC1 ${ }^{+} \mathrm{HLA}-\mathrm{DR}^{+}$MPs in kidney that align with MP1 (Supplementary Fig. 10e, f).

\section{Identification of a distinct resident macrophage population in healthy kidney}

Due to unique aspects of our study, including short ischemic times to which resident macrophages are especially sensitive ${ }^{43,44}$, and use of flushed living donor-derived kidney tissue, we examined shared and unique MP populations in healthy kidney compared to those reported previously in kidney tissue from other sources. $C D 68^{+}$cells from three prior studies ${ }^{3,45,46}$ were 

classified to match cluster identities of our study. MPs from these studies most resembled MP5 (classical $\mathrm{CD}_{14}{ }^{+}$monocyte-like), the lowest abundance MP cluster in living donor samples (Supplementary Fig. 13a). MP3 (DC-like and lipid-associated MPs) as well as MP2 and MP4 (CD16 non-classical monocyte-like) were shared across datasets. Strikingly, few cells from these studies corresponded to MP1 (resident macrophages) - the largest MP population in living donor kidney. Next, $C D 68^{+}$cells from these prior studies $3,45,46$ and our study were merged, identifying five myeloid cell states (CS) across all studies (Fig. 3d). Based on transcriptomic profiles, CS2 and CS4 include resident macrophages and antigen-presenting cells, CSO is consistent with non-classical CD16 monocytes, CS3 represents classical CD14 ${ }^{+}$monocytes and CS1 may represent a transition state, supported by trajectory analysis (Supplementary Fig. 13b, c). CS2, which was almost entirely comprised of living donor kidney cells (Supplementary Fig. 13b), is defined by expression of genes associated with alternatively activated macrophages (C1QA $\left.B / C^{+} R N A S E 1^{+} C D 163^{+} L Y V E 1^{+} F O L R 2^{+}\right)$, in contrast to all other CS which expressed markers associated with monocytes and classically activated macrophages (S100 family members, $F C N 1, L Y Z$, and pro-inflammatory SOD2) (Fig. 4d, Supplementary Fig. 13b). CS2 constitutes the predominant MP population in healthy kidney (MP1), while CS3 and CS4 abundance is limited (Fig. 4e)

\section{Kidney-resident lymphocytes are antigen-experienced with distinct gene expression}

Due to unexpected heterogeneity and novel transcriptional profiles in kidney lymphocyte populations (Fig. 4a-c), we directly compared lymphocyte proportions, signatures, and phenotypes to those in healthy donor blood. Increased proportions of NK $\left(\mathrm{CD} 3^{-} \mathrm{CD} 56^{+}\right)$and NKT cells $\left(\mathrm{CD}^{+} \mathrm{CD}^{+} 6^{+}\right)$ were noted in kidney, while T cell $\left(\mathrm{CD}^{+}{ }^{+} \mathrm{CD} 56^{-}\right)$abundance was unchanged (Fig. 5a). CD8 ${ }^{+} \mathrm{T}$ cells were present in higher proportions than $\mathrm{CD}^{+} \mathrm{T}$ cells in kidney and the presence of $\gamma \delta \mathrm{T}$ cells was validated by flow cytometry (Fig. 5b, Supplementary Fig. 9a). 
To identify specific markers and transcriptional profiles of kidney-resident lymphocytes, we

244 integrated our dataset with public PBMC scRNA-seq datasets ${ }^{47,48}$ (Supplementary Fig. 14a-j, Supplementary Table 4) and validated differences by flow cytometry. Unsurprisingly, blood lymphocytes exhibited higher expression of naïve T cell genes (CCR7, SELL, LEF1, TCF7). In contrast, the tissue residency-associated transcription factor PRDM1 (BLIMP-1) ${ }^{49}$ was upregulated in kidney lymphocytes, as was CD69, which marks Trms in several organs and prevents tissue egress via S1PR1 antagonism $^{50}$ (Supplementary Fig. 14j). Antigen-experienced T cells upregulate CD45RO and can become $\mathrm{Trm}^{51} \cdot 60-98 \%$ of kidney $\mathrm{CD}^{+}$and $\mathrm{CD} 8^{+} \mathrm{T}$ cells were $\mathrm{CD} 45 \mathrm{RO}^{+}$in contrast to low proportions of memory T cells in blood (Fig. 5c). NK cells with memory functions may also express $\mathrm{CD}_{4} \mathrm{RO}^{52}$; however, this was not observed in renal NK cells (Fig. 5c). Flow cytometry confirmed elevated CD69 on $\mathrm{T}$ cells and NK cells, with CD69-CD103 co-expression by $\mathrm{CD}^{+} \mathrm{T}$ cells, consistent with a Trm phenotype (Supplementary Fig. 9c). Further characterization of memory CD4 ${ }^{+} \mathrm{T}$ helper (Th) cell subsets revealed enrichment of Th1/17 cells with reduced Th2 marker expression (Fig. 5d,

\section{Supplementary Fig. 9b).}

We also sought to validate Granzyme K production in kidney lymphocytes, as T4 cluster was marked by high GZMK expression. In agreement with scRNAseq findings, Granzyme K was detected in $21 \%$ of kidney $\mathrm{T}$ cells (Fig. 5e), with minimal co-expression with Granzyme B, indicating that Granzyme $\mathrm{K}^{+} \mathrm{T}$ cells form a distinct subset of renal T cells (Fig. 5e). Most Granzyme $\mathrm{K}^{+} \mathrm{T}$ cells also did not have detectable perforin expression (Fig. 5e), in line with Granzyme K produced by these T cells having extracellular functions rather than the canonical cytolytic function of granzymes dependent on intracellular delivery via perforin.

Kidney lymphocytes were distinguished from circulating lymphocytes by elevated expression of chemokine receptors (CXCR4, CXCR6), integrin components (ITGB1, ITGA4), and inhibitory NK receptors (KLRD1, KLRC1) (Fig. 5f, Supplementary Fig. 14j). Flow cytometry confirmed VLA-4 integrin components $\alpha 4$ (CD49d) and $\beta 1$ (CD29) were highly expressed in renal T cells suggesting VLA-4 
contributes to their residency or function (Fig. $\mathbf{5 g}$ ). This is consistent with expression of VLA-4 ligands

fibronectin and VCAM-1 in kidney ${ }^{53}$. Kidney NK cells have higher levels of CD69 compared to circulating NK cells, while no difference in CD29 or CD49d was detected (Fig. 5h). Finally, CXCR6 protein expression was elevated on kidney T and NK cells, while CXCR4 was not, despite high gene expression (Fig. $\mathbf{5 g}, \mathbf{h}, \mathbf{i}$ ). Notably, renal myeloid cells expressed CXCL16, the chemokine ligand for

CXCR6, indicating participation in lymphocyte recruitment, supported by significant aggregate rank scores using cell-cell communication inference (Supplementary Fig. 9d, Supplementary Tables 5, 6). Other differentially expressed genes suggest tissue-adapted function of kidney lymphocytes. AREG, encoding the growth factor amphiregulin, was highly expressed by NK1 and validated by flow cytometry (Supplementary Fig. 10d, Supplementary Fig, 11f, g), suggesting tissue-reparative functions. The prostaglandin E2 (PGE2) receptor PTGER4 and prostaglandin D synthase PTGDS were upregulated (Supplementary Fig. 14j), indicating kidney lymphocytes synthesize and recognize prostaglandins, known mediators of kidney function ${ }^{54}$. PGE2 promotes Th17 and Th1/17 cell development and function, perhaps explaining Th1/17 cell enrichment in kidney (Fig. 4d) ${ }^{55}$. Collectively these studies capture the heterogeneity of myeloid and lymphocyte populations within healthy human kidney and provide an important reference of immune cell phenotypes and functions at steady state.

\section{Discussion}

We present a scRNAseq atlas of healthy human kidney using biopsies from living donors. Our resolution of healthy kidney PT, endothelial, epithelial, and immune subpopulations will inform

future studies addressing underling mechanisms of kidney pathologies, including chronic kidney disease, fibrosis, IRI, renal cancer and allograft rejection. 
by small sample size and use of animal models, or instead used bulk transcriptional analysis where sex-specific signatures of individual kidney cell populations cannot be resolved ${ }^{19,23,57}$. Our study is aligned with the conclusion of scRNAseq studies in mouse by Ransick et al. ${ }^{23}$ that PT cells are sexually dimorphic. However, the overlap in sexually dimorphic PT genes between human and mouse is small, perhaps due to distinct orthologues in mouse, small number of samples sequenced, or true biological differences between human and mouse.

We report striking sex-based transcriptional differences in PT cells, suggesting higher baseline metabolic activity in males, and enhanced expression of antioxidant genes in females. We validated these sex-based observations at the level of gene expression, metabolite generation, and metabolic function in vitro. Increased oxidative stress is reported in males ${ }^{58}$, while female sex hormones augment antioxidant gene transcription ${ }^{59}$. Metallothionein genes (MT1F, MT1G, MT1H), which are potent endogenous antioxidants ${ }^{60}$, were increased in female PT cells. Metallothionein depletion exacerbates diabetic and hypoxia-induced kidney injury ${ }^{61,62}$, whereas augmented expression is protective $^{63}$. Several sex-altered genes further relate to cysteine-glutathione metabolism. Glutathione is critical to cellular antioxidant defences ${ }^{64}$ and glutathione metabolism exhibits sexual dimorphism ${ }^{22,65}$. These sex-based differences in PT gene expression discovered by use of scRNAseq which can capture transcripts localized to the mitochondria and cytosol, may provide insights into the well-recognized, but previously unexplained sexual dimorphism observed in most kidney diseases. In particular, why females may be less susceptible to metabolism-related kidney injury ${ }^{6-}$ $8,66,67$. predominantly Trms and exhibit unique phenotypes previously unreported in kidney, including Granzyme $\mathrm{K}^{+} \mathrm{T}$ cells. The function of Granzyme $\mathrm{K}^{+} \mathrm{T}$ cells in humans is poorly characterized, and here we show that Granzyme $\mathrm{K}^{+} \mathrm{T}$ cells are a distinct subset separate from Granzyme $\mathrm{B}^{+}$Perforin ${ }^{+} \mathrm{T}$ cells in 
the kidney. The lack of perforin co-expression suggests that Granzyme $\mathrm{K}$ produced by renal T cells

may have extracellular targets, such as inducing endothelial cell activation ${ }^{68}$, promoting sensitivity to LPS-induced inflammation $^{69}$, and regulating angiogenesis ${ }^{70}$. rejection ${ }^{71,72}$. Renal abundance of $\mathrm{CD} 56^{+} \mathrm{CD} 16^{+} \mathrm{NK}$ cells with high expression of amphiregulin compared to circulating NK cells suggests non-canonical tissue-adapted functions. We demonstrate an enrichment of a resident macrophage population with little-to-no presence in prior datasets from discarded deceased donor or tumor nephrectomy specimens, suggesting altered kidney environments impact this myeloid population. Indeed, sensitivity of self-renewing resident macrophage populations to extended ischemic injury and inflammation is reported ${ }^{44}$. Additional comparison of lymphocyte populations in tumor-unaffected versus living donor renal tissue revealed alterations in tumor-unaffected tissue relative to the steady-state immune niche in healthy living donor kidney. Increased B and T cell proportions, increased expression of activation and exhaustionassociated molecules by lymphocytes, in addition to a trend for increased immune infiltration in nephrectomy specimens was observed (Supplementary Fig. 11), in agreement with prior reports that tumour-affected kidneys can have altered immune infiltrates ${ }^{5,56}$. Future studies exploring alterations in immune cells in tumor-unaffected kidney tissue of renal cancer patients may have implications for development of immunotherapies.

Collectively, our description of healthy human kidney provides a reference point for understanding the cellular basis of kidney disease development, represents a 'normal' target for gene expression and kidney-resident immune populations. 


\section{References}

344 1. Kurts C, Panzer U, Anders HJ, Rees AJ. The immune system and kidney disease: basic concepts and clinical implications. Nat Rev Immunol 2013;13:738-53.

$3462 . \quad$ Rogers NM, Ferenbach DA, Isenberg JS, Thomson AW, Hughes J. Dendritic cells and macrophages in the kidney: a spectrum of good and evil. Nature reviews Nephrology 2014;10:62543.

3. Stewart BJ, Ferdinand JR, Young MD, et al. Spatiotemporal immune zonation of the human kidney. Science 2019;365:1461-6.

351 4. Saat TC, Susa D, Roest HP, et al. A comparison of inflammatory, cytoprotective and injury gene expression profiles in kidneys from brain death and cardiac death donors. Transplantation 2014;98:15-21.

354 5. Damman J, Bloks VW, Daha MR, et al. Hypoxia and Complement-and-Coagulation Pathways in the Deceased Organ Donor as the Major Target for Intervention to Improve Renal Allograft Outcome. Transplantation 2015;99:1293-300.

357 6. Clotet S, Soler MJ, Riera M, et al. Stable Isotope Labeling with Amino Acids (SILAC)-Based Proteomics of Primary Human Kidney Cells Reveals a Novel Link between Male Sex Hormones and Impaired Energy Metabolism in Diabetic Kidney Disease. Mol Cell Proteomics 2017;16:368-85.

7. Aufhauser DD, Jr., Wang Z, Murken DR, et al. Improved renal ischemia tolerance in females influences kidney transplantation outcomes. J Clin Invest 2016;126:1968-77.

8. Neugarten J, Golestaneh L. Female sex reduces the risk of hospital-associated acute kidney injury: a meta-analysis. BMC Nephrol 2018;19:314.

9. Clark JZ, Chen L, Chou CL, Jung HJ, Lee JW, Knepper MA. Representation and relative abundance of cell-type selective markers in whole-kidney RNA-Seq data. Kidney Int 2019;95:78796.

10. Wu H, Uchimura K, Donnelly EL, Kirita Y, Morris SA, Humphreys BD. Comparative Analysis and Refinement of Human PSC-Derived Kidney Organoid Differentiation with Single-Cell Transcriptomics. Cell Stem Cell 2018;23:869-81 e8.

11. Smeets B, Boor P, Dijkman $\mathrm{H}$, et al. Proximal tubular cells contain a phenotypically distinct, scattered cell population involved in tubular regeneration. J Pathol 2013;229:645-59.

12. Berger K, Bangen JM, Hammerich $L$, et al. Origin of regenerating tubular cells after acute kidney injury. Proc Natl Acad Sci U S A 2014;111:1533-8.

13. Kirita $\mathrm{Y}, \mathrm{Wu} \mathrm{H}$, Uchimura K, Wilson PC, Humphreys BD. Cell profiling of mouse acute kidney injury reveals conserved cellular responses to injury. Proc Natl Acad Sci U S A 2020;117:15874-83.

14. Ahmed SM, Luo L, Namani A, Wang XJ, Tang X. Nrf2 signaling pathway: Pivotal roles in inflammation. Biochim Biophys Acta Mol Basis Dis 2017;1863:585-97.

15. Yoshida $T$, Sugiura $H$, Mitobe $M$, et al. ATF3 protects against renal ischemia-reperfusion injury. J Am Soc Nephrol 2008;19:217-24.

16. Milatz S, Himmerkus N, Wulfmeyer VC, et al. Mosaic expression of claudins in thick ascending limbs of Henle results in spatial separation of paracellular $\mathrm{Na}+$ and $\mathrm{Mg} 2+$ transport. Proc Natl Acad Sci U S A 2017;114:E219-E27.

17. Rocha SF, Schiller M, Jing D, et al. Esm1 modulates endothelial tip cell behavior and vascular permeability by enhancing VEGF bioavailability. Circ Res 2014;115:581-90.

18. Barry DM, McMillan EA, Kunar B, et al. Molecular determinants of nephron vascular specialization in the kidney. Nat Commun 2019;10:5705.

19. Oliva M, Munoz-Aguirre M, Kim-Hellmuth S, et al. The impact of sex on gene expression across human tissues. Science 2020;369.

20. Liao J, Yu Z, Chen Y, et al. Single-cell RNA sequencing of human kidney. Sci Data 2020;7:4. 
21. Wu H, Lai CF, Chang-Panesso M, Humphreys BD. Proximal Tubule Translational Profiling during Kidney Fibrosis Reveals Proinflammatory and Long Noncoding RNA Expression Patterns with Sexual Dimorphism. J Am Soc Nephrol 2020;31:23-38.

22. Vinas JL, Porter CJ, Douvris A, et al. Sex diversity in proximal tubule and endothelial gene expression in mice with ischemic acute kidney injury. Clin Sci (Lond) 2020;134:1887-909.

23. Ransick A, Lindstrom NO, Liu J, et al. Single-Cell Profiling Reveals Sex, Lineage, and Regional Diversity in the Mouse Kidney. Dev Cell 2019;51:399-413 e7.

24. Planells B, Gomez-Redondo I, Pericuesta E, Lonergan P, Gutierrez-Adan A. Differential isoform expression and alternative splicing in sex determination in mice. BMC Genomics 2019;20:202.

25. Clement TM, Anway MD, Uzumcu M, Skinner MK. Regulation of the gonadal transcriptome during sex determination and testis morphogenesis: comparative candidate genes. Reproduction 2007;134:455-72.

26. Doring A, Gieger C, Mehta D, et al. SLC2A9 influences uric acid concentrations with pronounced sex-specific effects. Nat Genet 2008;40:430-6.

27. Khan S, Gaivin R, Abramovich C, Boylan M, Calles J, Schelling JR. Fatty acid transport protein2 regulates glycemic control and diabetic kidney disease progression. JCI Insight 2020;5.

28. Reichold M, Klootwijk ED, Reinders J, et al. Glycine Amidinotransferase (GATM), Renal Fanconi Syndrome, and Kidney Failure. J Am Soc Nephrol 2018;29:1849-58.

29. Ruttkay-Nedecky B, Nejdl L, Gumulec J, et al. The role of metallothionein in oxidative stress. Int J Mol Sci 2013;14:6044-66.

30. Woodard LE, Welch RC, Veach RA, et al. Metabolic consequences of cystinuria. BMC Nephrol 2019;20:227.

31. Tukiainen T, Villani AC, Yen A, et al. Landscape of X chromosome inactivation across human tissues. Nature 2017;550:244-8.

32. Smolina N, Bruton J, Kostareva A, Sejersen T. Assaying Mitochondrial Respiration as an Indicator of Cellular Metabolism and Fitness. Methods Mol Biol 2017;1601:79-87.

33. Chaudhry R, Varacallo M. Biochemistry, Glycolysis. StatPearls. Treasure Island (FL)2021.

34. Jose C, Bellance N, Rossignol R. Choosing between glycolysis and oxidative phosphorylation: a tumor's dilemma? Biochim Biophys Acta 2011;1807:552-61.

35. Canto C, Menzies KJ, Auwerx J. NAD(+) Metabolism and the Control of Energy Homeostasis: A Balancing Act between Mitochondria and the Nucleus. Cell Metab 2015;22:31-53.

36. Park CO, Kupper TS. The emerging role of resident memory T cells in protective immunity and inflammatory disease. Nat Med 2015;21:688-97.

37. Mogilenko DA, Shpynov O, Andhey PS, et al. Comprehensive Profiling of an Aging Immune System Reveals Clonal GZMK(+) CD8(+) T Cells as Conserved Hallmark of Inflammaging. Immunity 2021;54:99-115 e12.

38. Nehar-Belaid D, Hong $S$, Marches R, et al. Mapping systemic lupus erythematosus heterogeneity at the single-cell level. Nat Immunol 2020;21:1094-106.

39. Sakai $R$, Ito $M$, Komai $K$, et al. Kidney GATA3 $(+)$ regulatory T cells play roles in the convalescence stage after antibody-mediated renal injury. Cell Mol Immunol 2021;18:1249-61.

40. Epelman S, Lavine KJ, Randolph GJ. Origin and functions of tissue macrophages. Immunity 2014;41:21-35.

41. Gottschalk C, Kurts C. The Debate about Dendritic Cells and Macrophages in the Kidney. Front Immunol 2015;6:435.

42. Ramachandran $P$, Dobie R, Wilson-Kanamori JR, et al. Resolving the fibrotic niche of human liver cirrhosis at single-cell level. Nature 2019;575:512-8.

43. Liu F, Dai S, Feng D, et al. Distinct fate, dynamics and niches of renal macrophages of bone marrow or embryonic origins. Nat Commun 2020;11:2280. 
44. Yue S, Zhou H, Wang X, Busuttil RW, Kupiec-Weglinski JW, Zhai Y. Prolonged Ischemia Triggers Necrotic Depletion of Tissue-Resident Macrophages To Facilitate Inflammatory Immune Activation in Liver Ischemia Reperfusion Injury. J Immunol 2017;198:3588-95.

45. Zimmerman KA, Bentley MR, Lever JM, et al. Single-Cell RNA Sequencing Identifies Candidate Renal Resident Macrophage Gene Expression Signatures across Species. J Am Soc Nephrol 2019;30:767-81.

46. Arguello RJ, Combes AJ, Char R, et al. SCENITH: A Flow Cytometry-Based Method to Functionally Profile Energy Metabolism with Single-Cell Resolution. Cell Metab 2020;32:1063-75 e7. 47. Wang $X$, Sun Z, Zhang $Y$, et al. BREM-SC: a bayesian random effects mixture model for joint clustering single cell multi-omics data. Nucleic Acids Res 2020;48:5814-24.

48. https://support.10xgenomics.com/single-cell-gene-expression/datasets/3.0.2/5k_pbmc_v3. 2019. at https://support.10xgenomics.com/single-cell-geneexpression/datasets/3.0.2/5k_pbmc_v3.)

49. Mackay LK, Minnich M, Kragten NA, et al. Hobit and Blimp1 instruct a universal transcriptional program of tissue residency in lymphocytes. Science 2016;352:459-63.

50. Cibrian D, Sanchez-Madrid F. CD69: from activation marker to metabolic gatekeeper. Eur J Immunol 2017;47:946-53.

51. Clark RA. Resident memory T cells in human health and disease. Sci Transl Med 2015;7:269rv1.

52. Fu X, Liu Y, Li L, et al. Human natural killer cells expressing the memory-associated marker CD45RO from tuberculous pleurisy respond more strongly and rapidly than CD45RO- natural killer cells following stimulation with interleukin-12. Immunology 2011;134:41-9.

53. Chakravorty SJ, Howie AJ, Cockwell P, Adu D, Savage CO. T lymphocyte adhesion mechanisms within inflamed human kidney: studies with a Stamper-Woodruff assay. Am J Pathol 1999;154:503-14.

54. Kim GH. Renal effects of prostaglandins and cyclooxygenase-2 inhibitors. Electrolyte Blood Press 2008;6:35-41.

55. Boniface K, Bak-Jensen KS, Li Y, et al. Prostaglandin E2 regulates Th17 cell differentiation and function through cyclic AMP and EP2/EP4 receptor signaling. J Exp Med 2009;206:535-48.

56. Aran D, Camarda R, Odegaard J, et al. Comprehensive analysis of normal adjacent to tumor transcriptomes. Nat Commun 2017;8:1077.

57. Si H, Banga RS, Kapitsinou P, et al. Human and murine kidneys show gender- and speciesspecific gene expression differences in response to injury. PLoS One 2009;4:e4802.

58. Tower J, Pomatto LCD, Davies KJA. Sex differences in the response to oxidative and proteolytic stress. Redox Biol 2020;31:101488.

59. Pan JS, Sheikh-Hamad D. Mitochondrial dysfunction in acute kidney injury and sex-specific implications. Med Res Arch 2019;7.

60. Schanz M, Schaaf L, Dippon J, et al. Renal effects of metallothionein induction by zinc in vitro and in vivo. BMC Nephrol 2017;18:91.

61. Tachibana H, Ogawa D, Sogawa N, et al. Metallothionein deficiency exacerbates diabetic nephropathy in streptozotocin-induced diabetic mice. Am J Physiol Renal Physiol 2014;306:F10515.

62. Wu H, Zhou S, Kong L, et al. Metallothionein deletion exacerbates intermittent hypoxiainduced renal injury in mice. Toxicol Lett 2015;232:340-8.

63. Park L, Min D, Kim H, et al. Tat-enhanced delivery of metallothionein can partially prevent the development of diabetes. Free Radic Biol Med 2011;51:1666-74.

64. Wu G, Fang YZ, Yang S, Lupton JR, Turner ND. Glutathione metabolism and its implications for health. J Nutr 2004;134:489-92.

65. Wang L, Ahn YJ, Asmis R. Sexual dimorphism in glutathione metabolism and glutathionedependent responses. Redox Biol 2020;31:101410. 
66. Saran R, Robinson B, Abbott KC, et al. US Renal Data System 2016 Annual Data Report: Epidemiology of Kidney Disease in the United States. American journal of kidney diseases : the official journal of the National Kidney Foundation 2017;69:A7-A8.

67. Clotet-Freixas S, Soler MJ, Palau V, et al. Sex dimorphism in ANGII-mediated crosstalk between ACE2 and ACE in diabetic nephropathy. Lab Invest 2018;98:1237-49.

68. Sharma M, Merkulova $\mathrm{Y}$, Raithatha $\mathrm{S}$, et al. Extracellular granzyme K mediates endothelial activation through the cleavage of protease-activated receptor-1. FEBS J 2016;283:1734-47. 69. Wensink AC, Kemp V, Fermie J, et al. Granzyme K synergistically potentiates LPS-induced cytokine responses in human monocytes. Proc Natl Acad Sci U S A 2014;111:5974-9.

70. Li S, van Dijk CGM, Meeldijk J, et al. Extracellular Granzyme K Modulates Angiogenesis by Regulating Soluble VEGFR1 Release From Endothelial Cells. Front Oncol 2021;11:681967.

71. Turner JE, Paust HJ, Steinmetz OM, Panzer U. The Th17 immune response in renal inflammation. Kidney Int 2010;77:1070-5.

72. Chung $\mathrm{BH}$, Yang CW, Cho ML. Clinical significance of Th17 cells in kidney transplantation. Korean J Intern Med 2018;33:860-6.

\section{Acknowledgments:}

First and foremost, we would like to thank the kidney transplant patients who made this work

possible. We would also like to thank the nurses, physicians and surgeons at Toronto General

Hospital and the Ajmera Transplant Centre Biobank for efforts to obtain tissue samples, and

acknowledge technical support provided by the Princess Margaret Genomics Centre, particularly

Troy Ketela and Julissa Tsao, and the Princess Margaret Cancer Centre flow cytometry core. CMM

was supported by the Menkes Family Fellowship and an Ajmera Transplant Centre fellowship. JMM was supported a QE II/Aventis Pasteur Graduate Scholarship and a Peterborough K.M. Hunter

Foundation scholarship. This work supported by funding from the Canadian Institutes for Health

Research (CIHR) grant 168960 to SQC and AK and the Ajmera Transplant Centre/Toronto General

and Western Hospital Foundation (TGWHF). SQC was also supported by the Medicine by Design

program (Canada First Research Excellence Fund) and Canada Foundation for Innovation (CFI) grant

38308. AK was supported by Kidney Foundation of Canada (KFOC) Predictive Biomarker grant

KFOC160010, CIHR 347479, CFI grant 37205, KFOC Biomedical Research grant KFOC160010, and

Kidney Research Scientist Core Education and National Training (KRESCENT) program grants

CIHR148204, KRES160004, and KRES160005, as well as funding from TGWHF (TGTWF 1617-464; 


\section{Author contributions:}

$525 \mathrm{CMM}, \mathrm{JMM}, \mathrm{AK}$, and SQC designed and implemented the study. AK and SS established the ATC

526 biobank and the infrastructure required for sample retrieval. SS, CMM, JMM, SZ, KAL, AF and AK

527 liaised with patient care teams to obtain tissues for study. CMM, JMM, JAM, SCF, JA, AK and SQC

528 developed tissue dissociation protocols with input from LL and SAM, and performed experiments.

$529 \mathrm{SCF}, \mathrm{OZ}, \mathrm{HR}, \mathrm{RA}$, contributed to PT validation experiments. CMM, JMM and LZ designed and

530 implemented the bioinformatic pipeline with advice and assistance from MK, DP, BW, GDB, AK and

531 SQC. CMM, JMM, SAM, AK and SQC provided tissue and immune compartment expertise and

532 annotated cell types. BW, SAM, GDB, AK, and SQC supervised the work. CMM, JMM, AK, and SQC

533 wrote the manuscript, which all authors reviewed and edited.

535 Competing interests: Authors declare that they have no competing interests

Materials and correspondence

538 Correspondence and requests for materials should be addressed to Dr. Sarah Crome

539 (sarah.crome@utoronto.ca) and Dr. Ana Konvalinka (Ana.Konvalinka@uhn.ca)

541 Supplementary Information is available for this paper. 
bioRxiv preprint doi: https://doi.org/10.1101/2021.12.09.471943; this version posted December 10, 2021. The copyright holder for this

preprint (which was not certified by peer review) is the author/funder, who has granted bioRxiv a license to display the preprint in perpetuity. It is made available under aCC-BY-NC-ND 4.0 International license.

553 
bioRxiv preprint doi: https://doi.org/10.1101/2021.12.09.471943; this version posted December 10, 2021. The copyright holder for this preprint (which was not certified by peer review) is the author/funder, who has granted bioRxiv a license to display the preprint in perpetuity. It is made available under aCC-BY-NC-ND 4.0 International license.

a

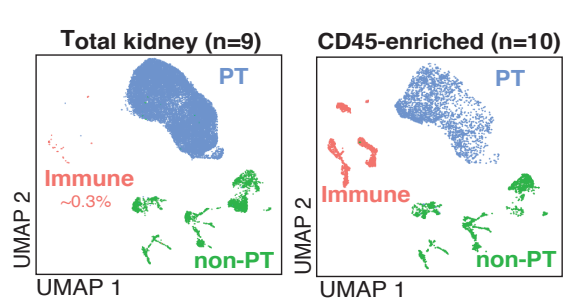

d

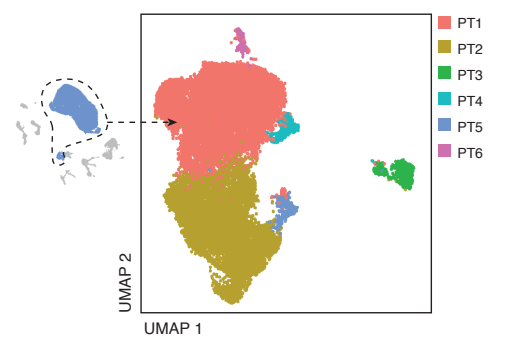

e

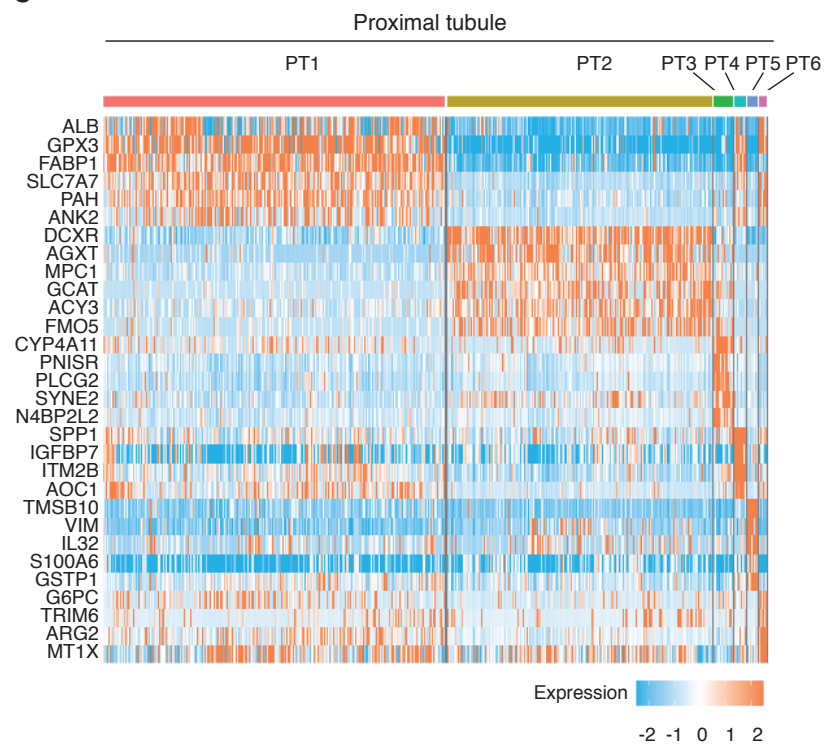

f

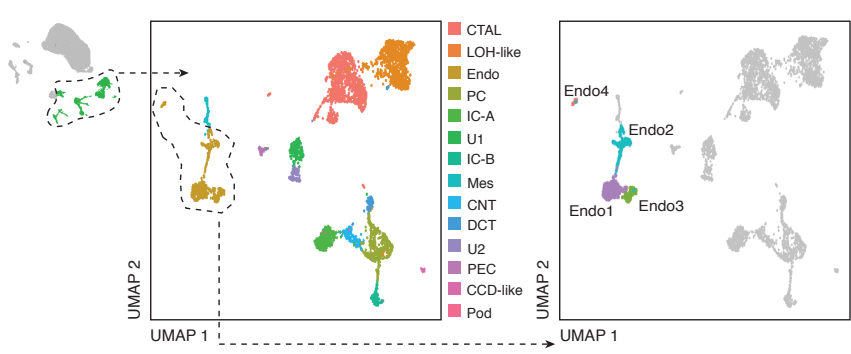

b

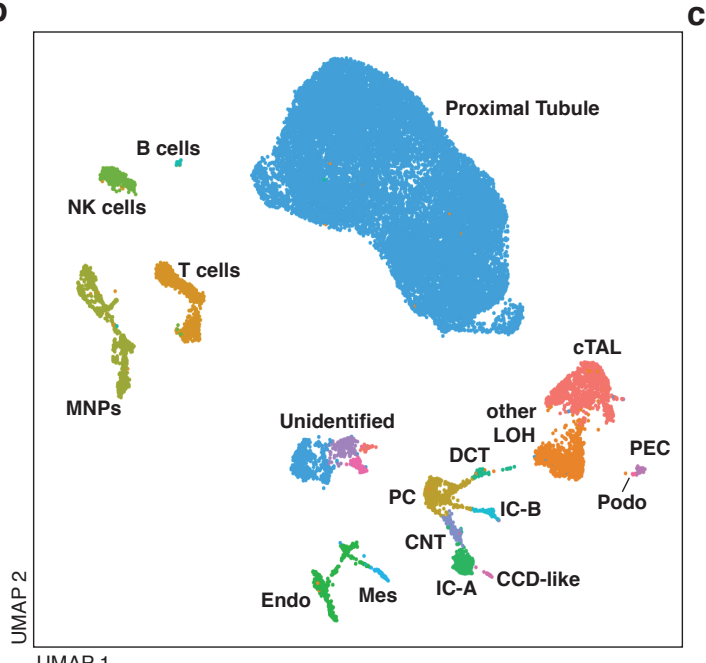

C
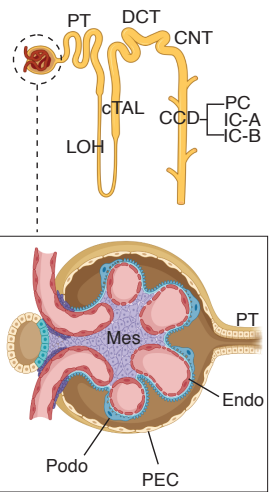

g
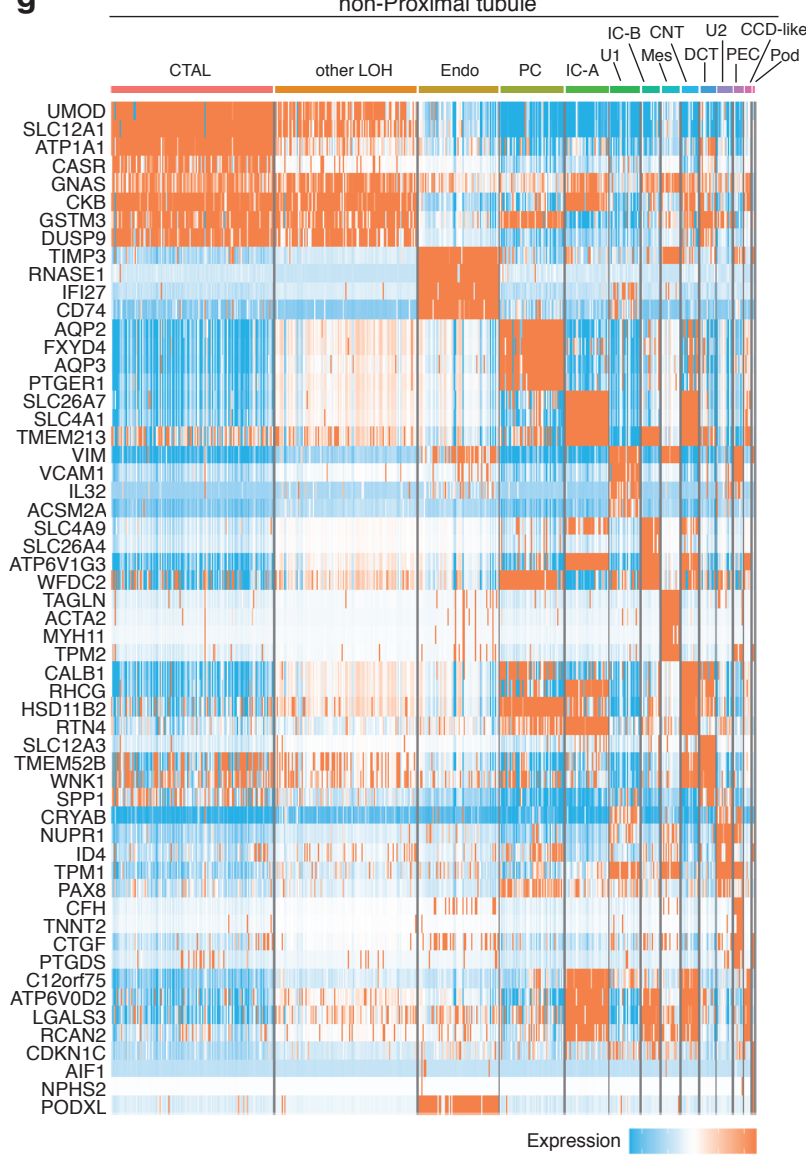

$\begin{array}{lllll}-2 & -1 & 0 & 1 & 2\end{array}$

Figure 1. Identification and annotation of kidney parenchymal cells. (a) Different cell type proportions were captured by sequencing total kidney homogenate and CD45-enriched samples to create the total combined dataset. (b) UMAP clustering of total combined dataset with cell type annotations. (c) Graphical depiction of location of nephron cell types captured within the data. (d) UMAP plot of compartment-specific analysis of 20772 proximal tubular cells, comprising 6 clusters. (e) Heat map showing the expression levels of cluster marker genes. (f) UMAP plot of compartment-specific analysis of 4436 non-proximal tubular parenchymal cells, with 14 cell populations represented, including four distinct endothelial clusters. (g) Heat map showing the expression levels of cell type marker genes across the 14 non-PT cell populations. 
a

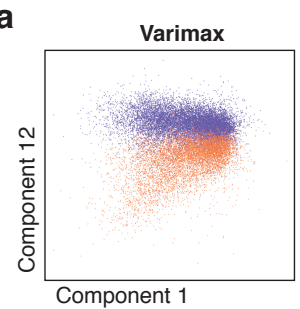

b

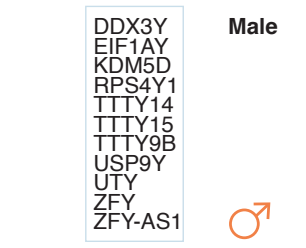

C

MAST+

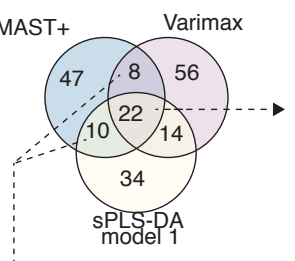

564
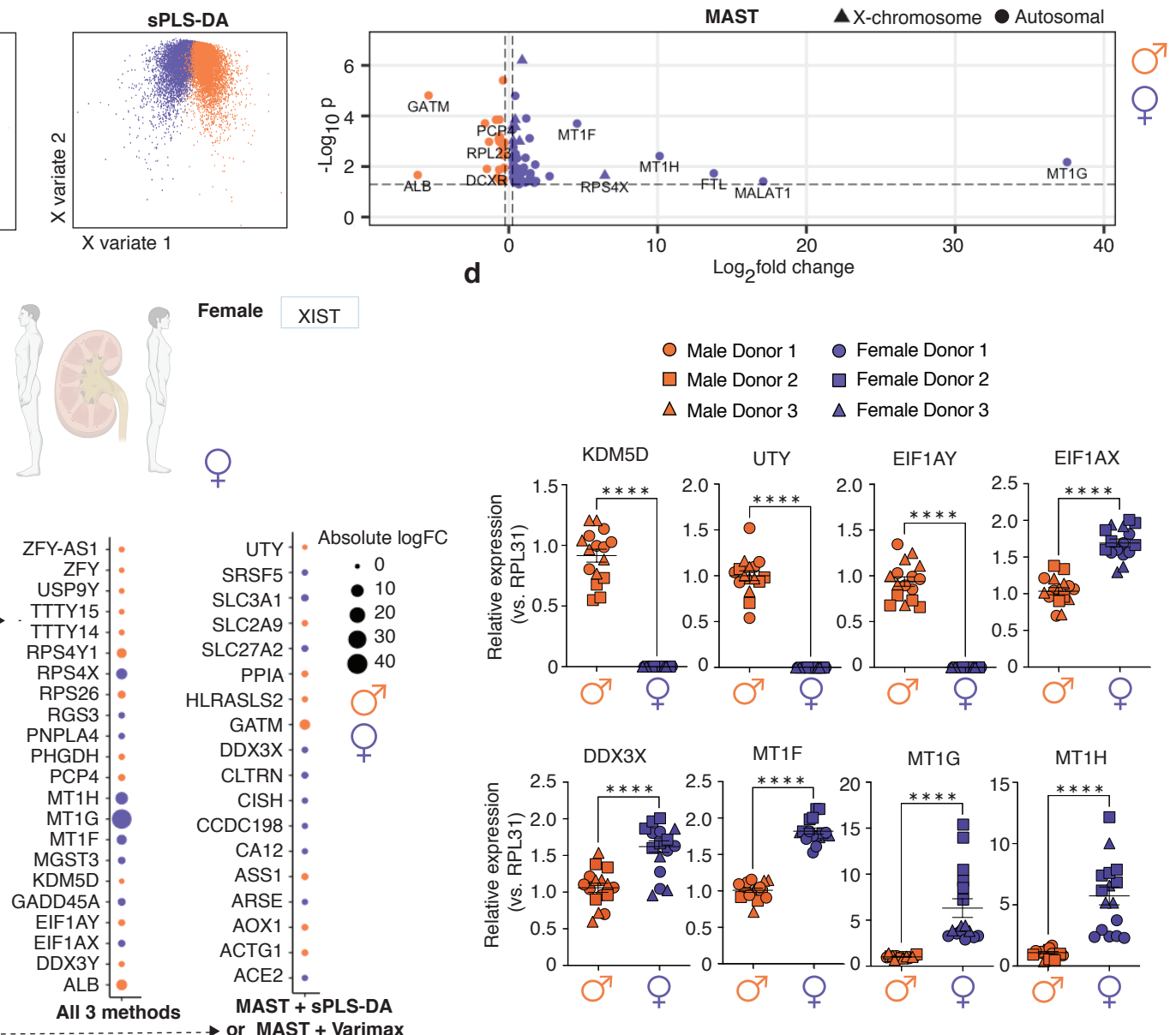

$$
\begin{array}{cc}
\text { O Male Donor 1 } & \text { ○ Female Donor 1 } \\
\square \text { Male Donor 2 } & \square \text { Female Donor 2 } \\
\Delta \text { Male Donor 3 } & \Delta \text { Female Donor 3 }
\end{array}
$$
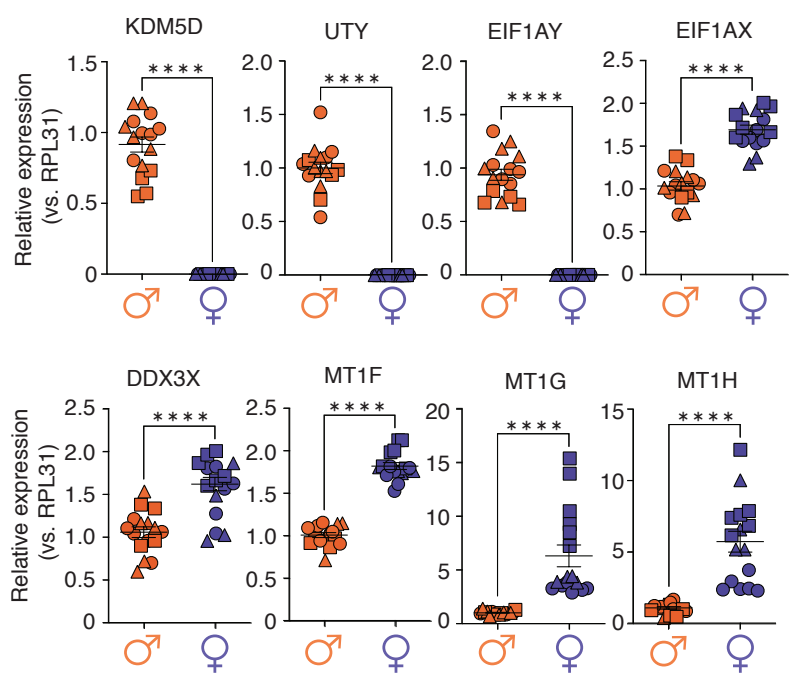

Figure 2. Identifying genes differentially expressed between male and female proximal tubular cells. (a) 2Dimensional plots of Varimax-rotated PCA and SPLS-DA showing separation of male and female cells, and volcano plot showing differential expression of genes between sexes from MAST analysis with sample random effect. (b) Genes expressed exclusively by all samples of one sex and none of the opposite sex, which were added to the MAST results for comparison across methods in c. (c) Venn diagram depicting genes identified through each analysis, with bubble plots highlighting genes identified by all three methods or by MAST plus one additional method. The size of the circle is proportional to absolute logFC and the colour indicates whether the gene was higher in male (orange) or female (dark purple) PT cells. (d) Differences in gene expression of $K D M 5 D(\mathrm{p}<0.0001, \mathrm{t}=17.32, \mathrm{df}=30), \operatorname{UTY}(\mathrm{p}<0.0001, \mathrm{t}=18.75, \mathrm{df}=30), \operatorname{EIF1AY}(\mathrm{p}<0.0001, \mathrm{t}=18.04$, $\mathrm{df}=30), \operatorname{EIF1AX}(\mathrm{p}<0.0001, \mathrm{t}=9.077, \mathrm{df}=29), D D X 3 X(\mathrm{p}<0.0001, \mathrm{t}=5.619, \mathrm{df}=29), M T 1 F \quad(\mathrm{p}<0.0001, \mathrm{t}=16.04$, $\mathrm{df}=30), M T 1 G(p<0.0001, \mathrm{u}=0)$, and $M T 1 H(p<0.0001, \mathrm{t}=6.286, \mathrm{df}=30)$ were determined in primary male and female PT cells, and normalized to RPL31 ( $n=3$ donors/sex; $n=4-6$ replicates/donor). Group-to-group differences were assessed using two-tailed unpaired t-tests for variables following a normal distribution, and Mann-Whitney tests for variables with a non-parametric distribution. ${ }^{* * * *} p<0.0001$. PT, proximal tubule. 
a

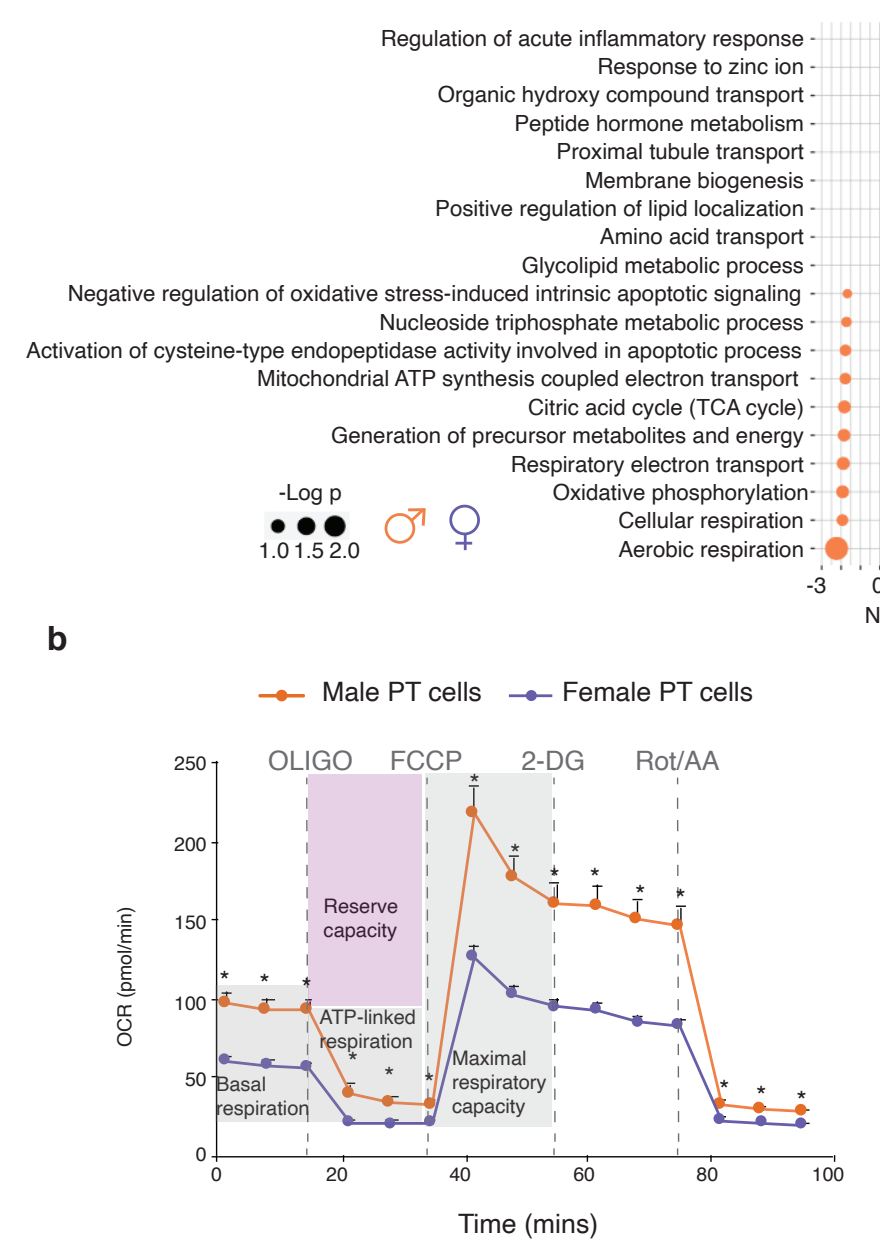

c

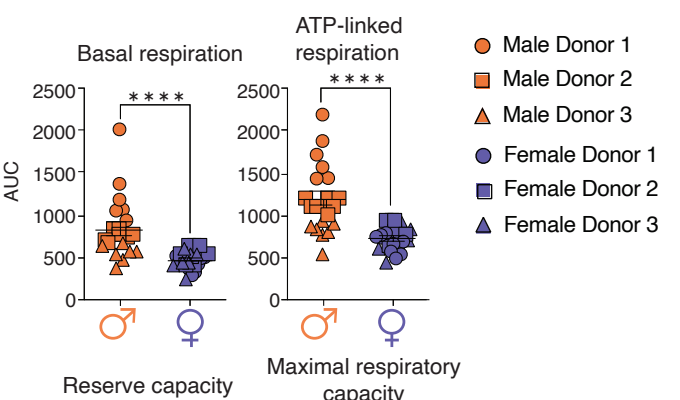

capacity d
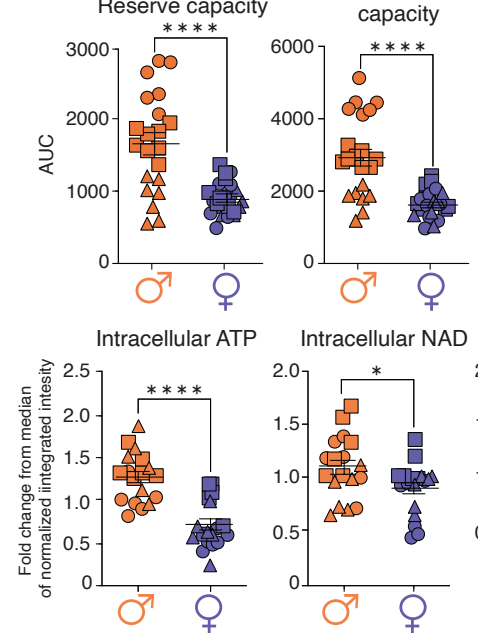

Intracellular

$\beta$-nicotinamide
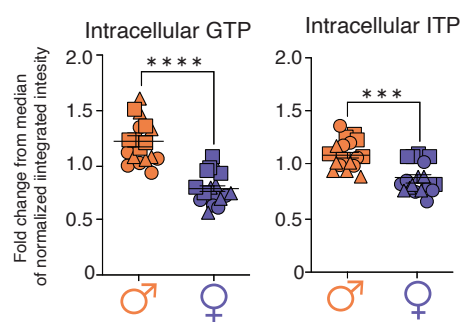

Intracellular UTP

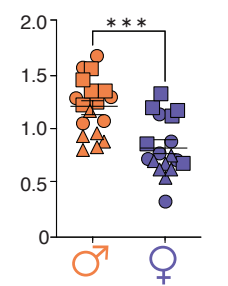

Figure 3. Sex differences in the mitochondrial respiration and energy precursor metabolism of proximal tubular cells. (a) Depiction of selected significant (FDR $<0.25)$ terms identified by GSEA analysis as being enriched in males and females respectively. (b) Oxygen consumption rate (OCR) was monitored to assess the mitochondrial respiration of male and female PT cells at baseline and after metabolic stress. To induce metabolic stress, the following sequence of drugs was injected: $1 \mu \mathrm{M}$ oligomycin, $0.3 \mu \mathrm{M} \mathrm{FCCP,100mM} \mathrm{2-DG,}$ $1 \mathrm{mM}$ Rot/AA. The OCR was monitored in male and female PT cells ( $n=3$ donors/sex; $n=6-8$ replicates/donor). (c) The basal OCR $(p<0.0001, u=48)$, ATP-linked respiration $(p<0.0001, t=5.223$, $d f=42)$, reserve capacity $(p<0.0001, t=5.018, d f=42)$ and maximal respiratory capacity $(p<0.0001, t=5.281, d f=42)$ of male and female PT cells were calculated from the OCR curves in panel B. Group-to-group differences were assessed using twotailed unpaired $T$ tests for variables following a normal distribution, and Mann-Whitney tests for variables with a non-parametric distribution. (d) In a separate experiment, the intracellular levels of ATP $(p<0.0001$, $t=5.959, d f=34), N A D(p=0.029, u=93), \beta$-nicotinamide mononucleotide $(p<0.0001, t=4.575, d f=34), G T P$ $(p<0.0001, t=7.45, d f=34)$, ITP $(p=0.0001, u=46)$, and UTP $(p=0.0001, t=4.316, d f=34)$ were determined in male and female PT cells ( $n=3$ donors/sex; $n=6$ replicates/donor). Group-to-group differences were assessed using two-tailed unpaired T tests for variables following a normal distribution, and Mann-Whitney tests for variables with a non-parametric distribution. , ${ }^{*} p<0.05 ;{ }^{* *} p<0.01 ;{ }^{* * *} p<0.001 ; * * * * p<0.0001$. PT, proximal tubule; AUC, area under the curve; OCR, oxygen consumption rate; FCCP, p-trifluoromethoxy carbonyl cyanide phenyl hydrazone; 2-DG, 2-deoxyglucose; Rot, rotenone; AA: antimycin A; df: degrees of freedom. 


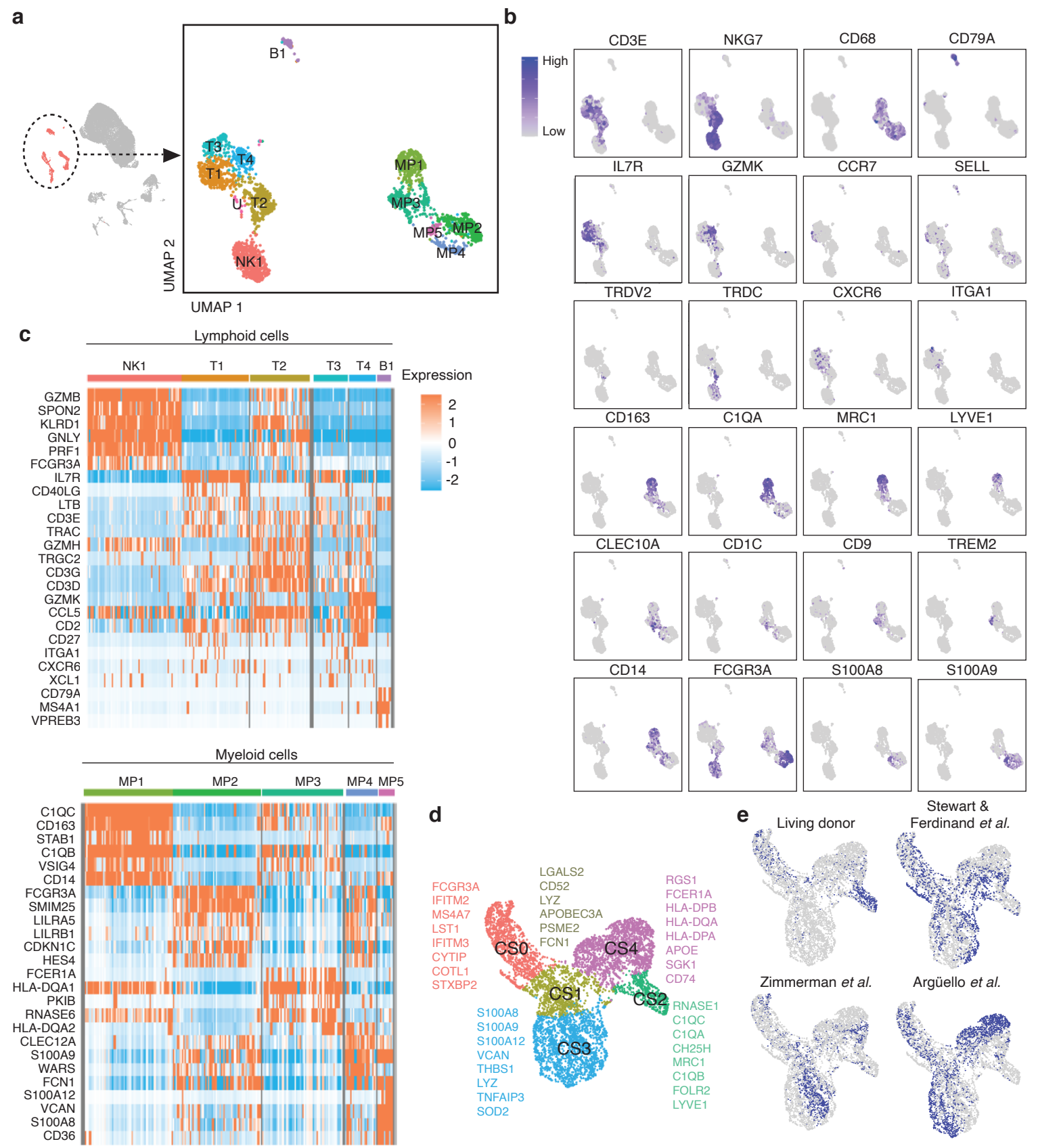

Figure 4. Identification and annotation of kidney immune cells. (a) Compartment-specific analysis of 2491 immune cells comprising 12 clusters and (b) cell type markers used for cluster annotations (c) Heatmap of celltype defining and highly expressed genes by each cluster separated by lymphoid and myeloid lineage. (d) UMAP plot showing the living donor myeloid cell data clustered together with the same three published datasets to define five cell states across datasets and their respective cluster markers. (e) UMAP plots highlighting the distribution of dataset membership across the cell states. 
a
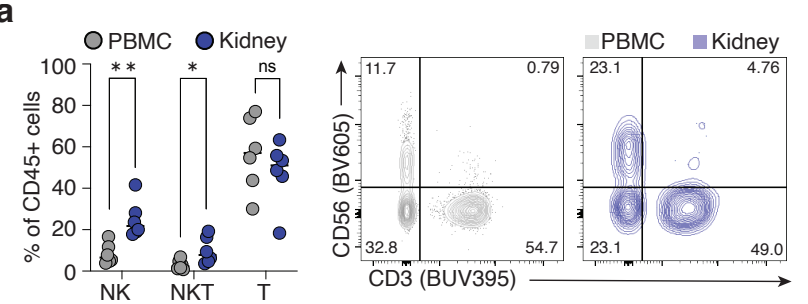

C

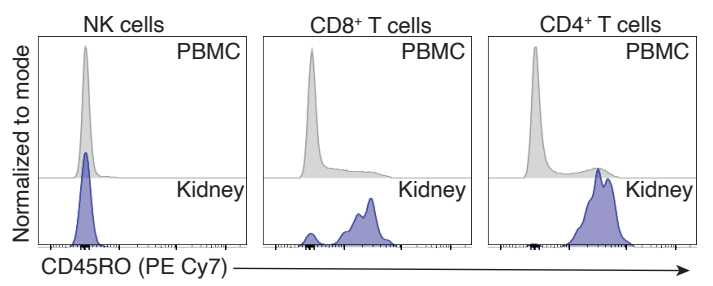

e

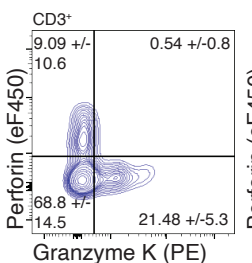

h
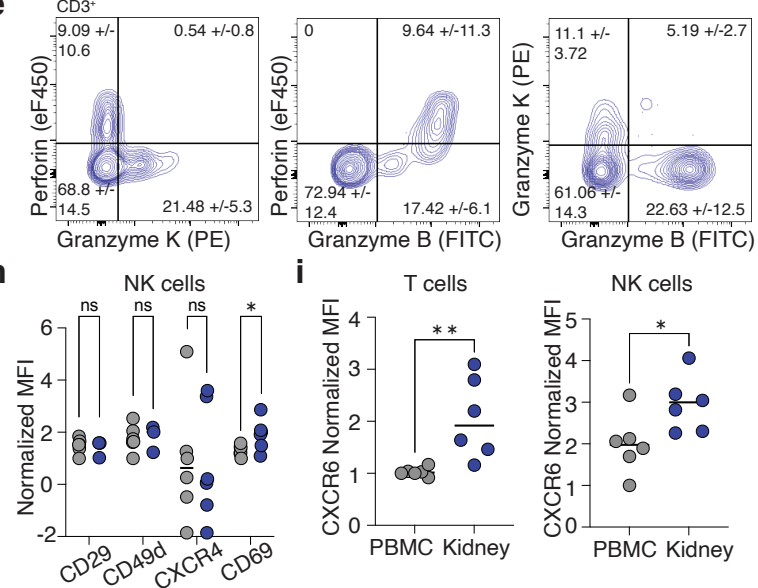

j

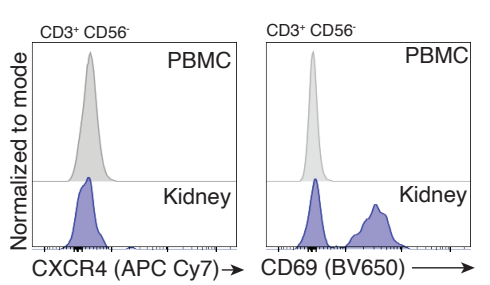

b
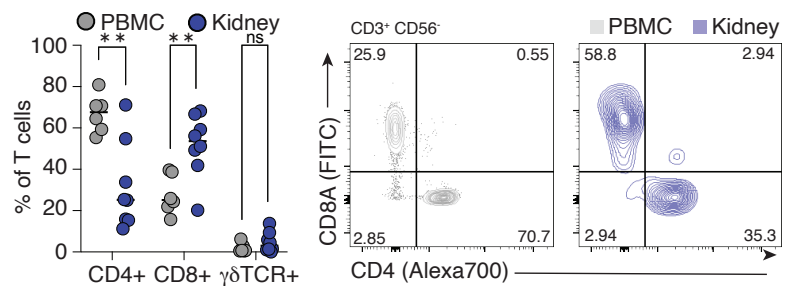

d
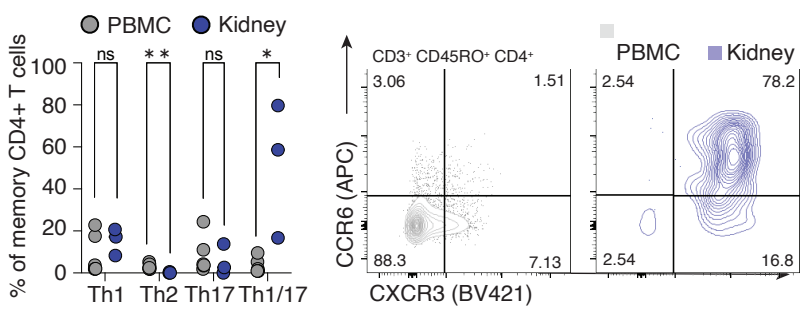

613
Figure 5: Characterization of kidney-resident $T$ and NK cells. (a) NK cells ( $p=0.0025, t=3.998, d f=10$ ) and NKT cells $(p=0.0327, t=2.476, d f=10)$ are proportionally enriched in kidney relative to blood, while T cell $(p=0.379$, $t=0.918, d f=10)$ abundance is unchanged. $(n=6)(b)$ Within the kidney $T$ cell population, there is an enrichment of CD8 ${ }^{+} T$ cells ( $\left.p=0.0060, t=3.327, d f=12\right)$ and a reduction in $C D 4+T$ cell $(p=0.0025, t=3.815, d f=12)$ abundance with no change in TCRgd ${ }^{+} T$ cells $(p=0.2158, u=14)$ relative to blood. $(n=6)(c)$ Kidney $T$ cells are predominantly antigen-experienced, marked by expression of CD45RO, while NK cells express minimal CD45RO. (d) Within kidney memory CD4 ${ }^{+} \mathrm{T}$ cells, there is an enrichment in the Th1/17 subpopulation $\left(\mathrm{CXCR3}^{+}{ }^{+} \mathrm{CR} 6^{+}\right)(p=0.0238$, $\mathrm{u}=0)$ and a reduction in Th2 subpopulation $\left(\mathrm{CRTh2} 2^{+}\right)(\mathrm{p}=0.0098, \mathrm{t}=3.513, \mathrm{df}=7)$ abundance relative to blood while Th1 $\left(\mathrm{CXCR}^{+}\right)(p=0.3810, u=5)$ and Th17 $\left(\mathrm{CCR}^{+}\right)(p=0.5476, u=6)$ proportions were unchanged. $(n=3)(e)$ $T$ cells expressing Granzyme $K$ do not co-express perforin, indicating that they are a distinct $T$ cell subset from Granzyme $B^{+}$Perforin ${ }^{+}$cytotoxic $T$ cells. (f) Violin plots showing differential gene expression of select markers in kidney T cells and NK cells relative to blood. (g) Surface levels of CD29 ( $p=0.0061, t=3.869, d f=7), C D 49 d$ $(p=0.0027, t=4.519, d f=7)$ and $\operatorname{CD69}(p=0.0203, t=2.756, d f=10)$ were higher on kidney $T$ cells relative to blood as measured by flow cytometry, while CXCR4 $(p=0.5887, u=14)$ was not $(n=6)$. (h) Surface levels of CD69 $(p=0.0427, t=2.321, d f=10)$ was higher on kidney NK cells relative to blood while CD29 $(p=0.6899, t=0.4159$, $d f=7), C D 49 d(p=0.9040, t=0.1250, d f=7)$, and CXCR4 ( $p=0.9326, t=0.0868, d f=10)$ were not. $(n=6)(i)$ CXCR6 abundance was higher at the protein level on both T cells $(p=0.0086, t=3.258, d f=10)$ and NK cells $(p=p=0.0364$, $t=2.414, d f=10$ ) relative to blood. (j) Histograms showing no difference in CXCR4, increased CD69 and increased CXCR6 protein abundance in kidney T cells relative to blood. Group-to-group differences were assessed using two-tailed unpaired T tests for variables following a normal distribution, and Mann-Whitney tests for variables with a non-parametric distribution. , ${ }^{*} p<0.05$; $^{* *} p<0.01 ;^{* * *} p<0.001$; $^{* * *} p<0.0001$. 


\section{Materials and Methods}

\section{EXPERIMENTAL MODEL AND SUBJECT DETAILS}

\section{Human Specimens}

Kidney tissue from tumour-unaffected nephrectomy specimens was used for initial method optimization.

Pre-implantation core biopsies were obtained from living donor kidneys after organ retrieval and flushing.

20 live donor kidney samples (10 male donors and 10 female donors) were processed for sequencing.

Additional living donor kidney samples were used in flow cytometry experiments for method optimization and immunophenotyping. All experiments were conducted with institutional ethics approval from University Health Network (CAPCR: 18-5914.0, Living donor; CAPCR: 18-5489.0, Tumour nephrectomy). Patient demographic information for sequenced samples is summarized in Supplementary Table 7. All patients provided informed written consent for inclusion in this study.

\section{Murine Specimens}

Murine kidneys from C57BL/6 mice (AUP: 6156) were used for digestion optimization experiments.

\section{EXPERIMENTAL METHOD DETAILS}

\section{Tissue digestion and CD45-enrichment}

All living donor samples used for sequencing were processed within one hour of organ retrieval. Briefly, biopsies were collected in RPMI 1640 (Gibco, cat \# 11875119) on ice, and mechanically dissociated with a blade before enzymatic digestion at 37으 with $0.1 \mathrm{mg} / \mathrm{ml}$ DNase I (STEMCELL, cat \# 07470), 3300 CDA units/ml Collagenase MA (VitaCyte, cat \# 001-2030) and 1430 NP units/ml BP neutral protease (VitaCyte, cat

657 \# 003-1000) for 20 minutes at 37으 with intermittent agitation in an dissociation protocol optimized to 658 maximize viability and to preserve representation of rare and fragile cell populations (Supplementary Fig.

659 15). Cell suspensions were filtered through $35 \mu \mathrm{m}$ cell strainer snap-cap FACS tubes (Falcon, cat\# 352235)

660 and a plunger from a $1 \mathrm{ml}$ syringe was used to gently mash remaining tissue in the strainer before rinsing

661 strainer lid with 1:1 volume of FBS (HyClone, cat \# SH3039603PM) on ice. A low frequency $(<1 \%)$ of immune 
bioRxiv preprint doi: https://doi.org/10.1101/2021.12.09.471943; this version posted December 10, 2021. The copyright holder for this preprint (which was not certified by peer review) is the author/funder, who has granted bioRxiv a license to display the preprint in perpetuity. It is made available under aCC-BY-NC-ND 4.0 International license.

cells in the single cell suspension from a kidney biopsy core (Fig. 1a) necessitated immune enrichment in 10 samples (5 males, 5 females) using magnetic EasySep Human CD45 depletion kit II (STEMCELL, cat\# 17898), as per the manufacturer's modified instructions for positive selection of CD45-expressing cells.

\section{Single-cell RNA sequencing}

Samples were prepared according to $10 \mathrm{X}$ Genomics Single Cell 3' v3 Reagent kit user guide ${ }^{73}$. The pilot sequencing sample from nephrectomy tissue was sequenced using 10X Genomics Single Cell 5' v2 Reagents. Samples were washed twice in PBS (Life Technologies) plus 0.04\% BSA, and viability was determined by a hemocytometer (Thermo Fisher) via Trypan Blue staining. Following counting, the appropriate volume for each sample was calculated for a target capture of 9,000 cells. For CD45-enriched samples, all cells were sequenced. Samples that were too low in cell concentration as defined by the user guide were washed, resuspended in a reduced volume and counted again using a haemocytometer prior to loading onto the $10 \mathrm{x}$ single cell B chip. After droplet generation, samples were transferred onto a pre-chilled 96 well plate (Eppendorf), heat sealed and incubated overnight in a Veriti 96-well thermos cycler (Thermo Fisher). The next day, sample cDNA was recovered using Recovery Agent provided by 10x and subsequently cleaned up using a Silane DynaBead (Thermo Fisher) mix as outlined by the user guide. Purified cDNA was amplified for 11 cycles before being cleaned up using SPRIselect beads (Beckman). Samples were diluted 4:1 (elution buffer (Qiagen):CDNA) and run on a Bioanalyzer (Agilent Technologies) to determine cDNA concentration. cDNA libraries were prepared as outlined by the Single Cell 3' Reagent Kits v3 user guide with modifications to the PCR cycles based on the calculated cDNA concentration.

The molarity of each library was calculated based on library size as measured bioanalyzer (Agilent Technologies) and qPCR amplification data (Roche). Samples were pooled and normalized to $1.5 \mathrm{nM}$. Library pool was denatured using $0.2 \mathrm{~N} \mathrm{NaOH}$ (Sigma) for 8 minutes at room temperature, neutralized with $400 \mathrm{mM}$ Tris-HCL (Sigma). Library pool at a final concentration of 300pM were loaded to sequence on Novaseq 6000 (Illumina). Samples were sequenced with the following run parameters: Read 1-28 cycles, Read 2- 90, index 1-10 cycles, index 2-10 cycles. Across samples, cells were sequenced to a target depth of 40,000 reads per 
bioRxiv preprint doi: https://doi.org/10.1101/2021.12.09.471943; this version posted December 10, 2021. The copyright holder for this preprint (which was not certified by peer review) is the author/funder, who has granted bioRxiv a license to display the preprint in perpetuity. It is made available under aCC-BY-NC-ND 4.0 International license.

cell. Mapping and quantification were performed using the 10X Genomics CellRanger pipeline version

3.1.0. Cell metric summaries for each sample in Supplementary Table 8.

\section{Single-nucleus RNA sequencing}

A pilot single-nucleus RNA sequencing experiment was undertaken to compare single cell versus single nuclear results from a matched sample. The biopsy was collected fresh and divided into 8 segments, evenly distributed to be processed fresh for single cell RNA sequencing as above, and the remainder was flash frozen in liquid nitrogen. The sample was later retrieved from liquid nitrogen and processed on dry ice according to the protocol in ${ }^{74}$ with a lysis buffer containing: $0.32 \mathrm{mM}$ sucrose (BioShop SUC507.1), $5 \mathrm{mM}$ CaCl2 (VWR, 97062-820), 3 mM MgCl2 (Thermo Fisher AM9530G), 20 mM Tris-HCl pH 7.5 (Thermo Fisher, 15567027), 0.1\% TritonX-100 (Sigma Aldrich T8787-50ML), 0.1 mM EDTA pH 8.0 (Thermo Fisher AM9260G), $40 \mathrm{U} / \mathrm{ml}$ Protector RNAse inhibitor (Sigma Aldrich 3335399001) in UltraPure DNAse/RNAse-free water (Thermo Fisher 10977015). The nuclei were captured and sequenced using 10X Genomics Single Cell 3' v3 Reagents as above.

\section{Data quality control, clustering, differential expression, pathway analysis and cell-cell interaction}

\section{inference}

Original study recruitment included samples from 20 donors, however, data from one male donor was poor quality and was excluded from downstream analysis. Thus, our final dataset consisted of 19 donors (10 female, 9 male), with 10 CD45-enriched samples ( 5 female, 5 male) and 9 samples not enriched for $C D 45^{+}$ cells referred to as "total kidney" (5 female, 4 males). To preserve representation of rare cell types with uniquely expressed genes, we retained genes expressed in a minimum of 1 cell in the individual datasets. Ambient RNA contamination was corrected using the AutoEst function in SoupX ${ }^{75}$ (Supplementary Fig. 16). DoubletFinder ${ }^{76}$ was used to identify and remove cells most likely to be doublets, rather than implementation of a maximum gene or feature threshold. For total samples, a high doublet rate threshold of 7.5\% was applied (as utilized in comparable studies ${ }^{77}$ ), while for $C D 45$-enriched samples, the doublet rate was calculated as $0.8 \%$ per 1000 cells captured, as per $10 \mathrm{X}$ Genomics estimated doublet rates ${ }^{73}$. The 
individual datasets were then merged. Upon merging all of the individual datasets, the cells clustered according to cell type rather than donor/batch, and importantly, no batch correction of the data was required.

Cell type-specific thresholds were set to remove low quality cells. For immune cells (clusters expressing PTPRC), all cells with $>10 \%$ of UMls mapped to mitochondrial genes were removed, along with cells that had low transcript abundance $(<1000)$ or gene diversity ( $<200$ unique genes). Separately, prior to removing cells with low transcripts/features, data was mined for the presence of granulocyte lineage cells such as neutrophils which are often removed by typical QC thresholds due to high RNAse activity and low gene content, however very few neutrophils $(>20)$ were identified by marker expression in the raw data across all samples. For parenchymal cells, all cells with $>40 \%$ of mitochondrial-mapped UMIs were removed; this high threshold was imposed due to known high mitochondrial content of proximal tubular cells ${ }^{78}$. Additionally, cells with low transcript abundance $<1000)$ and low gene diversity ( $<750$ unique genes) were removed. Cells expressing hemoglobin genes $(H B B, H B A 1 / 2)(n=160)$ were removed. Following normalization $\left(\mathrm{SCTransform}^{79}\right)$ and feature selection (M3Drop/DANB $\left.{ }^{80}\right)$, principal component analysis was used for dimensionality reduction (RunPCA) and cells were clustered using the Louvain algorithm with 30 principal components (FindNeighbors and FindClusters) (Seurat ${ }^{81}$ ). Clusters were visualized using UMAP algorithm ${ }^{82}$. The dataset was divided into 3 broad subgroups identified as being Immune $\left(P T P R C^{+}\right)$or Parenchymal (Proximal Tubular (expressing CUBN, HNF4A, SLC34A1, LRP2, SLC17A1) or non-Proximal Tubular) in origin. These subgroups were re-clustered and further annotated using a curated marker list (Supplementary Table 6). Cluster defining genes were identified by Seurat's FindMarkers ${ }^{81}$. Ranked gene lists were generated using Wilcoxon rank sum testing from the presto package (wilcoxauc function) ${ }^{83}$ were used as input for pathway analysis using GSEA ${ }^{84}$. Reference gene sets were acquired from the Bader lab repository (http://download.baderlab.org/EM Genesets/) - Geneset used: (Human_GOBP_AllPathways_no_GO_iea_January_13_2021_symbol.gmt.txt). To identify pathways enriched in immune cell clusters, the ranked gene lists were generated for each cluster comparing that cluster versus all other clusters. 
bioRxiv preprint doi: https://doi.org/10.1101/2021.12.09.471943; this version posted December 10, 2021. The copyright holder for this preprint (which was not certified by peer review) is the author/funder, who has granted bioRxiv a license to display the preprint in perpetuity. It is made available under aCC-BY-NC-ND 4.0 International license.

Cell-cell communication was inferred from the sequencing data using LIANA which generates a

742 consensus ranking across several methods ${ }^{85}$. The OmniPath interaction database was used ${ }^{86}$ with the

743 following methods for inferring interactions implemented through the package: SingleCellSignalR ${ }^{87}$, iTalk ${ }^{88}$,

744 NATMI ${ }^{89}$, Connectome $^{90}$, CellChat $^{91}$ and CellPhoneDB ${ }^{92}$. Results are summarized in Supplementary Table 5.

745 Separately, SingleCellSignalR, NATMI, iTALK and Connectome methods were used to generate a consensus

746 score using the CellPhoneDB database to infer interactions inclusive of multimeric complexes as accounted

747 for in the CellPhoneDB interaction database, summarized in Supplementary Table 6.

\section{Identification of innate lymphoid cells}

A predictive tool for cell type classification $\left(\mathrm{scPred}^{93}\right)$ was trained on single-cell data generated from flow

cytometry-sorted ILCs ${ }^{94}$ and T cells ${ }^{95}$. Using this classifier, some cells present within our dataset were putatively identified as ILCs.

\section{Transcription factor analysis}

Top cluster defining genes for PT5 and PT3, respectively were uploaded to $\mathrm{CHEA}^{96}$

(https://maayanlab.cloud/chea3/), and the top 10 predicted upstream regulators were identified.

\section{Comparison of kidney immune cells to PBMCs}

To identify differences in gene expression between T cells and NK cells from peripheral blood versus kidney, PBMC data (GSE148665) ${ }^{47}$ was integrated with the immune only kidney data using Harmony ${ }^{97}$. A second independent PBMC dataset ${ }^{48}$, was separately integrated with the kidney data for dataset-independent validation. NK cells and T cells (clusters expressing NKG7 and/or CD3E) were compared using Seurat's FindAllMarkers function. Violin plots and volcano plots were created using Seurat and EnhancedVolcano ${ }^{98}$.

\section{Comparison of Myeloid cells}

766 To identify differences in myeloid cell populations in living kidney donors compared to publicly available 
bioRxiv preprint doi: https://doi.org/10.1101/2021.12.09.471943; this version posted December 10, 2021. The copyright holder for this preprint (which was not certified by peer review) is the author/funder, who has granted bioRxiv a license to display the preprint in perpetuity. It is made available under aCC-BY-NC-ND 4.0 International license.

sources, CD68-expressing clusters from Stewart \& Ferdinand et al., ${ }^{3}$ Zimmerman et al., ${ }^{45}$ and Argüello et al. ${ }^{46}$ were scored using a random forest classifier (SingleCellNet ${ }^{99}$ ) to identify cells from the published datasets corresponding to the five myeloid clusters in the living donor data. Separately, all myeloid cells from this data and the three published studies were integrated and clustered to identify cell states using OCAT ${ }^{100}$. The datasets were also integrated and batch corrected using Seurat v3 integration (FindIntegrationAnchors and IntegrateData functions). The cell state identities from OCAT were mapped onto the integrated object and marker genes of cell states were identified using Seurat's FindAllMarkers function. Lineage analysis by pseudotime inference was applied to the OCAT-identified clustering of the combined myeloid populations using slingshot ${ }^{101}$, without indicating any clusters as either start or end points.

\section{Sex differences analysis}

Principal component analysis (PCA) followed by Varimax rotation was performed on all major parenchymal and immune populations. Varimax-rotated principal components 2:25 were serially plotted against component 1 , to identify whether a separation on the basis of sex was evident. If seen, the top 100 genes (50 from each end of the gene loading list) associated with the Varimax-rotated principal component were retained for further analysis.

$$
\text { Sex differences in proximal tubular cells were identified using sparse partial least squares }
$$

discriminant analysis (sPLS-DA) in mixOmics ${ }^{102}$. Using the tuning function (tune.splsda), the optimal values for sparsity parameters were determined to be 1 component with 80 variables (genes). To test the classifier, the data were separated into a training dataset (2/3 of cells sampled) and a query dataset (remaining $1 / 3$ ). Next, our 80-gene signature was applied to an external dataset (Liao et al. ${ }^{20}$ ) for validation. Here, the entire living donor dataset was used as the training dataset and the external dataset was used as the query dataset. To determine the contribution of sex chromosome encoded genes to the model, all X-and Ychromosome encoded genes were removed from the datasets prior to analysis, where the tuned parameters identified the optimal model to include 1 component with 15 variables. This 15 -gene signature was also validated in the Liao et al. dataset. Hierarchical structure, zero inflation, and pseudoreplication bias in single-cell data pose specific challenges for differential expression analyses ${ }^{103-105}$. To circumvent these 
bioRxiv preprint doi: https://doi.org/10.1101/2021.12.09.471943; this version posted December 10, 2021. The copyright holder for this preprint (which was not certified by peer review) is the author/funder, who has granted bioRxiv a license to display the preprint in perpetuity. It is made available under aCC-BY-NC-ND 4.0 International license.

795 limitations, we implemented a mixed effects model using MAST ${ }^{105,106}$. For differential expression testing

796 between male and female proximal tubule cells, the dataset was filtered to include only genes which were expressed in each sample (9792 genes). Differential expression testing was conducted using MAST with a random effect for sample (zlm $\sim$ cellular detection rate + donor sex $+(1 \mid$ sampleID)). As this approach excluded genes expressed exclusively by one sex (e.g. Y chromosome encoded genes, and XIST), such genes were added to MAST differentially expressed genes (MAST+) for comparison with the results of the other methods (Varimax, sPLS-DA). All significant genes returned using MAST analysis were subjected to enrichment analysis (GSEA ${ }^{84,107}$ ) using reference gene sets acquired from the Bader lab repository:

(http://download.baderlab.org/EM Genesets/); Geneset used:

(Human_GOBP_AllPathways_no_GO_iea_January_13_2021_symbol.gmt.txt).

\section{Cryopreservation}

808 Cells from additional (non-sequenced) fresh living donor biopsies or cells remaining following 10X cell capture for sequencing were resuspended in 90\% human serum (Sigma, cat\# H4522) and 10\% DMSO for cryopreservation and cooled to $-80^{\circ} \mathrm{C}$ in a Mr.Frosty (Sigma, cat \#C1562), then transferred to liquid nitrogen for long term storage.

\section{Flow Cytometry}

814 After fresh tissue digestion, cells were washed in PBS + 2\% FCS before staining. Cryopreserved cells were 815 thawed and washed twice in PBS $+2 \%$ FCS. Cells were incubated at 4 으 for 15 minutes with an Fc receptor blocker (BioLegend TruStain FcX, cat \# 422302) according to manufacturer instructions before cocktails of

817 surface antibodies were added for 30 minutes at 4 으. If intracellular targets/transcription factors were 818 included in the panel, cells were resuspended in FOXP3 transcription factor fix perm buffer (eBio, cat \# 00819 5523-00) and stained with intracellular antibodies in $1 \mathrm{X}$ permeabilization buffer (eBio, cat \# 00-8333-56). If no intracellular targets were included in the staining panel, cells were fixed in 2\% PFA (Thermo Scientific, cat \# J19443) after surface staining. 
bioRxiv preprint doi: https://doi.org/10.1101/2021.12.09.471943; this version posted December 10,2021 . The copyright holder for this preprint (which was not certified by peer review) is the author/funder, who has granted bioRxiv a license to display the preprint in perpetuity. It is made available under aCC-BY-NC-ND 4.0 International license.

Cells were stained with the following surface antibodies: Anti-human CD8a FITC (1:100, clone RPA-

T8, BioLegend, cat \# 301050), Anti-human TCRgd FITC (1:100, clone B1, BioLegend, cat \# 331208), Antihuman CD3 FITC (1:100, clone UCHT1, BioLegend, cat \# 300440), Anti-human CD8a PerCP (1:50, clone RPAT8, BioLegend, cat \# 301030), Anti-human CXCR6 PerCP Cy5.5 (1:50, clone K041E5, BioLegend, cat \# 356010), Anti-human CCR8 PE (1:100, clone L263G8, BioLegend, cat \# 360604), Anti-human CD127 PE (1:50, clone hIL-7R-M21, BD Biosciences, cat \# 557938), Anti-human CD15 PE (1:100, clone W6D3, BD Biosciences, cat \# 562371), Anti-human CD163 PE (1:50, clone GHI/61, BioLegend, cat \# 333606), Anti-human CD49d PE Dazzle 594 (1:100, clone 9F10, BioLegend, cat \# 304325), Anti-human CRTh2 PE Dazzle 594 (1:50, clone BM16, BioLegend, cat \# 350126), Anti-human CD31 PE Dazzle 594 (1:100, clone WM59, BioLegend, cat \# 303130), Anti-human CD16 PE Dazzle 594 (1:100, clone 3G8, BioLegend, cat \# 302054), Anti-human CD45 PECF594 (1:100, clone HI30, BD Biosciences, cat \# 562279), Anti-human CD29 PE Cy7 (1:100, clone TS2/16, BioLegend, cat \# 303025), Anti-human CD45RO PE Cy7 (1:50, clone UCHL1, BD Biosciences, cat \# 560608), Anti-human MerTK PE Cy7 (1:50, clone 590H11G1E3, BioLegend, cat \# 367610), Anti-human TIGIT PE Cy 7 (1:50, clone MBSA43, Invitrogen, cat \# 25-9500-42), Anti-human CD94 APC (1:100, clone HP-3D9, eBioscience, cat \# 17-5094-42), Anti-human CCR6 APC (1:25, clone G034E3, BioLegend, cat \# 353416), Antihuman CD206 APC (1:50, clone 15-2, BioLegend, cat \# 321110), Anti-human CD4 Alexa700 (1:50, clone RPAT4, eBioscience, cat \# 56-0049-42), Anti-human CD127 Alexa700 (1:50, clone eBioRDR5, eBioscience, cat \# 56-1278-42), Anti-human CXCR4 APC Cy7 (1:50, clone 12G5, BioLegend, cat \# 306528), Anti-human CTLA4 APC Cy7 (1:25, clone BNI3, BioLegend, cat \# 369634), Anti-human CD56 APC Cy7 (1:50, clone HCD56, BioLegend, cat \# 318332), Anti-human CD45 APC Cy7 (1:100, clone HI30, BioLegend, cat \# 304014), Antihuman CD14 APC eF780 (1:100, clone 61D3, eBioscience, cat \# 47-0149-42), Anti-human CXCR3 BV421 (1:50, clone G025H7, BioLegend, cat \# 353716), Anti-human CD13 BV421 (1:50, clone WM15, BioLegend, cat \# 301716), Anti-human TCRgd BV510 (1:100, clone B1, BioLegend, cat \# 331220), Anti-human TCRab BV510 (1:100, clone IP26, BioLegend, cat \# 306734), Anti-human CD5 BV510 (1:100, clone L17F12, BioLegend, cat \# 364018), Anti-human FcER1 BV510 (1:100, clone AER-37, BioLegend, cat \# 334626), Anti-human CD303 BV510 (1:100, clone 201A, BioLegend, cat \# 354232), Anti-human CD123 BV510 (1:100, clone 6H6, BioLegend, cat \# 306022), Anti-human CD34 BV510 (1:100, clone 581, BioLegend, cat \#343528), Anti-human 
CD20 BV510 (1:100, clone 2H7, BioLegend, cat \# 302340), Anti-human CD3 BV510 (1:100, clone OKT3,

BioLegend, cat \# 317332), Anti-human CD14 BV510 (1:100, clone M5E2, BioLegend, cat \# 301842), Anti-

BUV395 (1:100, clone HI30, BD Biosciences, cat \# 563792), Anti-human CD16 BUV395 (1:100, clone 3G8, BD

Biosciences, cat \# 563785), Anti-human CD3 BUV395 (1:100, clone UCHT1, BD Biosciences, cat \# 563546), 
875 Commercially available human primary PTs from 6 donors ( 3 males and 3 females, Lonza Walkersville Inc)

876 were expanded at passage 4 , and studied at passage 5 . The main donor characteristics are summarized in

877 Supplementary Table 2. Cells were grown in custom-made Dulbecco's modified Eagle's medium (DMEM)

878 containing $5.55 \mathrm{mM}$ D-glucose, $4 \mathrm{mM}$ L-glutamine, and $1 \mathrm{mM}$ sodium pyruvate, and supplemented with $87910 \mathrm{ng} / \mathrm{mL}$ human EGF, 0.05M hydrocortisone, 1x of Transferrin/Insulin/Selenium (Invitrogen), 10\% v/v dialyzed 880 fetal bovine serum (FBS), 50g/mL streptomycin, and 50 units $/ \mathrm{mL}$ penicillin, as previously ${ }^{108,109}$. Cells were 881 serum-starved for $24 \mathrm{~h}$ prior to collection for gene expression, metabolite measurements, and assessment of 882 metabolic function. For gene expression experiments, cells were washed with PBS, harvested with trypsin, and snap-frozen at $-80^{\circ} \mathrm{C}$ until further analysis.

\section{Assessment of metabolic function in human primary PT cells}

886 Mitochondrial respiration was assessed in male and female PTECs by measuring their oxygen consumption 887 rate (OCR) in a Seahorse XFe96 analyzer (Agilent). Glycolysis was also assessed by monitoring the extracellular 888 acidification rate (ECAR). Upon $80-90 \%$ confluence, cells were detached with $0.25 \%$ trypsin $\left(5 \mathrm{~min}, 37^{\circ} \mathrm{C}\right)$, counted and seeded in a Seahorse XFe96 Cell Culture Microplate at a density of 15,000 cells/well in 100 $\mu$ L of DMEM complete media. After adhering for $6 \mathrm{~h}$, PT cells were exposed to serum starvation conditions for $24 \mathrm{~h}$.

One hour prior to the metabolic function assay, cells were washed with phenol-free basal media (Agilent) and exposed to $150 \mu \mathrm{L}$ of assay media, which included $2 \mathrm{mM}$ glutamine and $5.55 \mathrm{mM}$ glucose. During the assay, OCR and ECAR were recorded at baseline and after metabolic stress. To induce metabolic stress, $25 \mu \mathrm{L}$ of oligomycin, p-trifluoromethoxy carbonyl cyanide phenyl hydrazone (FCCP), 2-deoxyglucose (2-DG), and

Rotenone + Antimycin A (Rot+AA) were sequentially injected into the microplate wells. After optimization, the following working concentrations were stablished for each drug: oligomycin: $1 \mu \mathrm{M}$; FCCP: $0.3 \mu \mathrm{M}, 2-\mathrm{DG}$ :

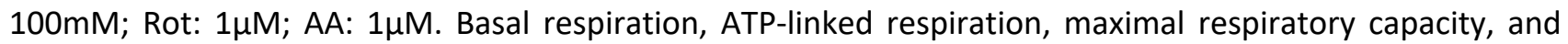
reserve capacity were assessed by calculating the area under the curve (AUC) from OCR curves (Fig. 3b, c ). 


\section{Cell metabolite measurements}

903

\section{Sample preparation}

Male and female primary PTs were grown on 6-well plates and subjected to starvation as described above. The levels of intracellular metabolites were then determined using liquid chromatography-mass spectrometry. After collecting the supernatant, $1 \mathrm{~mL}$ of extraction solvent (80:20 mixture of methanol:water) was added into each well, in order to extract intracellular metabolites. Plates were placed on dry ice. The adherent material was then triturated, collected into Eppendorf tubes, and stored at $-80^{\circ} \mathrm{C}$. Cell lysate collection was followed by 3 freeze-thawing cycles in dry ice (to shift sample temperature between $-80^{\circ} \mathrm{C}$ and $-20^{\circ} \mathrm{C}$ ). The insoluble material from each sample was then precipitated by centrifugation at full speed for $5 \mathrm{~min}$. The resulting pellet was dried at room temperature and used for total RNA quantification using the Quant-iT Ribogreen assay (Invitrogen). In turn, the metabolite extract was dried under high purity nitrogen gas (turbovap) and resuspended with appropriate volume of buffer ( $0.5 \mu \mathrm{L}$ of LC-MS grade water to $1 \mu \mathrm{g}$ of RNA) based on total RNA levels. The appropriate volumes of heavy-labelled $\left({ }^{13} \mathrm{C} /{ }^{15} \mathrm{~N}\right)$ reference metabolites were spiked into each reconstituted sample for quantitation. The heavy-labelled metabolites used as internal reference standards were acquired in as a metabolite extract from yeast that had been $99 \%$ labelled with ${ }^{13} \mathrm{C}$ glucose and ${ }^{15} \mathrm{~N}$-ammonia. To determine background metabolite signals, a mock plate without cells and equal volume of media was processed in parallel to the study plates.

\section{Liquid chromatography-mass spectrometry (LC-MS)}

Cellular metabolites were measured by injecting $2 \mu \mathrm{L}$ of sample in full scan MS1 mode using an Agilent 6550 qToF mass spectrometer coupled to an Agilent 1290 binary pump UPLC system. Most polar metabolite analytes presented here were measured using an Agilent ZORBAX ExtendC18 $1.8 \mu \mathrm{m}, 2.1 \mathrm{~mm}$ X $150 \mathrm{~mm}$ reverse phase chromatography using tributylamine as an ion paring agent as previously described ${ }^{110}$. The Agilent 6550 qToF was fitted with a dual AJS ESI source and an iFunnel with a gas temperature set to $150^{\circ} \mathrm{C}$ at $14 \mathrm{~L} / \mathrm{min}$ and $45 \mathrm{psig}$. Sheath gas temperature was set to $325^{\circ} \mathrm{C}$ at $12 \mathrm{~L} / \mathrm{min}$. Capillary and nozzle voltages were set to $2000 \mathrm{~V}$. Funnel conditions were changed from default to -30V DC, high pressure funnel drop -100V and RF voltage of $110 \mathrm{~V}$, low pressure funnel drop -50V and RF voltage of $60 \mathrm{~V}$. Metabolite annotation in full 
scan data was achieved by matching exact mass and retention time to an in-house database. The retention time and exact mass database were prepared by analyzing a collection of neat standards using the chromatographic method described above and confirming retention times by MS/MS fragmentation of neat standards.

Metabolite raw data was extracted directly from .d folders and integrated in profile mode using an R-based software package developed by the Rosebrock Lab; ChromXtractorPro (personal correspondence K. Laverty and A. Rosebrock, adam.rosebrock@stonybrook.edu). The metabolites whose intensity in all the study samples fell at or below their intensity in the blank (consisting of resuspension buffer only) were excluded from further analyses. Next, the integrated light (L) intensity of each metabolite was normalized to the intensity of its internal heavy $(\mathrm{H})$ standard. The $\mathrm{L} / \mathrm{H}$ ratio minimized the potential stochastic variation in the signal produced by the instrument due to changes in humidity and/or temperature, enabling the relative quantitation and GTP, ITP, UTP were interrogated.

\section{Gene expression validation studies}

RNA was extracted from the cell pellets of human primary male and female PT cells using the RNAeasy Mini

Kit (Qiagen). After quantifying RNA concentration in a Nanodrop instrument (Thermo), 300-700ng of RNA were retrotranscribed to cDNA using the High-Capacity cDNA Reverse Transcription Kit (Applied Biosystems).

951 Male and female PTs had been grown and serum-starved as above. In these cells, gene levels of KDM5D, UTY, 952 EIF1AY, EIF1AX, DDX3X, MT1F, MT1G, and MT1H were measured by real-time quantitative PCR using a Power 953 SYBR $^{\circledR}$ Green PCR Master Mix reagent (Applied Biosystems) and normalized to RPL31. The fluorescent signal 954 was measured in a LightCycler ${ }^{\circledR} 480$ Instrument II (Roche). All primer sequences employed in this study are 955 summarized in Supplementary Table 10. 


\section{Quantification and statistical analysis}

Statistical tests were conducted within R and using GraphPad Prism 9 software. For all comparisons, normality

was determined using a Shapiro-Wilk test. Group-to-group differences were assessed using two-tailed

unpaired T tests for variables following a normal distribution, and Mann-Whitney tests for variables with a

non-parametric distribution. All p values below 0.05 were considered significant. Significance level for each

test is indicated in the figures. For each experiment, $\mathrm{n}$ is reported in the figure legends and represents the

number of samples.

\section{Data availability}

Count matrices from our complete data object are being submitted to NCBI GEO, and will be made publicly available upon publication. Additional information and data are available from the authors upon reasonable request, and in line with University Health Network (UHN) and UHN Research Ethics Board policies.

\section{Code availability}

We are preparing a Github repository for the custom scripts generated for data analysis.

\section{Methods References}

73. potential cellular targets of kidney disease. Science 2018;360:758-63.

78. Pagliarini DJ, Calvo SE, Chang B, et al. A mitochondrial protein compendium elucidates complex I disease biology. Cell 2008;134:112-23. 
79. Hafemeister C, Satija R. Normalization and variance stabilization of single-cell RNA-seq data using regularized negative binomial regression. Genome Biol 2019;20:296.

80. Andrews TS, Hemberg M. M3Drop: dropout-based feature selection for scRNASeq. Bioinformatics 2019;35:2865-7.

81. Stuart T, Butler A, Hoffman P, et al. Comprehensive Integration of Single-Cell Data. Cell 2019;177:1888-902 e21.

82. Becht $E$, McInnes L, Healy J, et al. Dimensionality reduction for visualizing single-cell data using UMAP. Nat Biotechnol 2018.

83. (Accessed 03/05/2021, at https://github.com/immunogenomics/presto.)

84. Subramanian A, Tamayo P, Mootha VK, et al. Gene set enrichment analysis: a knowledgebased approach for interpreting genome-wide expression profiles. Proc Natl Acad Sci U S A 2005;102:15545-50.

85. Daniel Dimitrov DT, Charlotte Boys, James Nagai, Ricardo Ramirez Flores, Hyojin Kim, Bence Szalai, Ivan Costa, Aurelien Dugourd, Alberto Valdeolivas, Julio Saez Rodriguez. Cell-cell Communication Inference from Single-cell RNA-Seq Data: a Comparison of Methods and Resources. Research Square 2021.

86. Turei D, Valdeolivas A, Gul L, et al. Integrated intra- and intercellular signaling knowledge for multicellular omics analysis. Mol Syst Biol 2021;17:e9923.

87. Cabello-Aguilar S, Alame M, Kon-Sun-Tack F, Fau C, Lacroix M, Colinge J. SingleCellSignalR: inference of intercellular networks from single-cell transcriptomics. Nucleic Acids Res 2020;48:e55. 88. Wang Y WR, Zhang S, Song S, Jiang C, Han G, Wang M, Ajani J, Futreal A, Wang L. iTALK: an R Package to Characterize and Illustrate Intercellular Communication. BioRxiv 2019.

89. Hou R, Denisenko E, Ong HT, Ramilowski JA, Forrest ARR. Predicting cell-to-cell communication networks using NATMI. Nat Commun 2020;11:5011.

90. Raredon MSB, Junchen Yang, James Garritano, Meng Wang, Dan Kushnir, Jonas Christian Schupp, Taylor S. Adams, Allison M. Greaney, Katherine L. Leiby, Naftali Kaminski, Yuval Kluger, Andre Levchenko, Laura E. Niklason. Connectome: computation and visualization of cell-cell signaling topologies in single-cell systems data. bioRxiv 2021.

91. Jin S, Guerrero-Juarez CF, Zhang L, et al. Inference and analysis of cell-cell communication using CellChat. Nat Commun 2021;12:1088.

92. Efremova M, Vento-Tormo M, Teichmann SA, Vento-Tormo R. CellPhoneDB: inferring cellcell communication from combined expression of multi-subunit ligand-receptor complexes. Nat Protoc 2020;15:1484-506.

93. Alquicira-Hernandez J, Sathe A, Ji HP, Nguyen Q, Powell JE. scPred: accurate supervised method for cell-type classification from single-cell RNA-seq data. Genome Biol 2019;20:264.

94. Bernink JH, Ohne Y, Teunissen MBM, et al. c-Kit-positive ILC2s exhibit an ILC3-like signature that may contribute to IL-17-mediated pathologies. Nat Immunol 2019;20:992-1003.

95. https://support.10xgenomics.com/single-cell-gene-expression/datasets/2.1.0/t_4k. 2017. at https://support.10xgenomics.com/single-cell-gene-expression/datasets/2.1.0/t_4k.)

96. Keenan AB, Torre D, Lachmann A, et al. ChEA3: transcription factor enrichment analysis by orthogonal omics integration. Nucleic Acids Res 2019;47:W212-W24.

97. Korsunsky I, Millard N, Fan J, et al. Fast, sensitive and accurate integration of single-cell data with Harmony. Nat Methods 2019;16:1289-96.

98. Blighe K RS, Lewis M EnhancedVolcano: Publication-ready volcano plots with enhanced colouring and labeling. https://github.com/kevinblighe/EnhancedVolcano.2020.

99. Tan Y, Cahan P. SingleCellNet: A Computational Tool to Classify Single Cell RNA-Seq Data Across Platforms and Across Species. Cell Syst 2019;9:207-13 e2.

100. Wang C, Zhang L, Wang B. One Cell At a Time: A Unified Framework to Integrate and Analyze Single-cell RNA-seq Data. bioRxiv 2021:2021.05.12.443814. 
101. Street K, Risso D, Fletcher RB, et al. Slingshot: cell lineage and pseudotime inference for single-cell transcriptomics. BMC Genomics 2018;19:477.

102. Rohart F, Gautier B, Singh A, Le Cao KA. mixOmics: An R package for 'omics feature selection and multiple data integration. PLoS Comput Biol 2017;13:e1005752.

103. Soneson C, Robinson MD. Bias, robustness and scalability in single-cell differential expression analysis. Nat Methods 2018;15:255-61.

104. Wang T, Li B, Nelson CE, Nabavi S. Comparative analysis of differential gene expression analysis tools for single-cell RNA sequencing data. BMC Bioinformatics 2019;20:40. 105. Zimmerman KD, Espeland MA, Langefeld CD. A practical solution to pseudoreplication bias in single-cell studies. Nat Commun 2021;12:738.

106. Finak G, McDavid A, Yajima M, et al. MAST: a flexible statistical framework for assessing transcriptional changes and characterizing heterogeneity in single-cell RNA sequencing data. Genome Biol 2015;16:278.

107. Reimand J, Isserlin R, Voisin V, et al. Pathway enrichment analysis and visualization of omics data using g:Profiler, GSEA, Cytoscape and EnrichmentMap. Nat Protoc 2019;14:482-517. 108. Konvalinka A, Zhou J, Dimitromanolakis A, et al. Determination of an angiotensin IIregulated proteome in primary human kidney cells by stable isotope labeling of amino acids in cell culture (SILAC). J Biol Chem 2013;288:24834-47.

109. Clotet-Freixas S, McEvoy CM, Batruch I, et al. Extracellular Matrix Injury of Kidney Allografts in Antibody-Mediated Rejection: A Proteomics Study. J Am Soc Nephrol 2020;31:2705-24. 110. Wan LC, Mao DY, Neculai D, et al. Reconstitution and characterization of eukaryotic N6threonylcarbamoylation of tRNA using a minimal enzyme system. Nucleic Acids Res 2013;41:633246.

111. Clotet-Freixas S.; Zaslaver, O.; Pastrello, C.; Kotlyar, M.; McEvoy, C.M.; Farkona, S.; Saha, A.; Boshart, A.; Chan, S.; Riera, M.; Soler, M.J.; Isenbrandt, A.; Lamontagne-Proulx, J. ; Pradeloux, S.; Coulombe, K.; Soulet, D.; Dart, A.B.; Wicklow,B.; McGavock, J.M. ;Blydt-Hansen, T.D.; Jurisica, I.; Woo, M. ; Scholey, J.W. ; Röst, H.; Konvalinka, A. Cell Sex and Sex Hormones Modulate Kidney Glucose and Glutamine Metabolism in Health and Diabetes. BioRxiv 2021. 


\section{Supplementary Data}

1077

1078

1079

L080

L081

L082

$\lfloor 083$

1084

1085

1086

1087

1088

1089

1090

L091

1092

1093

1094

1095

1096

1097

1098

1099

ᄂ100

เ101

L102

$\lfloor 103$

$\lfloor 104$

$\lfloor 105$

$\llcorner 106$

$\lfloor 107$

เ108

Authors: Caitriona M. McEvoy ${ }^{\dagger 1,2,3}$, Julia M. Murphy ${ }^{1,2,4}$, Lin Zhang ${ }^{5}$, Sergi Clotet-Freixas ${ }^{\wedge 1,2}$, Jessica A. Mathews ${ }^{\wedge 1,2}$, James $\mathrm{An}^{1,2,4}$, Mehran Karimzadeh ${ }^{6}$, Delaram Pouyabahar ${ }^{7,8}$, Shenghui Su, ${ }^{1,2}$, Olga Zaslaver $^{7,8}$, Hannes Röst ${ }^{7,8}$, Madhurangi Arambewela ${ }^{1,2}$, Lewis Y. Liu ${ }^{1,2,4}$, Sally Zhang ${ }^{12}$, Keith A. Lawson $^{12}$, Antonio Finelli ${ }^{12}$, Bo Wang 6 ,9,10,11, Sonya A. MacParland ${ }^{1,2,4,10}$, Gary D. Bader ${ }^{7,8,12,13}$, Ana Konvalinka* ${ }^{*}, 1,2,3,10,14$, Sarah Q. Crome ${ }^{*}, 1,2,4$

\section{Affiliations:}

${ }^{1}$ Toronto General Hospital Research Institute, University Health Network; Toronto, ON, Canada.

${ }^{2}$ Ajmera Transplant Centre, University Health Network; Toronto, ON, Canada.

${ }^{3}$ Department of Medicine, Division of Nephrology, University Health Network; Toronto, ON, Canada. ${ }^{4}$ Department of Immunology, University of Toronto; Toronto, ON, Canada.

${ }^{5}$ Department of Statistical Sciences, University of Toronto; Toronto, ON, Canada.

${ }^{6}$ Vector Institute; Toronto, ON, Canada.

${ }^{7}$ Department of Molecular Genetics, University of Toronto; Toronto, ON, Canada.

${ }^{8}$ The Donnelly Centre, University of Toronto; Toronto, ON, Canada.

${ }^{9}$ Department of Computer Science, University of Toronto; Toronto, ON, Canada.

${ }^{10}$ Department of Laboratory Medicine and Pathobiology, University of Toronto; Toronto, ON, Canada.

${ }^{11}$ Peter Munk Cardiac Centre, University Health Network; Toronto, ON, Canada.

${ }^{12}$ Princess Margaret Cancer Centre, University Health Network; Toronto, ON, Canada

${ }^{13}$ The Lunenfeld-Tanenbaum Research Institute, Mount Sinai Hospital;Toronto, ON, Canada

${ }^{14}$ Institute of Medical Science, University of Toronto; Toronto, ON, Canada.

+ co-first authorship

* co-corresponding authorship

$\wedge$ equal contribution

\section{*co-corresponding authors:}

Sarah Q. Crome (sarah.crome@utoronto.ca)

Ana Konvalinka (Ana.Konvalinka@uhn.ca) 


\section{Supplementary Tables}

A total of 10 supplementary tables are prepared for this manuscript. As some of the individual tables are large and not in a format that can be easily incorporated into the manuscript, they are not included with the pre-print PDF. If of interest, please reach out to corresponding authors to discuss.

\section{Supplementary Tables}

Supplementary Table 1. ST1-Results of sex analyses. Results of genes identified with Varimax rotated PCA, sPLS-DA, and differential gene expression analysis using MAST comparing male and female proximal tubular cells.

Supplementary Table 2. ST2-Primary PT donor characteristics. Characteristics of the donors from which primary proximal tubular epithelial cells were isolated for metabolic studies.

Supplementary Table 3. ST3-GSEA significant results. Summary of significant gene set enrichment analysis terms between male and female proximal tubular cells.

Supplementary Table 4. ST4- DEGs LD NK \& T cells Vs PBMC. Results of differential gene expression analysis using Seurat comparing kidney NK and T lymphocytes to circulating lymphocytes from two studies.

Supplementary Table 5. ST5-Cell cell interactions Omnipath. Results of aggregate cell cell communication inference with consensus and individual scores across methods, with Omnipath used as the reference interaction database

Supplementary Table 6. ST5-Cell cell interactions with complexes CellPhoneDB. Results of aggregate cell cell communication inference with consensus and individual scores across methods, with CellPhoneDB used as the reference interaction database

Supplementary Table 7. ST7-Patient characteristics. Characteristics of the study population.

Supplementary Table 8. ST8- CellRanger summaries of sequenced samples. CellRanger summaries with sample metrics for each sequenced sample.

Supplementary Table 9. ST9- Curated cell annotation file. Curated marker gene list for cell type annotations.

Supplementary Table 10. ST10- qPCR sequences. Primer sequences used for qPCR validation of sex differences in PT cells. 
a

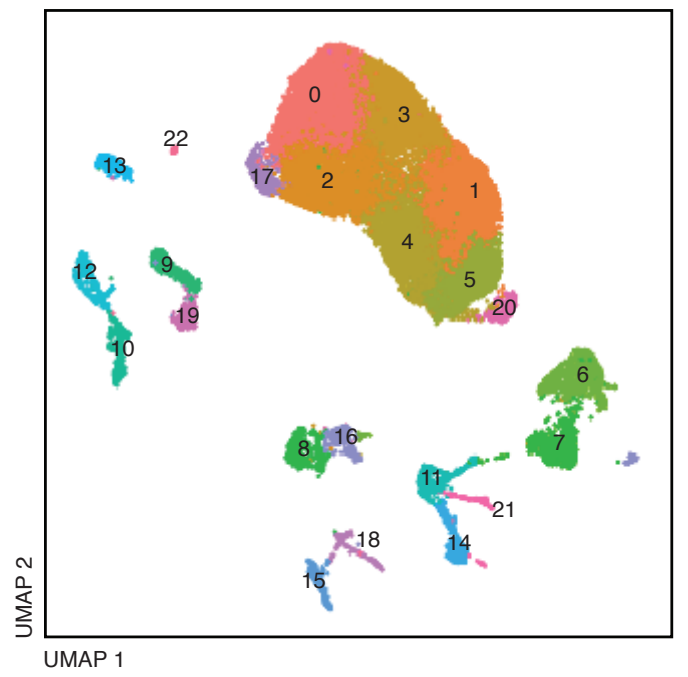

C

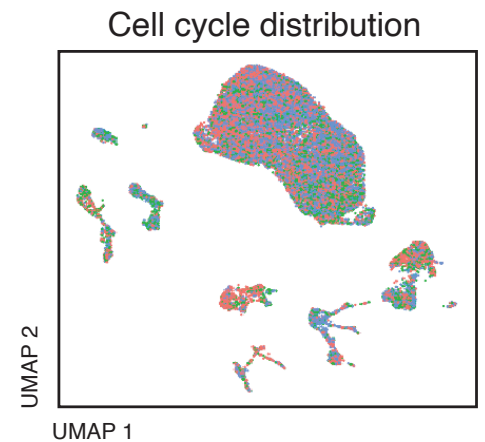

d

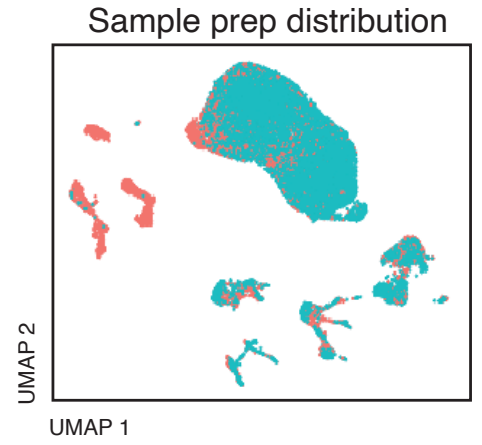

e

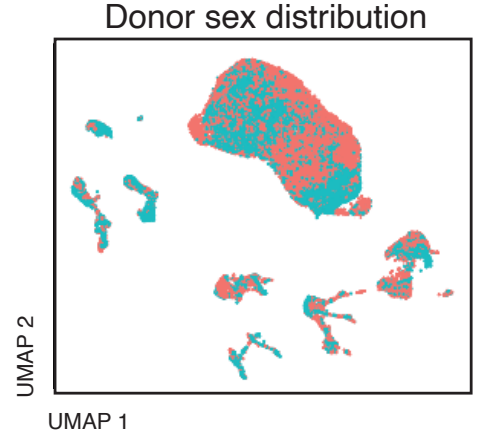

b
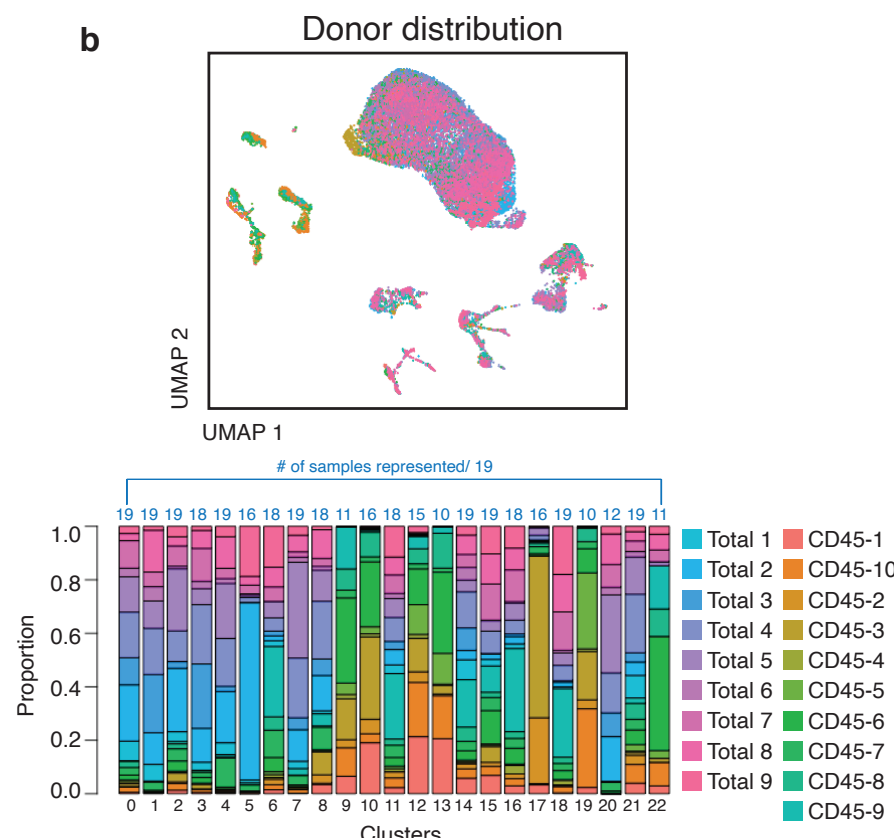

Clusters
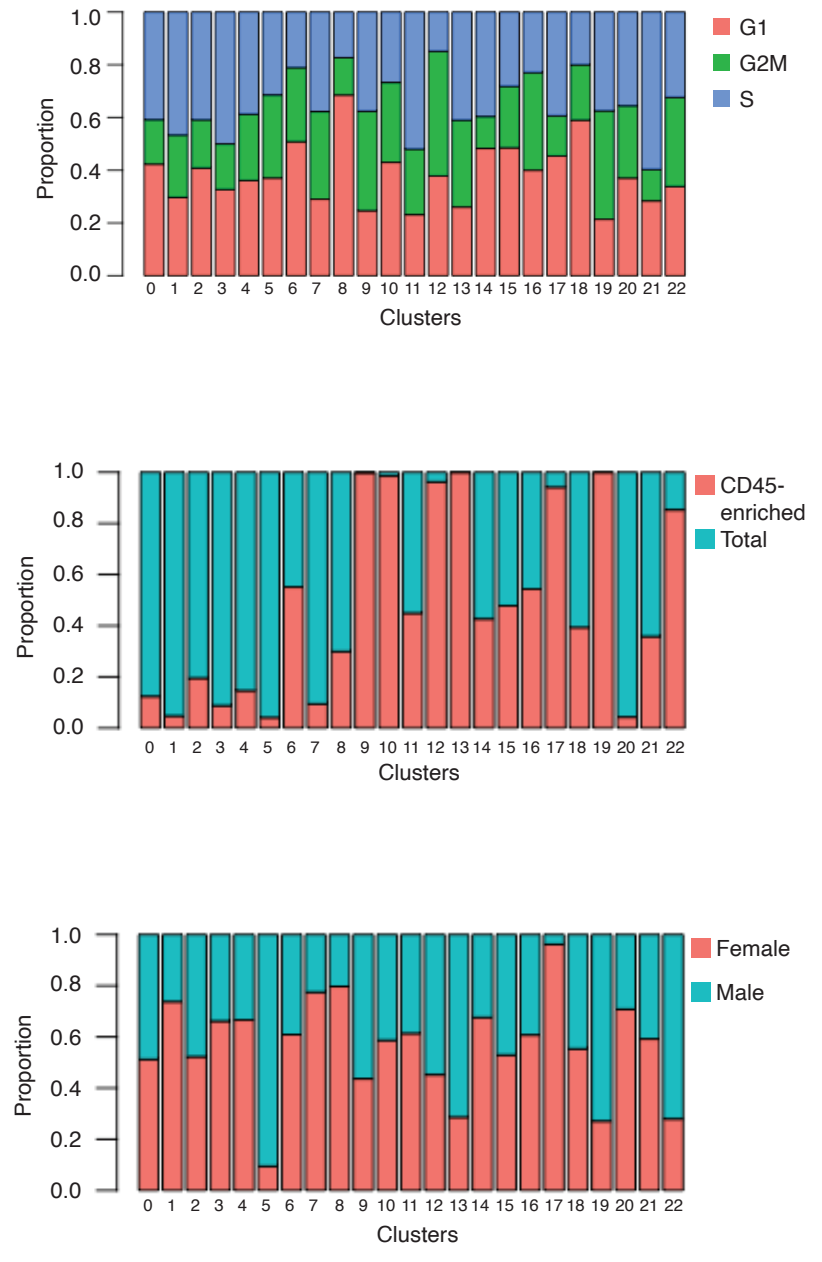

Supplementary Figure 1: Additional proportion plots of total kidney dataset.(a) Clustering of total combined dataset of 27677 cells results in 23 clusters (b) Individual sample contribution to clustering, demonstrating that clusters are comprised of cells captured from multiple donors and in most cases all 19 samples contribute to each cluster. (c) Cell cycle assignment of clusters, with no exceptional variability in cell cycle state across clusters. (d) Distribution of sample preparation method (total homogenate versus CD45-positive magnetic bead enrichment) across clusters. (e) Distribution of donor sex across clusters. 
a

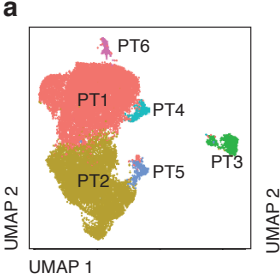

c
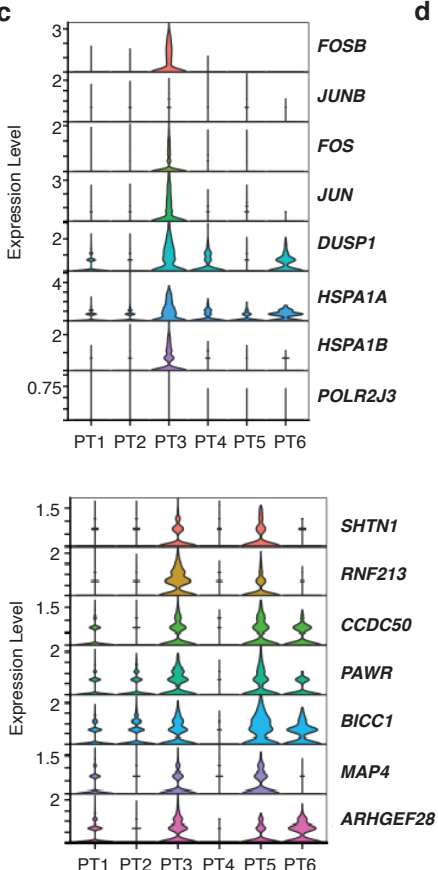

\begin{tabular}{|l|l|l|}
\hline $\begin{array}{l}\text { CHEA3- } \\
\text { Rank }\end{array}$ & $\begin{array}{l}\text { Transcription } \\
\text { Factor }\end{array}$ & $\begin{array}{l}\text { Overlapping } \\
\text { genes }\end{array}$ \\
\hline PT3 & \multicolumn{2}{|l|}{} \\
\hline 1 & POU5F1B & 38 \\
\hline 2 & ZNF581 & 56 \\
\hline 3 & PA2G4 & 22 \\
\hline 4 & ATF3 & 81 \\
\hline 5 & ZBED6 & 12 \\
\hline 6 & HES4 & 44 \\
\hline 7 & EGR1 & 82 \\
\hline 8 & FOS & 83 \\
\hline 9 & NFE2L2 & 67 \\
\hline 10 & JUN & 87 \\
\hline
\end{tabular}

b $\quad$ CD45-enriched

b Total homogenate

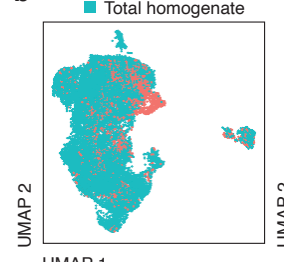

UMAP 1

d

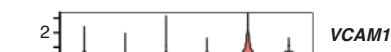

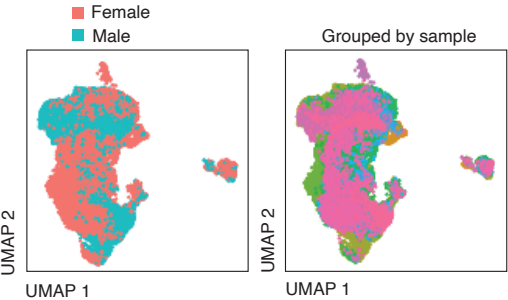

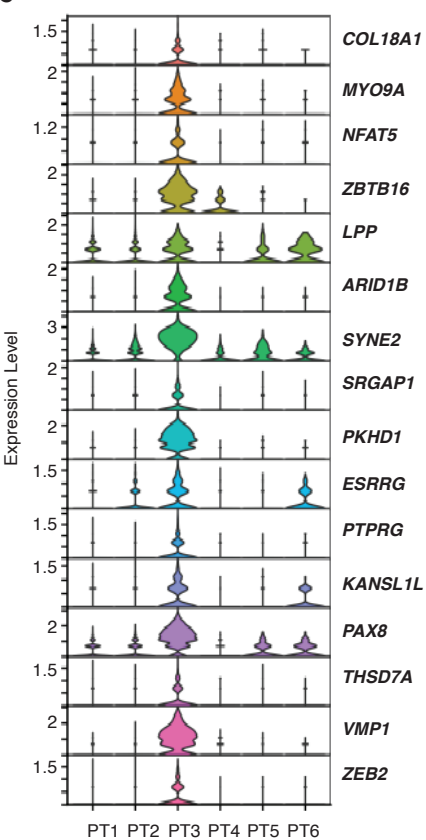

\begin{tabular}{|l|l|l|}
\hline $\begin{array}{l}\text { CHEA3- } \\
\text { Rank }\end{array}$ & $\begin{array}{l}\text { Transcription } \\
\text { Factor }\end{array}$ & $\begin{array}{l}\text { Overlapping } \\
\text { genes }\end{array}$ \\
\hline \multicolumn{2}{|l|}{ PT5 } & \multicolumn{2}{|l|}{} \\
\hline 1 & ZNF217 & 20 \\
\hline 2 & ELF3 & 12 \\
\hline 3 & NKX25 & 3 \\
\hline 4 & FOSL1 & 12 \\
\hline 5 & HOXB2 & 9 \\
\hline 6 & NFE2L2 & 14 \\
\hline 7 & RFX8 & 4 \\
\hline 8 & SNAI2 & 11 \\
\hline 9 & PBX3 & 14 \\
\hline 10 & ZNF581 & 7 \\
\hline
\end{tabular}

Supplementary Figure 2. Heterogeneity within Proximal Tubular (PT) dataset. (a) Subclustering of PT dataset yielded 6 clusters; PT6 is predominantly composed of cells from one donor: "Total6". (b) Distribution of sample preparation method, sex, and donor identity across the PT dataset; PT4 is composed of cells from CD45-enriched samples. (c) Stacked violin plots showing enrichment of dissociation stress markers in PT3. (df) Stacked violin plots showing markers of the 'scattered tubular cell' and 'failed PT repair' population enriched in PT5(d), PT3(e), and both PT3 and PT5(f). (g) Transcription factor analysis using CHEA3, which illustrates the top 10 transcription factors predicted to regulate PT3, and separately, PT5 genes. 
a

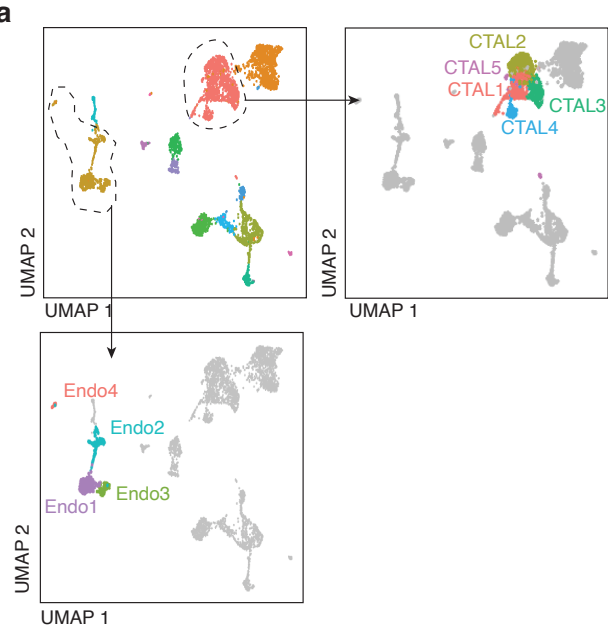

c

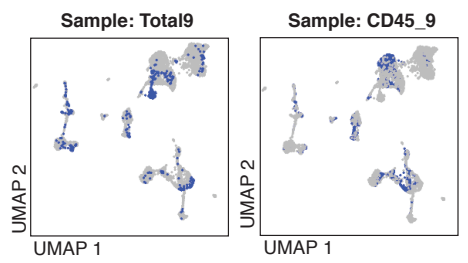

d

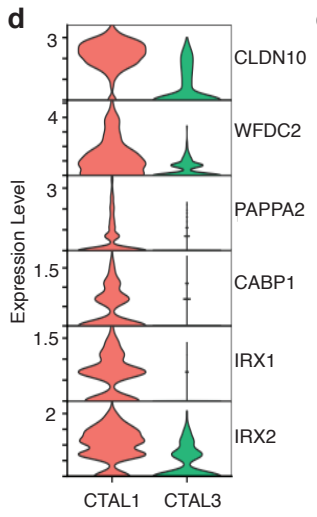

b
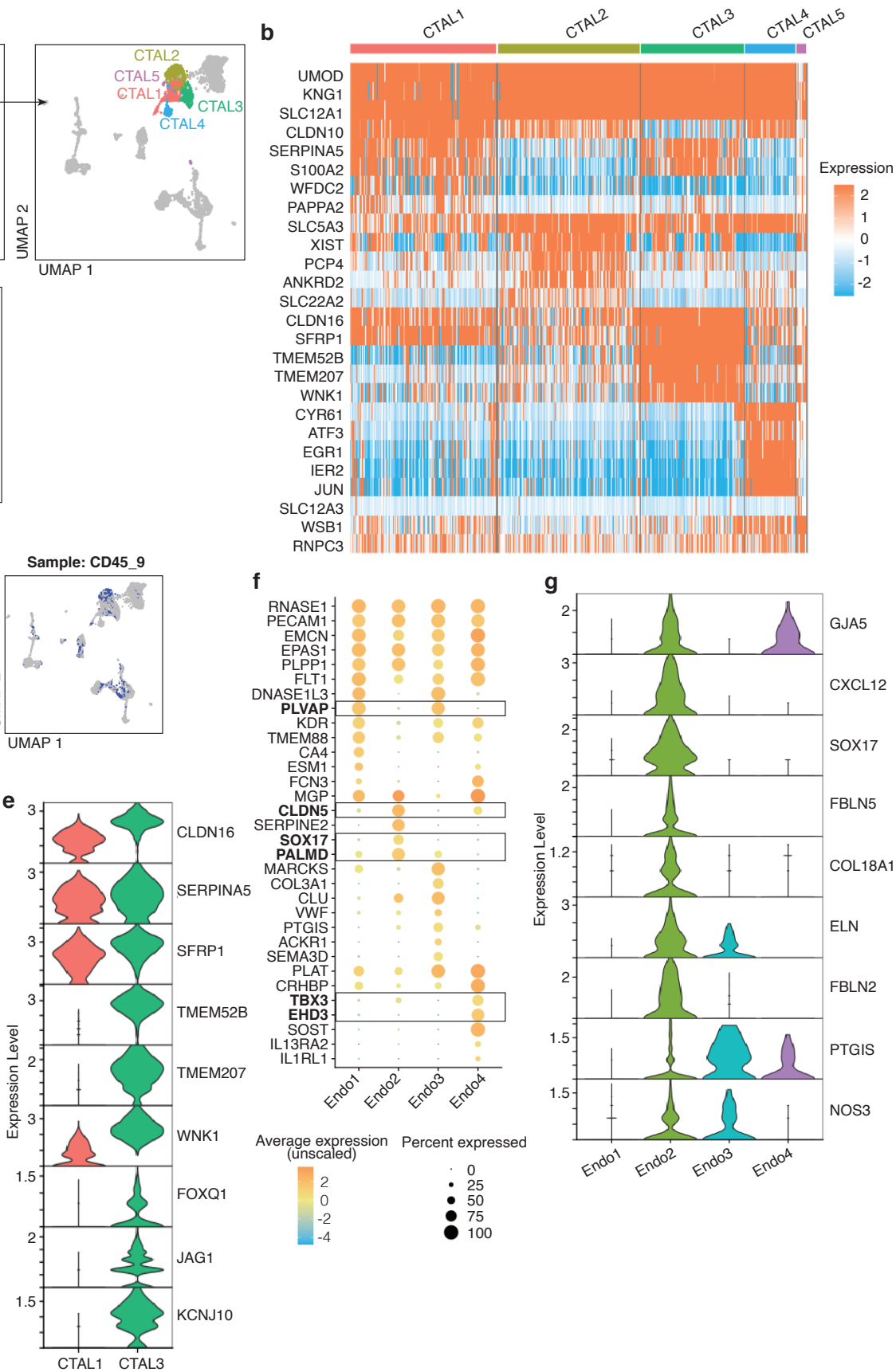

f

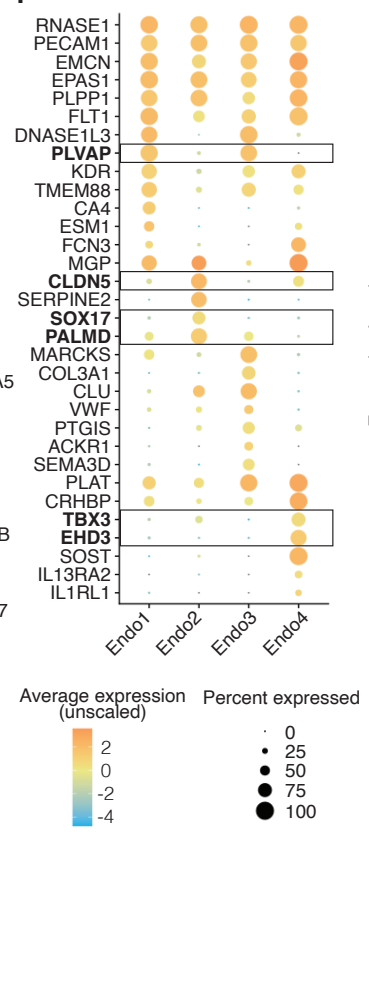

g

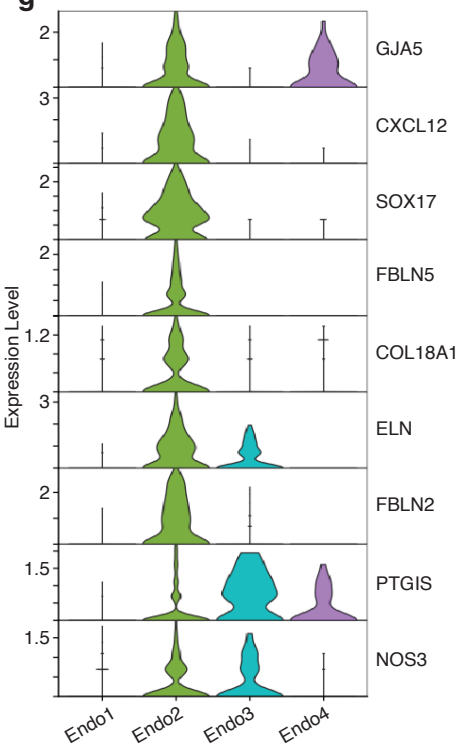

Supplementary Figure 3. Heterogeneity in CTAL and Endothelial cell populations. (a) 5 CTAL clusters and 4 endothelial clusters were identified. (b) Heatmap depicting expression of the marker genes of CTAL1-5. (c) CTAL2 and 4 are each chiefly comprised of cells from one donor (Total9 and CD45_9, respectively). Selected marker genes of CLDN10-enriched CTAL1 (d) and CLDN16- enriched CTAL3 (e) populations, respectively. (f) Bubble plot showing enrichment for specific endothelial cell markers in all subpopulations; expression of peritubular capillary markers (PLVAP, TMEM88, DNASE1L3) in Endo1 and Endo3 respectively; expression of afferent arteriole and vasa recta genes (SOX17, SERPINE2, CLDN5, CXCL12 and reduced KDR) in Endo2; and expression of glomerular microvascular endothelial cell markers in Endo4 (EDH3, SOST and $T B X 3) .(\mathbf{g})$ Increased expression of extracellular matrix genes seen in Endo2 (characterised as afferent arterioles and vasa recta). Of the two peritubular populations described (Endo1 and Endo3), Endo3 is shown to have higher expression of vasodilators (PTGIS and NOS3) than Endo1. Endo4 illustrates expression of GJA5 and PTGIS. 
a

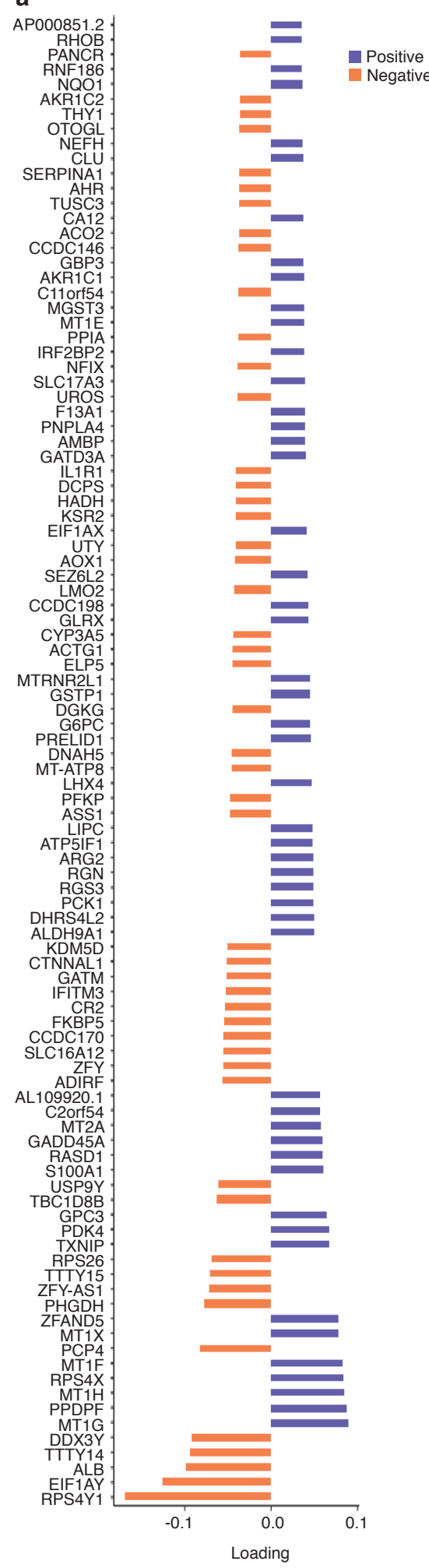

b

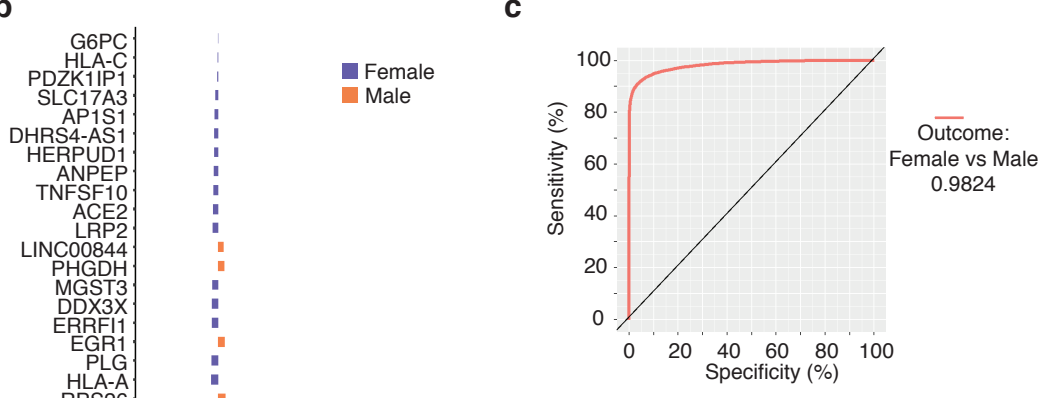

d

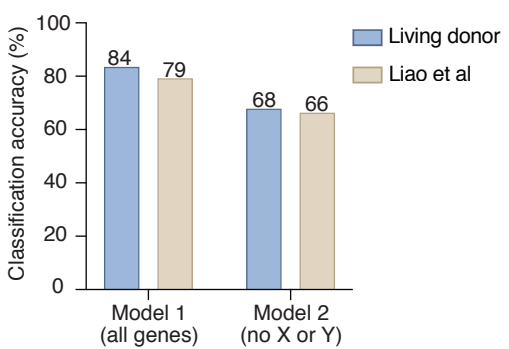

e

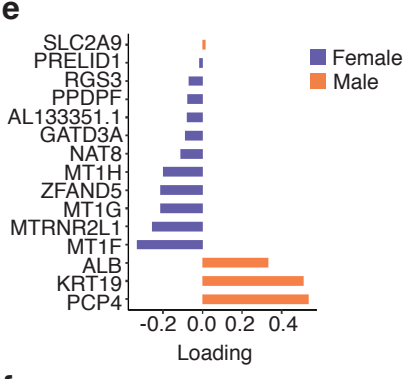

f

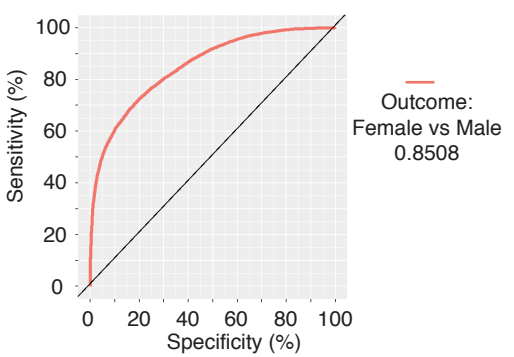

Supplementary Figure 4. Varimax PCA and sparse partial least squares discriminant analysis (sPLSDA) identifies sex differences in proximal tubular (PT) epithelial cells. (a) Top 100 genes (50 from each end of the component) associated with varimax-rotated principal component 12 which revealed sex differences in proximal tubule cells. (b) Plot of 80 genes that were selected as variables in the SPLS-DA classifier (Model 1) from all detected genes. (c) Receiver operating characteristic (ROC) curve from Model 1 predict male and female sex with accuracy of 98\%. (d) Plot of 15 genes in Model 2 (using all detected genes except those encoded on $\mathrm{X}$ or $\mathrm{Y}$ chromosomes as input) where 15 genes were selected as variables in the classifier. (e) ROC curve from Model 2. (f) Barplot of classification accuracy using Model 1 versus Model 2 to classify PT cells of the living donor data and of a validation dataset from Liao et al.20 
a

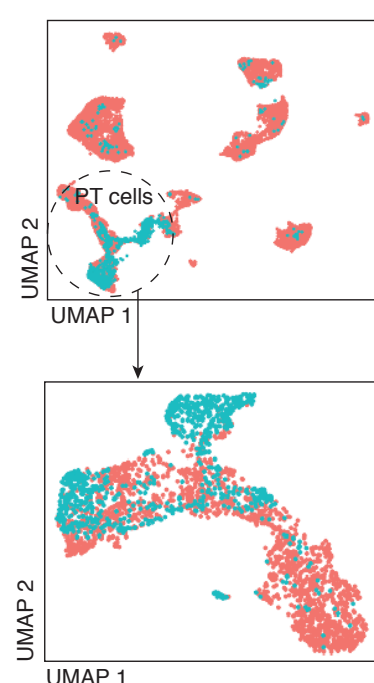

b
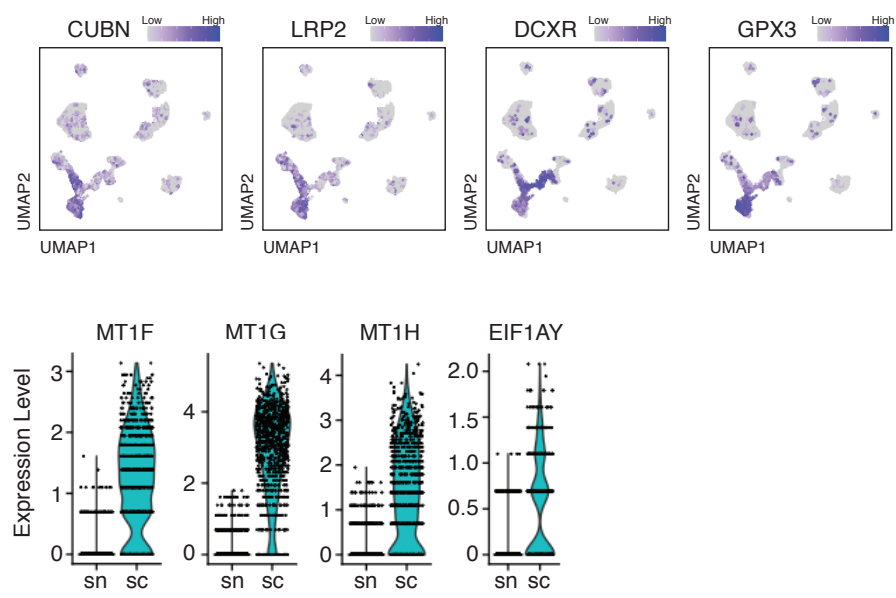

Supplementary Figure 5. Comparison of single nucleus RNA sequencing and single cell RNA sequencing. (a) Data integration from a pilot sequencing experiment in which a single biopsy was divided and subjected to scRNAseq and single nucleus RNAseq (snRNAseq). From the integrated data, PT cell clusters were identified and analyzed. (b) Expression of PT cell marker genes used to identify clusters of PT cells in the integrated datasets. (c) Comparison of select genes from scRNAseq and snRNAseq reveals that several key genes exhibiting dichotomous expression across sexes as reported here are differentially captured by the two sequencing techniques. 
bioRxiv preprint doi: https://doi.org/10.1101/2021.12.09.471943; this version posted December 10, 2021. The copyright holder for this preprint (which was not certified by peer review) is the author/funder, who has granted bioRxiv a license to display the preprint in perpetuity. It is made available under aCC-BY-NC-ND 4.0 International license.

a

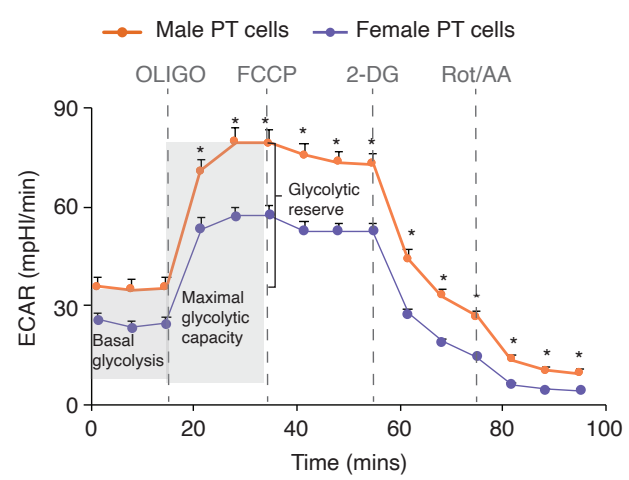

b

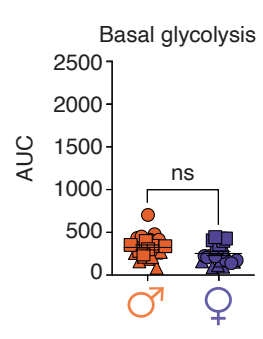

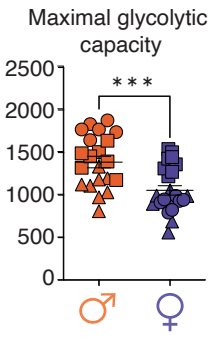

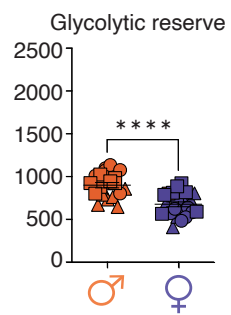

Supplementary Figure 6. Sex differences in the glycolytic rate of proximal tubular (PT) cells. (a) The extracellular acidification rate (ECAR) was monitored to assess the glycolytic metabolism of male and female PT cells at baseline and after metabolic stress. To induce metabolic stress, the following sequence of drugs was injected: $1 \mu \mathrm{M}$ oligomycin, $0.3 \mu \mathrm{M}$ FCCP, $100 \mathrm{mM}$ 2-DG, $1 \mathrm{mM}$ Rot/AA. (b) The basal glycolysis ( $p=0.063$, $\mathrm{u}=162)$, maximal glycolytic capacity $(\mathrm{p}=0.0004, \mathrm{t}=3.832, \mathrm{df}=42)$, and glycolytic reserve $(\mathrm{p}<0.0001, \mathrm{t}=5.331$, $\mathrm{df}=42)$ of male and female PT cells were calculated from the ECAR curves in $(a)$ ( $n=3$ donors/sex; $n=6-8$ replicates/donor). Group-to-group differences were assessed using two-tailed unpaired t-test for variables following a normal distribution, and Mann-Whitney tests for variables with a non-parametric distribution. ${ }^{*} p<0.05 ;{ }^{* \star *} p<0.001 ;{ }^{* * * *} p<0.0001$. PT, proximal tubule; AUC, area under the curve; ECAR, extracellular acidification rate; FCCP, p-trifluoromethoxy carbonyl cyanide phenyl hydrazone; 2-DG, 2-deoxyglucose; Rot, rotenone; $A A$ : antimycin $A$. 
a

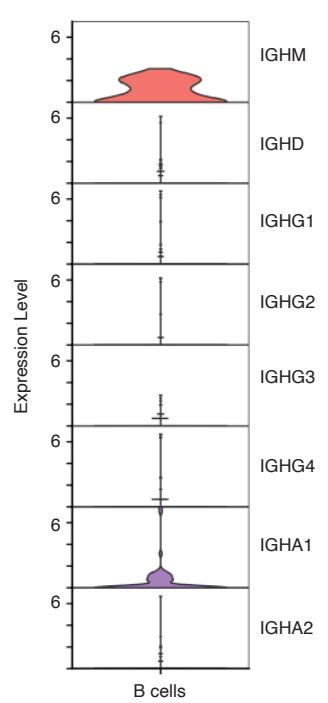

b
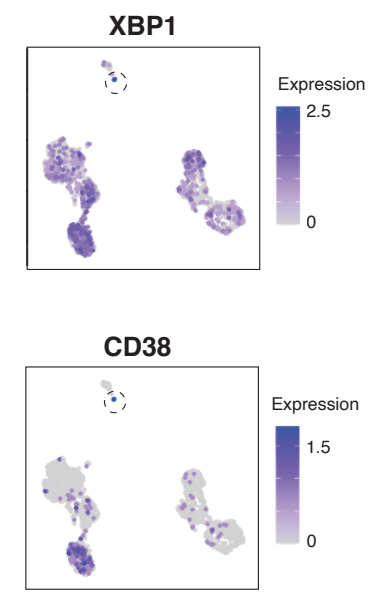

c
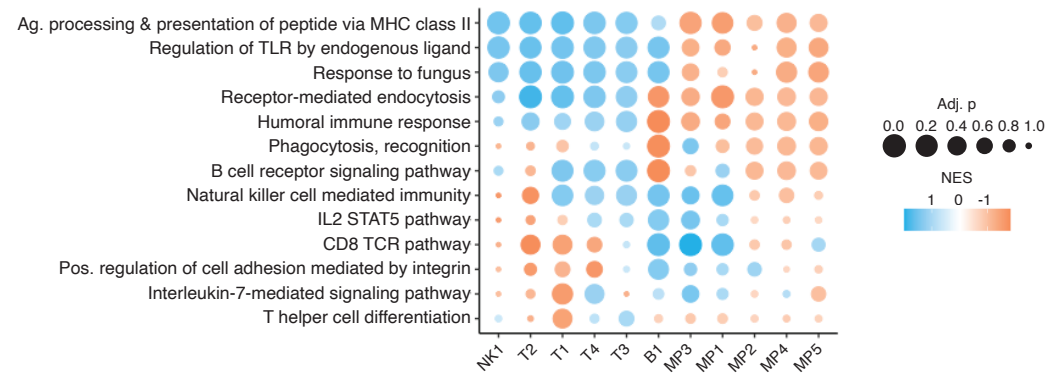

d

e
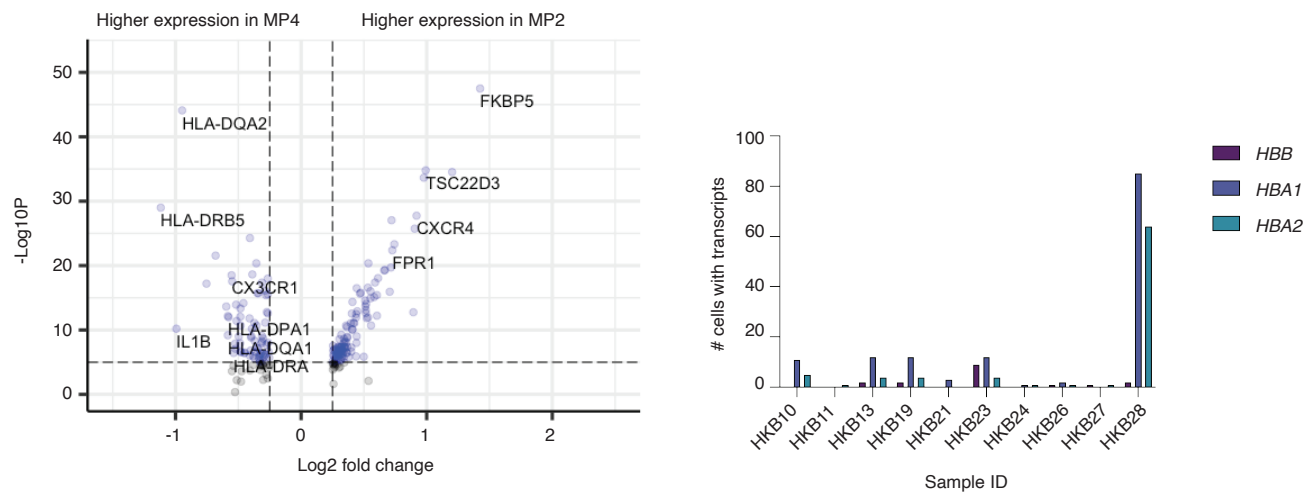

Supplementary Figure 7. Additional immune cell phenotyping data. (a)Expression of immunoglobulin heavy chain genes within the $B$ cell cluster, showing low abundance of class-switched $B$ cells in living donor kidney. No IGHE transcripts were detected. (b) Very few plasma cells marked by high XBP1 and CD38 expression were identified. (c) Pathway analysis summary for immune populations, indicating an enrichment in cell-type specific pathways in support of cluster annotations. (d) Differential gene expression between two clusters (MP2 and MP4) of CD16+ monocyte-like cells identified an enrichment in antigen presentation genes in MP4, and differential expression of CX3CR1 versus CXCR4. (e) Expression of hemoglobin transcripts in the CD45-enriched sequencing datasets, prior to any quality control thresholds or data cleanup steps. Sample HKB28 had the highest abundance of cells positive for hemoglobin transcripts, suggesting more circulating cells in this sample. 

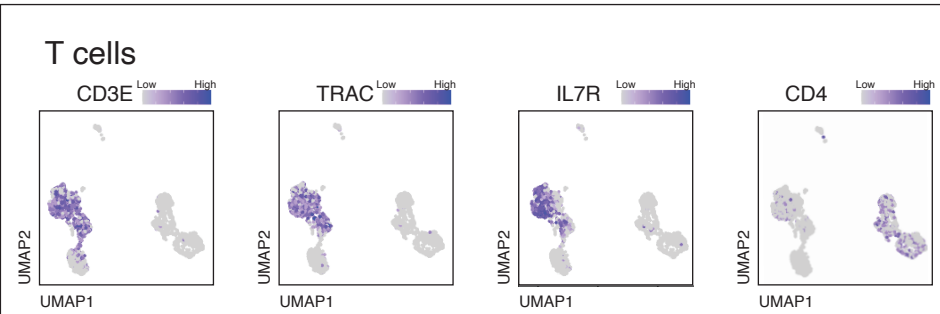

T resident memory cells

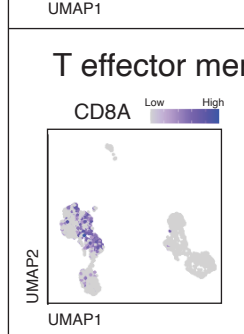

ory cells
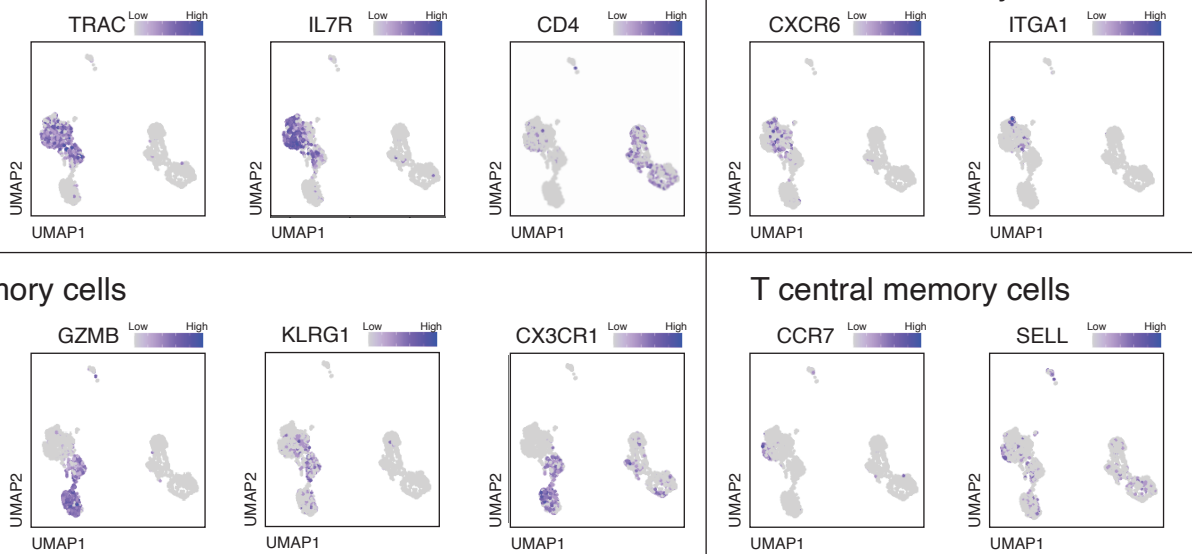

Regulatory T cells
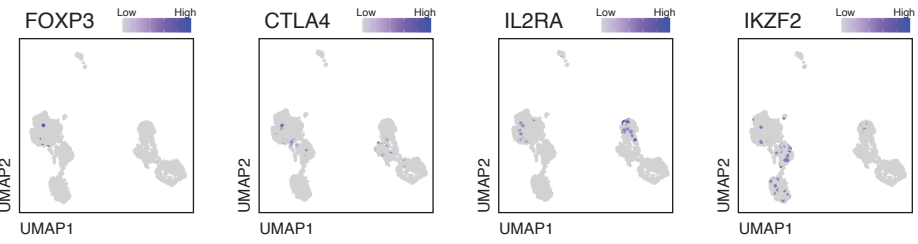

T central memory cells

Innate lymphoid cells
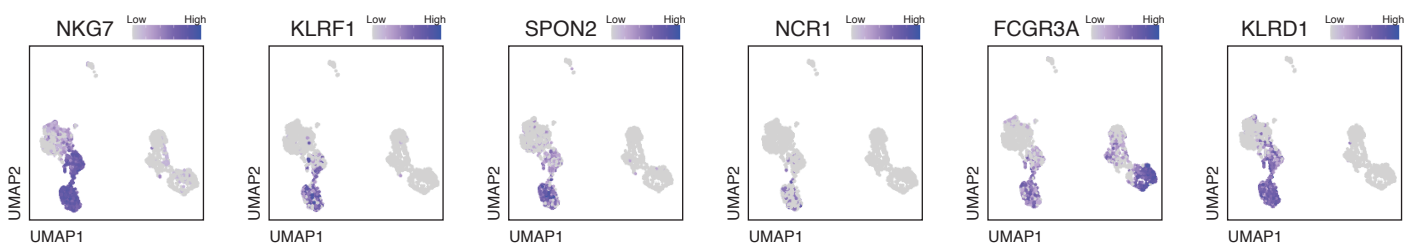

B cells
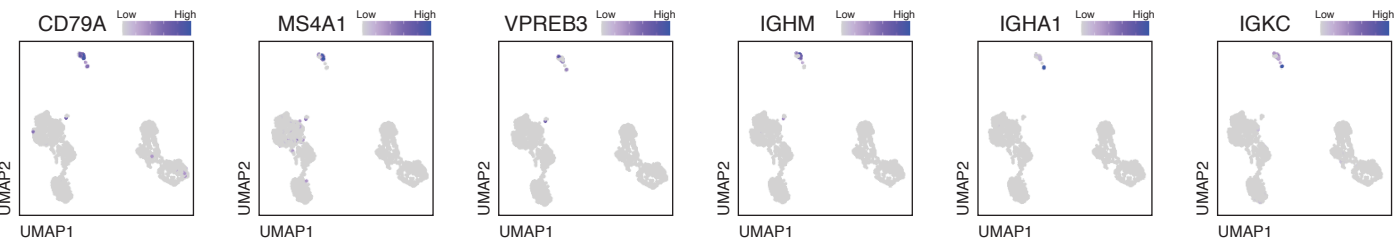

Supplementary Figure 8. Annotation of lymphocyte populations. Additional feature plots used to annotate of lymphocyte cell types including general T cell markers and subset-specific markers of T resident memory, $T$ effector memory, and T central memory cells, as well as markers of regulatory T cells, $\gamma \delta$ T cells, innate lymphoid cells and B cells. 


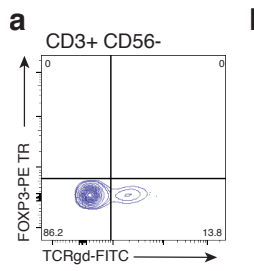

b
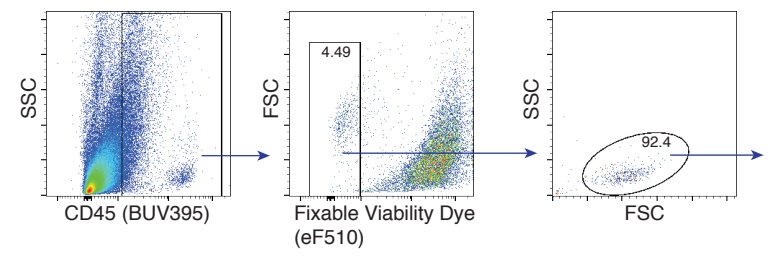

d

C

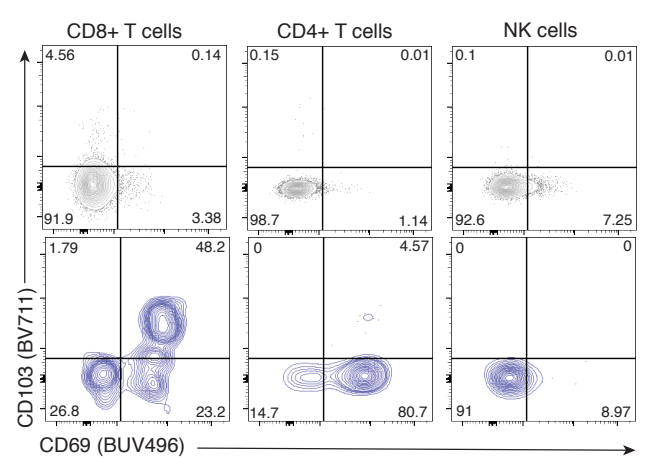

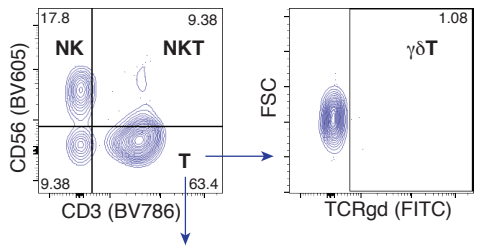
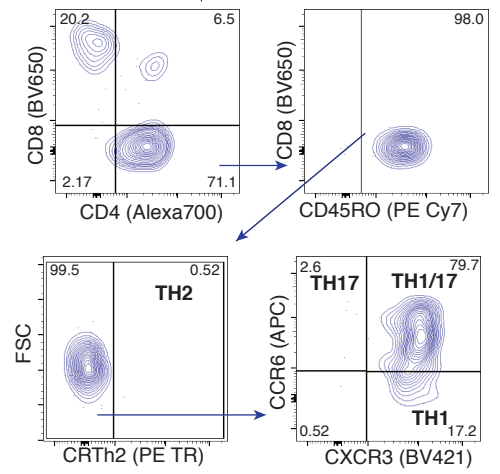

Supplementary Figure 9. Additional supporting data for the identification of resident signatures in kidney lymphocytes. (a) No FOXP3 expression was noted on T cells, and TCR $\gamma \delta$ staining validated the presence of $\gamma \delta \mathrm{T}$ cells within healthy kidney. (b) Gating strategy for the identification of T helper subsets. (c) Coexpression of CD69 and CD103, characteristic of Trm cells on CD8 ${ }^{+}$and CD4+ $\mathrm{T}$ cells and NK cells of the blood (grey, top row) versus kidney (blue, bottom row). (d) Expression of the chemokine CXCL16 in myeloid cells of the kidney supporting recruitment of CXCR6+ lymphocytes. 
bioRxiv preprint doi: https://doi.org/10.1101/2021.12.09.471943; this version posted December 10, 2021. The copyright holder for this preprint (which was not certified by peer review) is the author/funder, who has granted bioRxiv a license to display the preprint in perpetuity. It is made available under aCC-BY-NC-ND 4.0 International license.
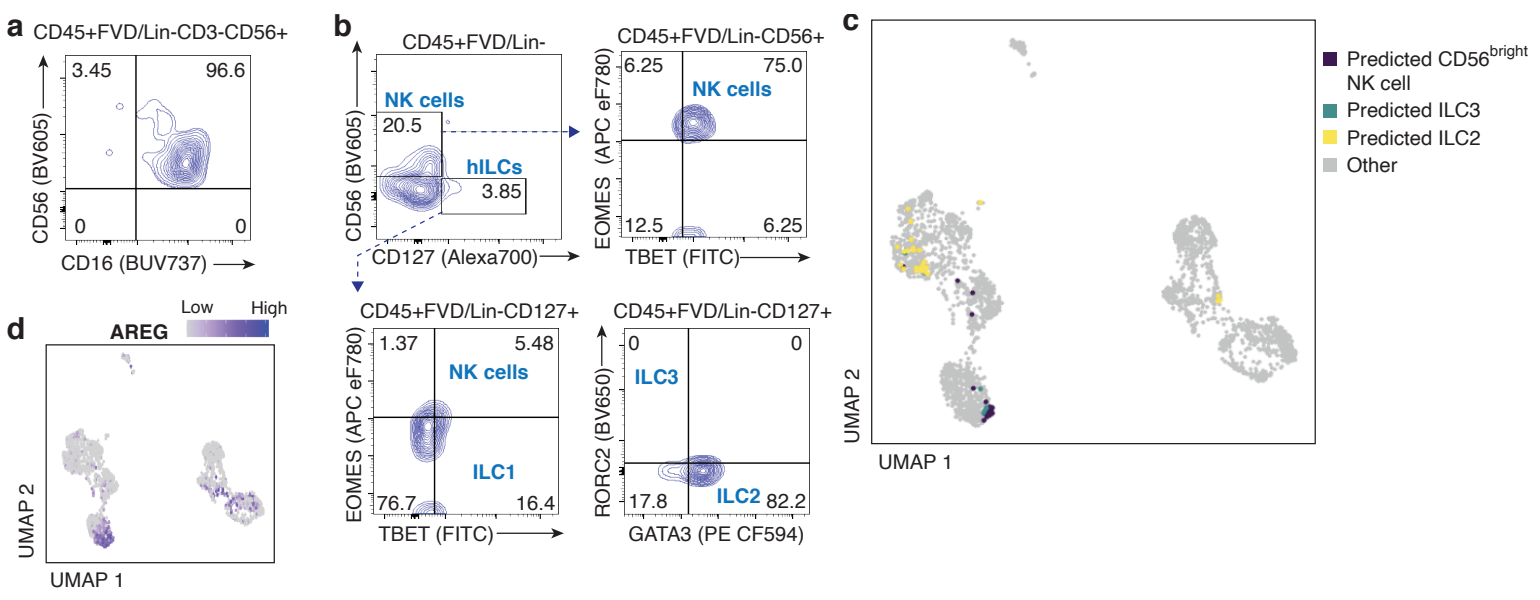

UMAP 1

e
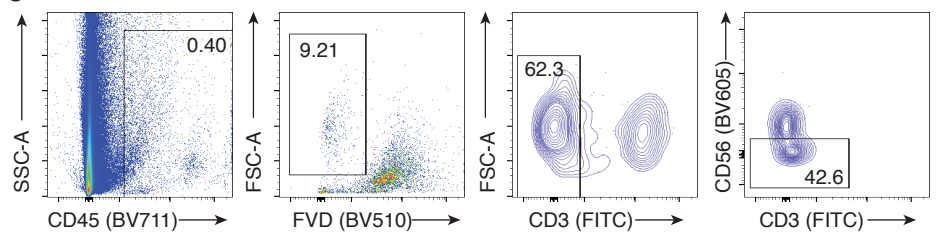

f Gated on CD45+ FVD- CD3- CD56-
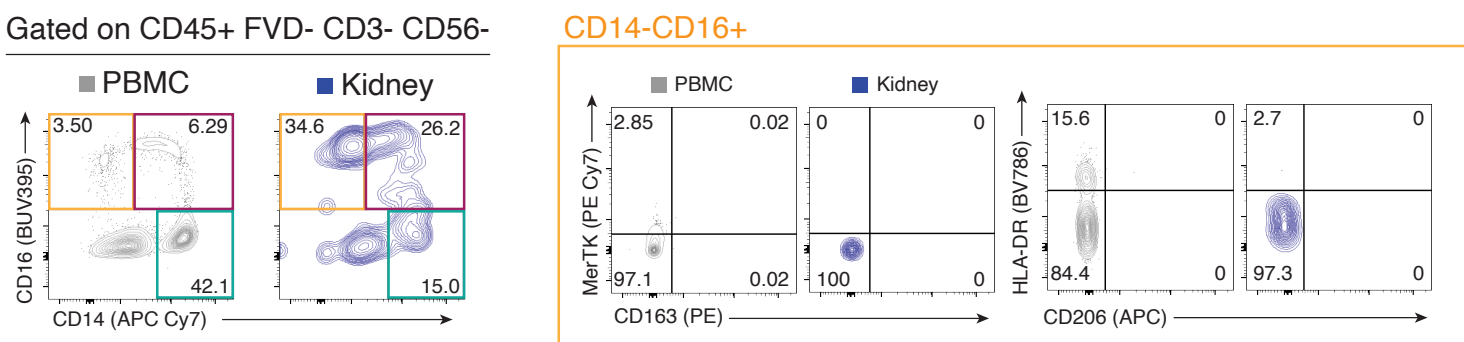

CD14+ CD16-

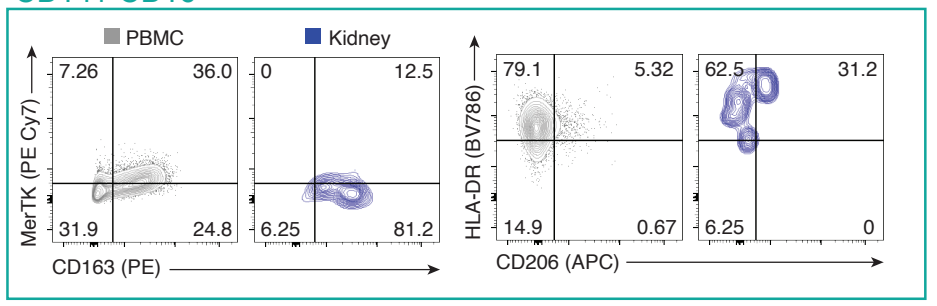

CD14+CD16+

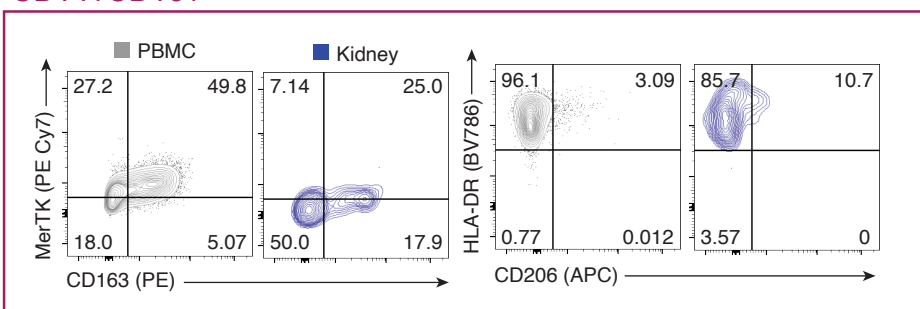

Supplementary Figure 10. Identification of innate lymphoid cell and myeloid populations in healthy human kidney. (a) The majority of NK cells within kidney are CD56dimCD16+, while (b) helper ILCs are present in very low abundance in kidney tissue. (c) Predictive identification of CD56 bright CD16- NK cells, ILC3s, and ILC2s within kidney immune transcriptomic data. (d) High expression of AREG encoding amphiregulin in kidney NK cells. (f) Gating strategy to remove lymphocytes from the population of interest. (f) Relative to blood, kidney tissue is enriched in CD16 myeloid populations, and also allowed for identification of a CD14+ CD206+HLADR+ population likely representing MP1. 


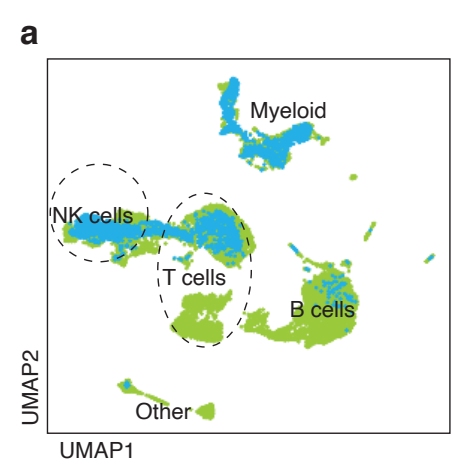

d

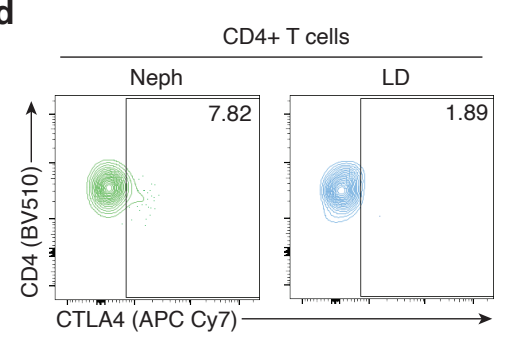

e

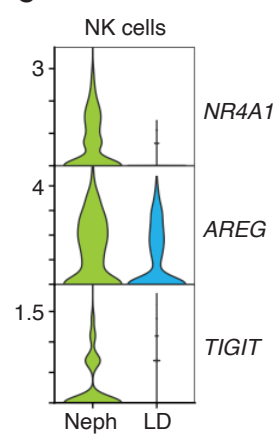

h

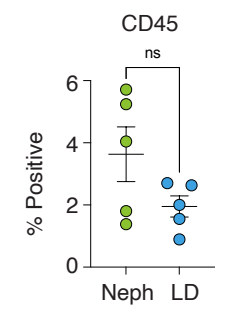

f

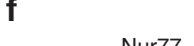

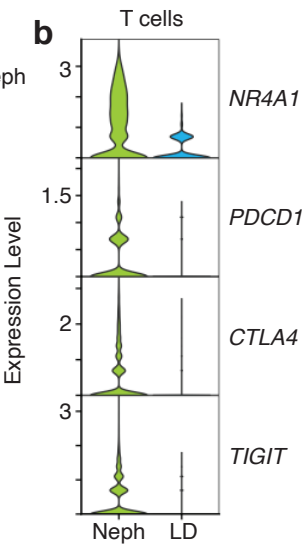

CD8+ $T$ cells

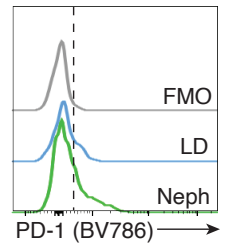

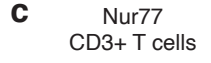
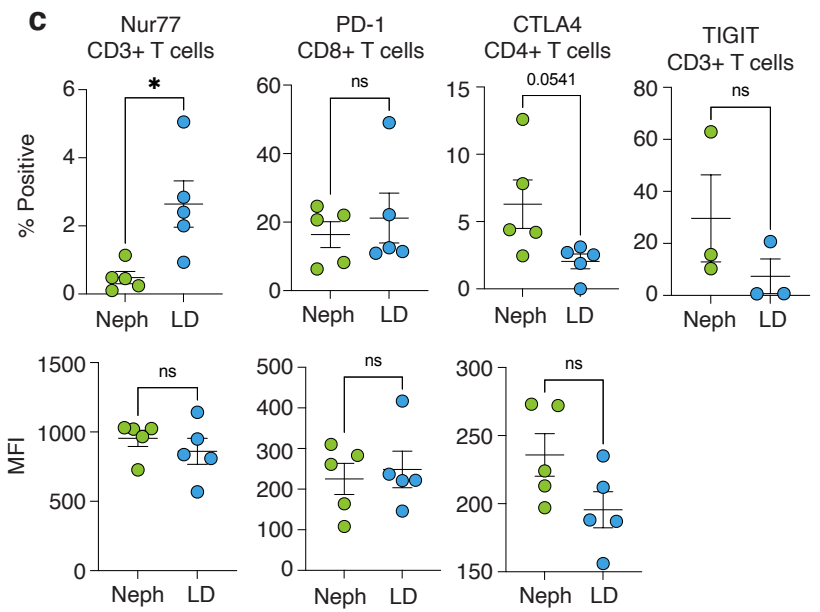

g
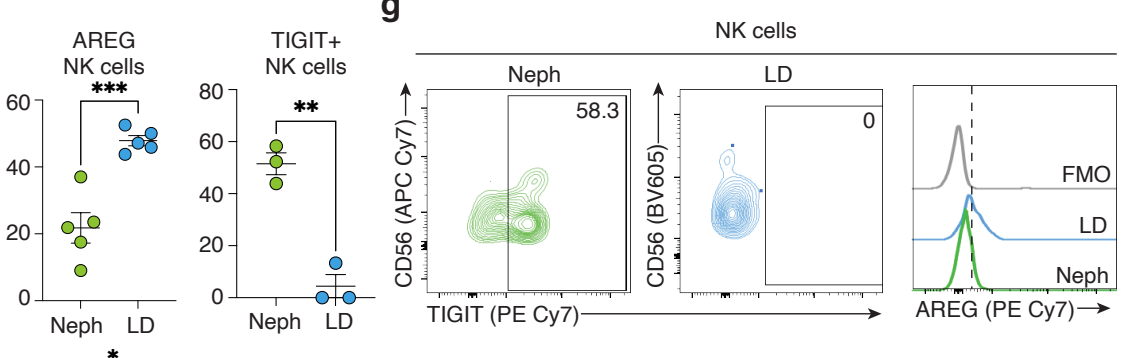

Supplementary Figure 11. Comparison of sequencing data from nephrectomy versus living donor kidney specimens. (a) Integrated UMAP of kidney immune cells highlighting the contributions of cells derived from living donor versus nephrectomy tissue. (b) Within the T cell compartment, the activation marker NR4A1 (encoding Nur77) along with checkpoint molecules PDCD1 (encoding PD-1), CTLA4 and TIGIT were more highly expressed in nephrectomy data. (c), NR4A1 percent positivity $(p=0.0152, t=3.076, d f=8)$ and MFI $(p=0.4206, u=8)$ on $C D 3^{+}$T cells, PD-1 percent positivity $(p=0.6905, u=10)$ and MFI $(p=0.7024 t=0.3961 \mathrm{df}=8)$ on $\mathrm{CD}^{+} \mathrm{T}$ cells, CTLA-4 percent positivity $(\mathrm{p}=0.0541, \mathrm{t}=2.256, \mathrm{df}=8)$ and MFI $(\mathrm{p}=0.0851, \mathrm{t}=1.964, \mathrm{df}=8)$ on CD4+ $T$ cells and TIGIT percent positivity $(p=0.2833, t=1.238, d f=4)$ on CD3+ $T$ cells were compared between living donor and nephrectomy-derived T cells. (d) Representative plots of CTLA-4 on CD4+ T cells and PD-1 on CD8+ T cells of living donor and nephrectomy-derived cells. (e) NK cells exhibited similar trends at the transcript level with higher NR4A1, AREG, and TIGIT gene expression in nephrectomy data. (f) While Nur77 protein was not differentially detected by percent positivity $(p=0.5397, u=9)$ or MFI $(p>0.999, u=12)$, AREG was higher in living donor NK cells by percentage $(p=0.0006, t=5.420, d f=8)$ and MFI $(p=0.0182, t=2.959, d f=8)$, and TIGIT ( $p=0.0015, t=7.728, d f=4)$ was more highly detected on nephrectomy NK cells as shown in representative plots in g. (h) CD45+ cell elevation in nephrectomy samples did not reach significance $(p=0.1129, t=1.780$, $\mathrm{df}=8)$, however, increased immune cell $\left(\mathrm{CD} 45^{+}\right)$abundance was observed in $3 / 5$ nephrectomy samples tested, 
bioRxiv preprint doi: https://doi.org/10.1101/2021.12.09.471943; this version posted December $10,2021$. The copyright holder for this preprint (which was not certified by peer review) is the author/funder, who has granted bioRxiv a license to display the preprint in perpetuity. It is made available under aCC-BY-NC-ND 4.0 International license.

with high donor heterogeneity in immune cell abundance was observed, indicative of greater differences in tissue microenvironment between nephrectomy specimens. Group-to-group differences were assessed using two-tailed unpaired t-test for variables following a normal distribution, and Mann-Whitney tests for variables with a non-parametric distribution. ${ }^{*} p<0.05 ;{ }^{\star *} p<0.01 ;{ }^{* \star *} p<0.001 ;{ }^{* \star \star *} p<0.0001$. Neph= nephrectomy, MFI=Median Fluoresence Intensity.

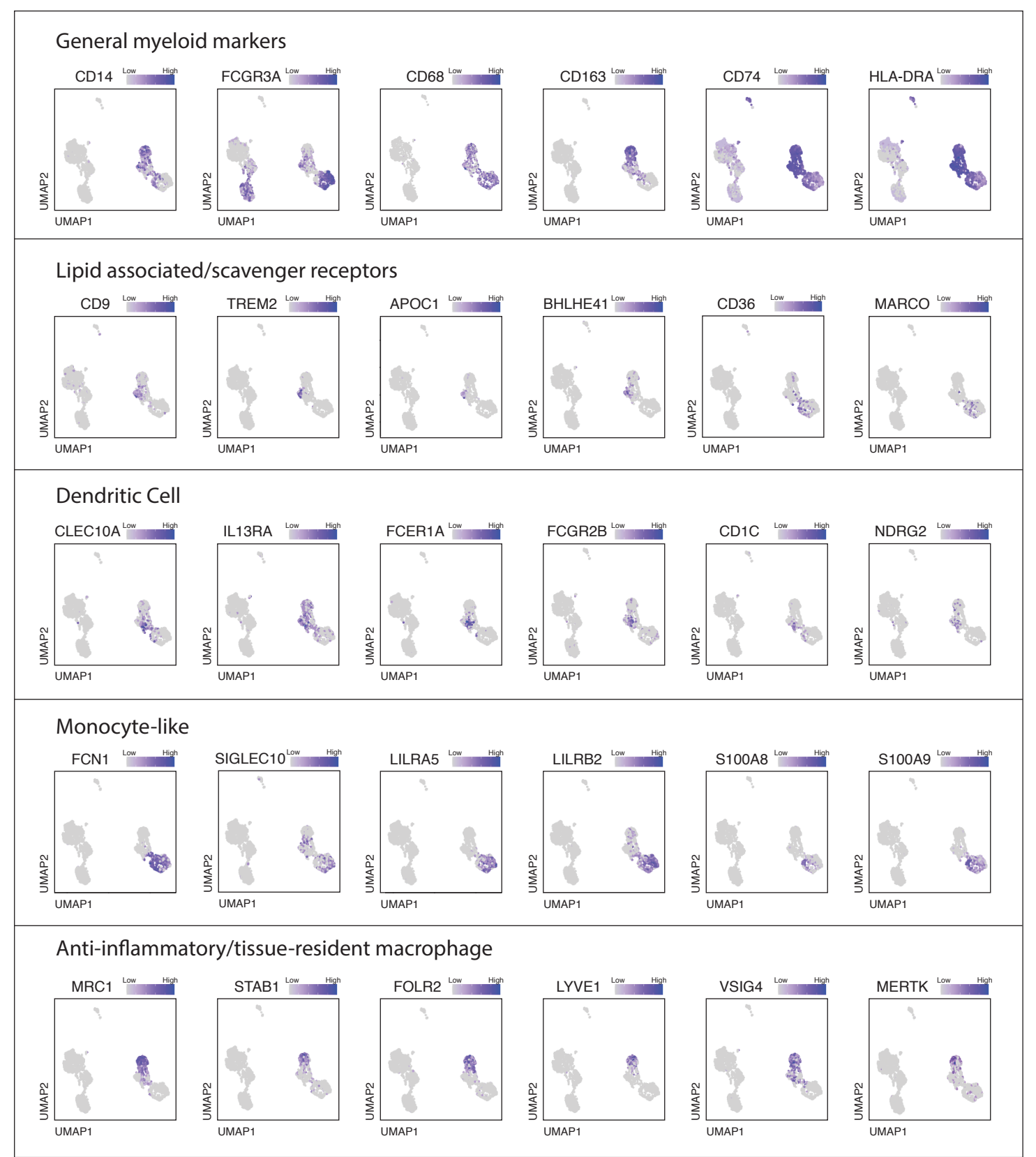

Supplementary Figure 12. Annotation of myeloid populations. Additional feature plots of myeloid cells supporting cell type annotations, highlighting general myeloid lineage markers, expression of scavenger receptors, and markers of dendritic cells, monocytes and macrophages. 
bioRxiv preprint doi: https://doi.org/10.1101/2021.12.09.471943; this version posted December 10, 2021. The copyright holder for this preprint (which was not certified by peer review) is the author/funder, who has granted bioRxiv a license to display the preprint in perpetuity. It is made available under aCC-BY-NC-ND 4.0 International license.

a

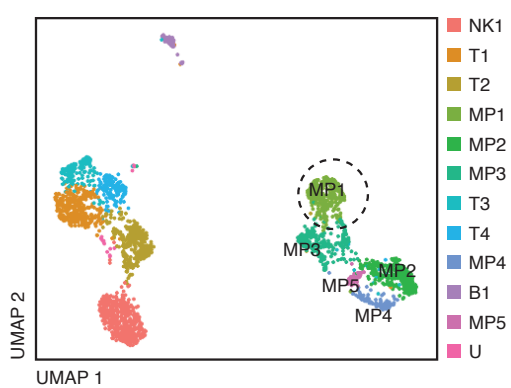

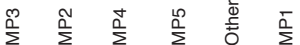

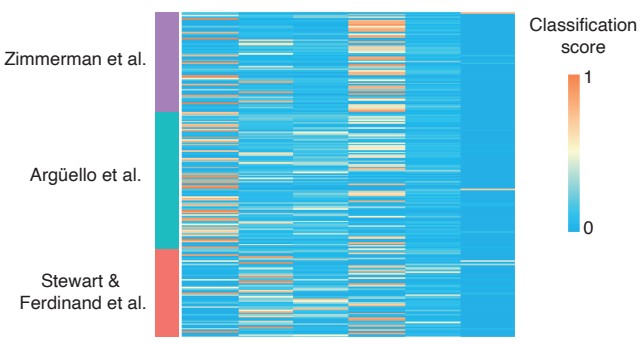

b

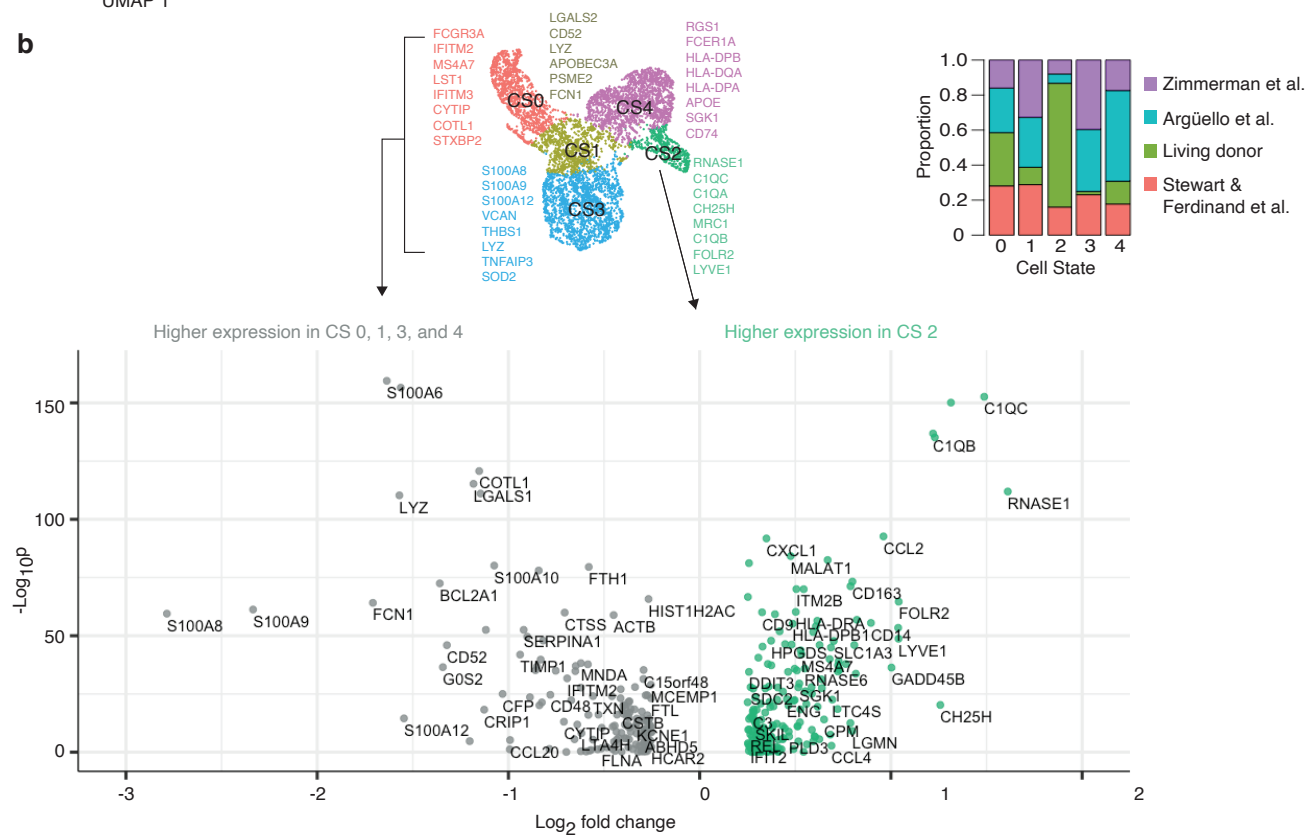

c
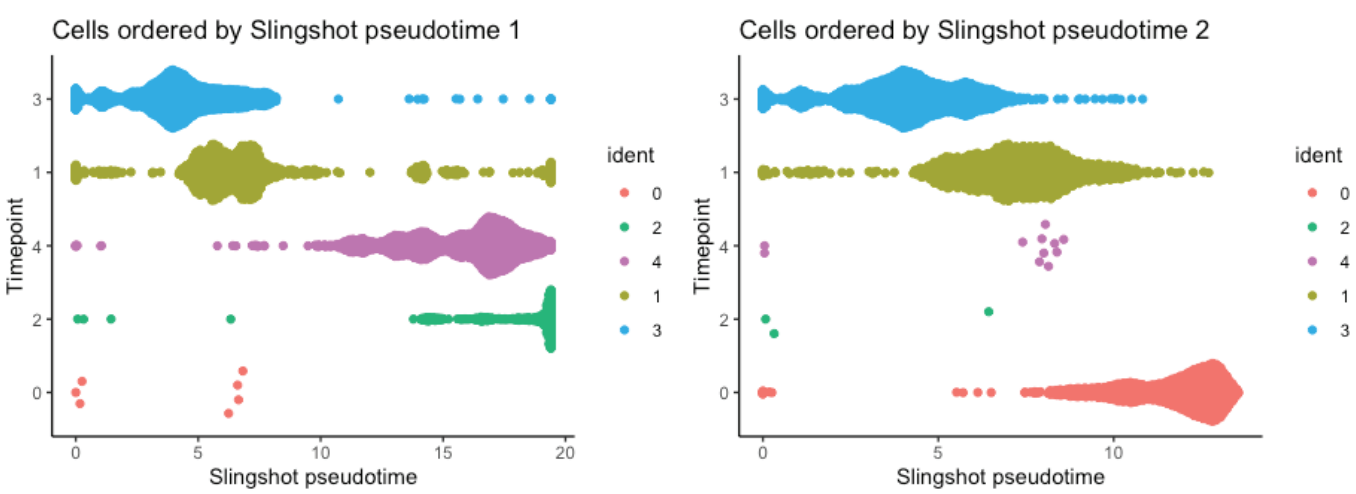

Supplementary Figure 13. Additional supporting plots for macrophage cell state identification. (a) Based on our identification of 5 clusters of myeloid lineage cells in living donor kidney, we used SingleCellNet to classify cells from previously published datasets $3,45,46$ into our 5 cluster framework. Most cells captured in prior studies were classified as MP5 (CD14+ monocytes), the smallest cluster in living donors; while MP1 (circled) the largest cluster in living donor data was scarcely represented in previously published data. (b) Merging the three datasets specified in (a) with our living donor dataset confirmed 5 cell states (CS) where living donor data comprised the majority of CS2. A volcano plot depicts genes enriched in CS2 versus the remaining four cell states, supporting that CS2 represents a resident alternatively-activated tissue macrophage population that is uniquely enriched in living donor kidney tissue. (c)Slingshot pseudotime analysis supporting the annotation of CS1 as a transitional myeloid population across two suggested trajectories which placed CS2 and CSO as the potential trajectory endpoints. 
a

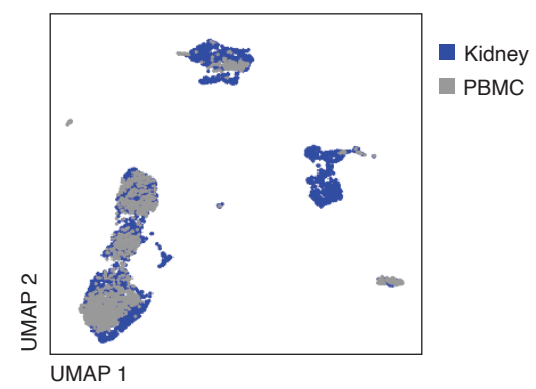

d
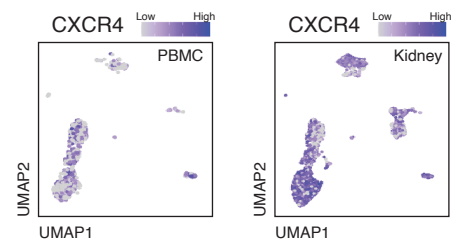

g
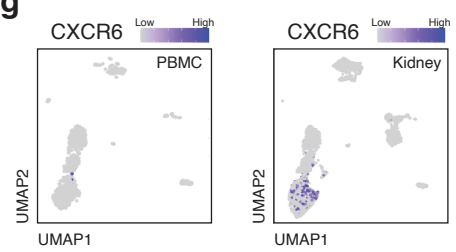

b

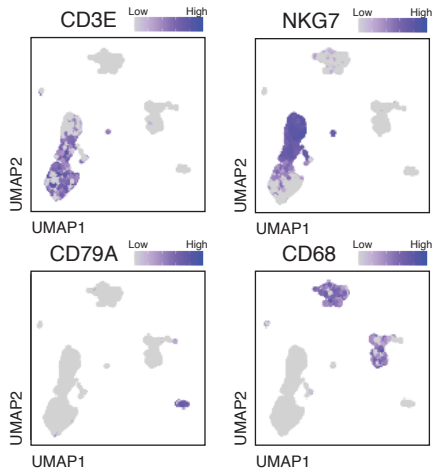

e

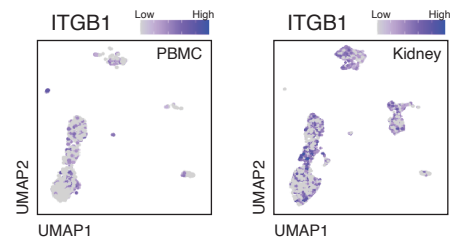

h
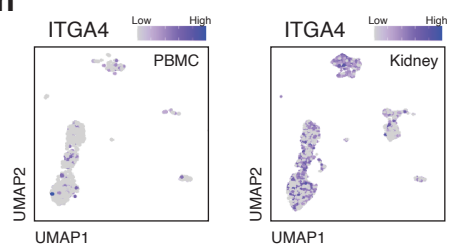

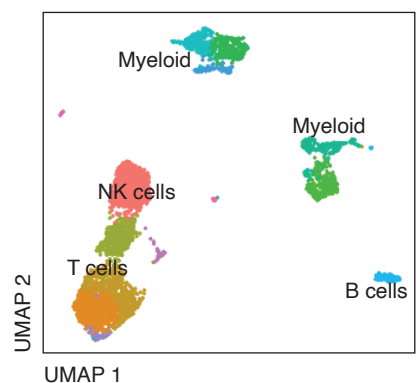

f

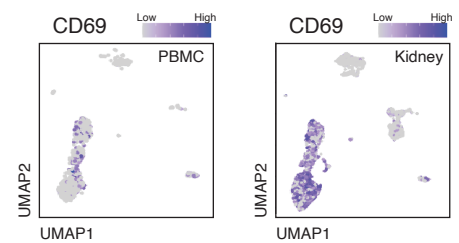

i

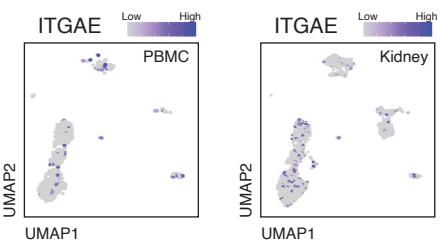

j

Supplementary Figure 14. Integration of PBMCs and kidney immune single-cell data. (a) scRNAseq data
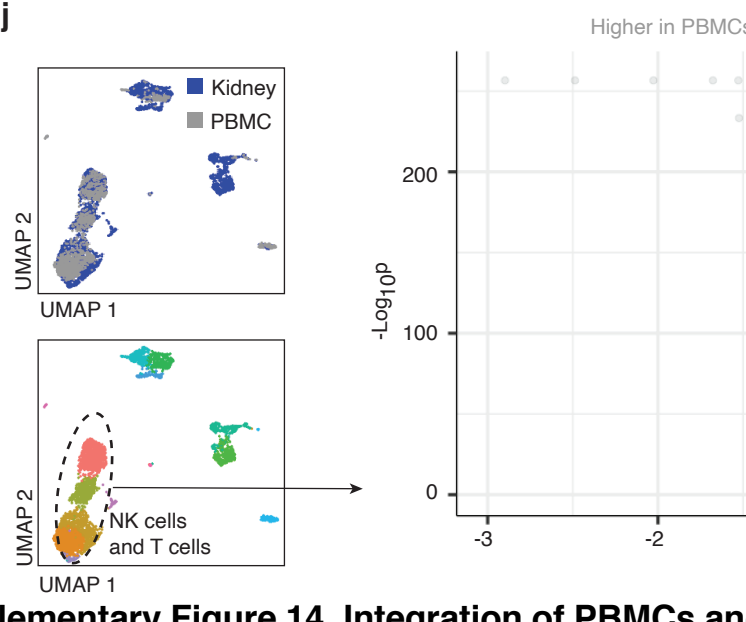

Higher in PBMCs
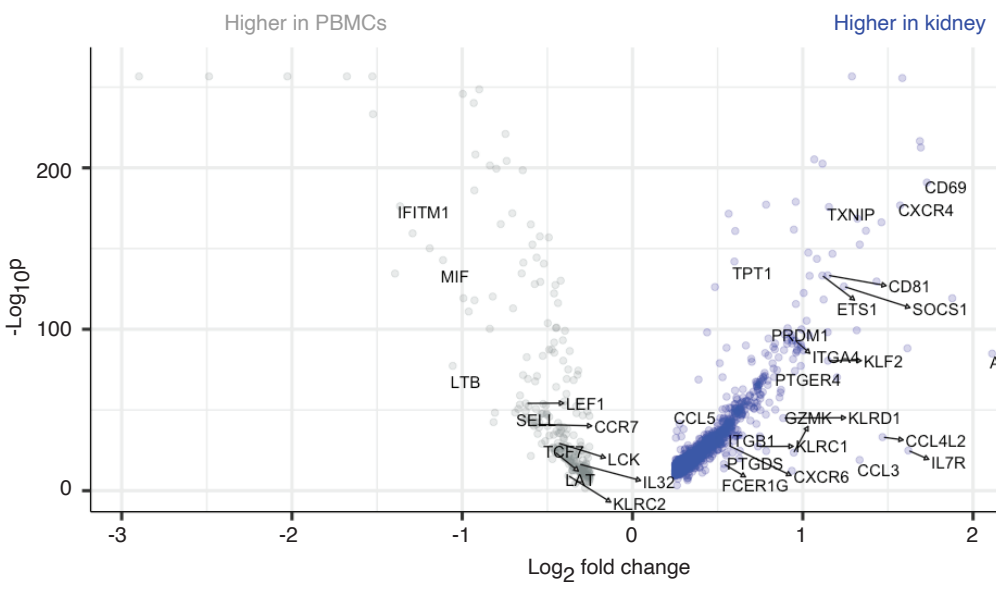

from living donor kidney immune cells and PBMCs ${ }^{48}$ were integrated using Harmony. (b) Feature plots demonstrating expression of CD3E, NKG7, CD79A, and CD68 used to annotate major immune populations in the combined dataset. (c) Annotation of major immune populations including T cells, NK cells, B cells and myeloid cells in the integrated PBMC and kidney immune dataset. Feature plots showing gene expression in PBMCs versus living donor kidney data of marker genes used for validation at the protein level including (d)CXCR4, (e)/TGB1, (f)CD69, (g)CXCR6, (h)/TGA4 and (i) ITGAE. (j) Differential expression analysis of the T cells and NK cell clusters identifies genes which are upregulated in kidney lymphocytes and may represent kidney-adapted gene expression of these cells. 
a

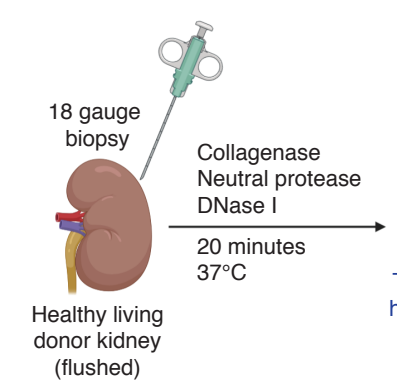

b

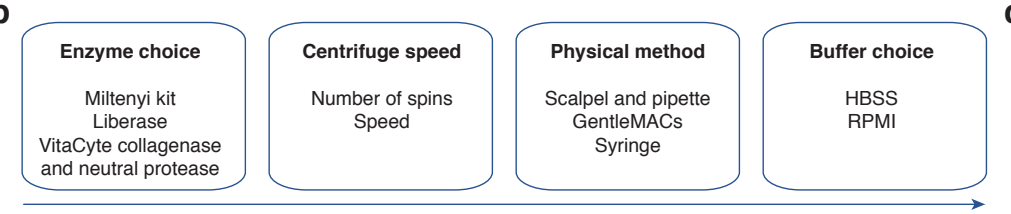

e

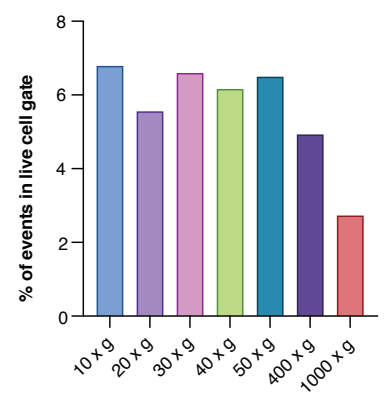

Centrifuge speed

g

g

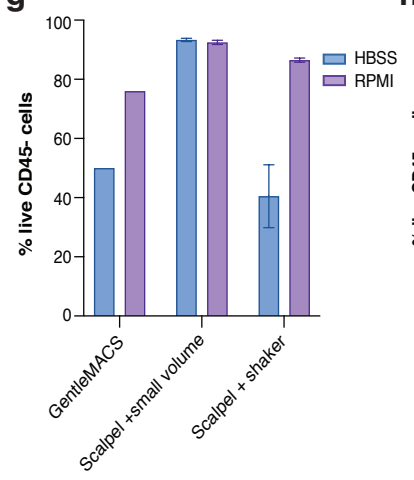

f

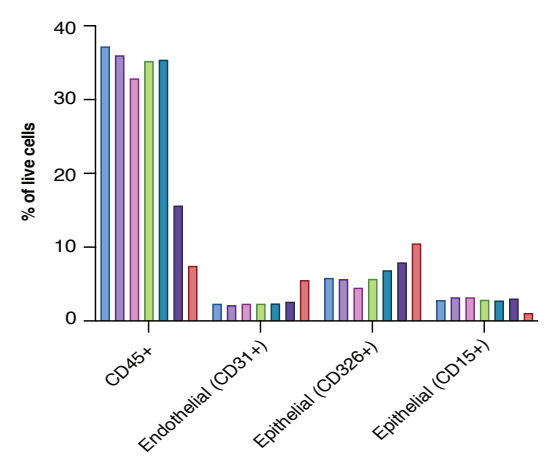

Total kidney

homogenate

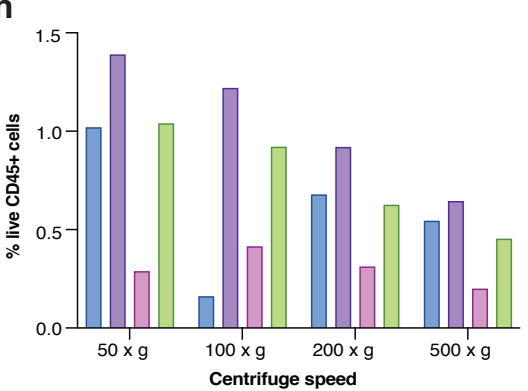

CD45-positive
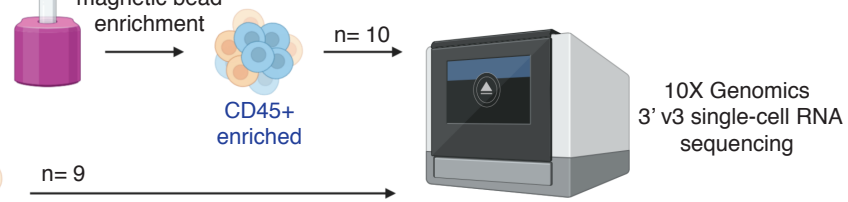

$n=9$

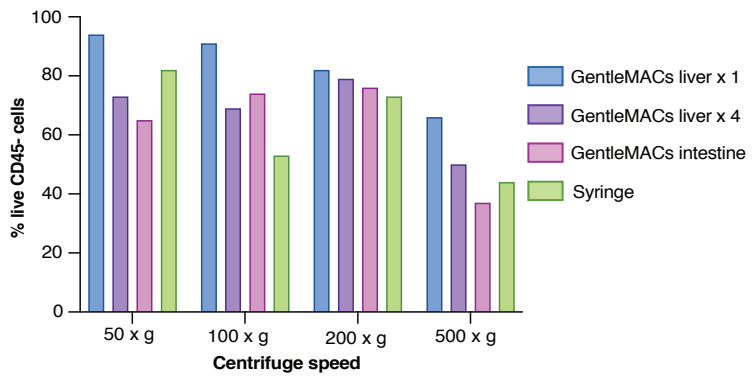

d
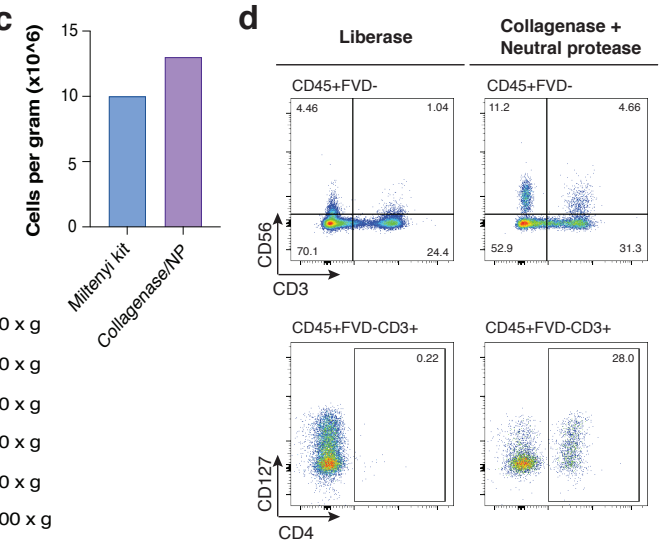

i
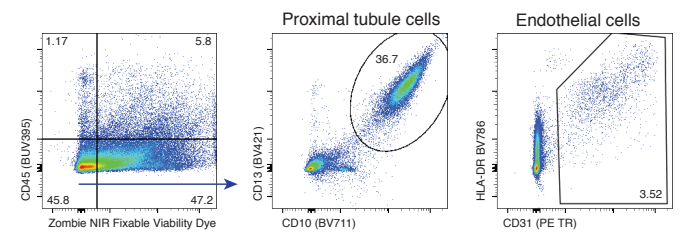

Supplementary Figure 15. Optimization of kidney tissue digestion protocol. (a) Final experimental protocol for generating single-cell RNA sequencing data from living donor kidney. (b) Workflow of options tested in determining the optimal digestion method. (c) Using mouse tissue, a commercial Miltenyi kidney digestion kit was compared to a collagenase and neutral protease mixture to compare yield and viability, with collagenase and neutral protease demonstrating superior yield and comparable viability. (d) Using human nephrectomy tissue, Liberase was compared with collagenase and neutral protease, and flow cytometry was used to determine viability and cell phenotype, where it was determined that collagenase/neutral protease preserved key surface markers that appear to be cleaved by Liberase. (e) Fractions of dissociated human nephrectomy were centrifuged at different speeds to determine cell viability, which was reduced beyond speeds of $400 \mathrm{xg}$. (f) Using markers of key cell populations, by flow cytometry the contribution of different cell populations to each fraction by differential centrifugation determined that cell types were captured proportionally up to speeds of $400 \times \mathrm{g}$. (g) To optimize yield and preservation of parenchymal cell viability, digestion in either HBSS or RPMI medium with collagenase and neutral protease was tested alongside physical methods of dissociation 
including using GentleMACs, a scalpel and a small volume of dissociation medium ( $n=2)$, and a scalpel with incubation with constant agitation in a shaker $(n=2)$. Over all methods, RPMI preserved parenchymal viability better than HBSS, while overall the greatest viability was in using a scalpel and small volume of dissociation medium. (h) Viability of immune $\left(\mathrm{CD}^{+} 5^{+}\right)$and parenchymal (CD45) populations across physical methods and centrifuge speeds to test whether the relative abundance of cell population viability changes with more aggressive physical dissociation, where generally more gentle dissociation preserved parenchymal cell viability whereas more aggressive physical dissociation improved yield of immune cells. Different Gentlemacs ${ }^{\mathrm{TM} T i s s u e}$ dissociator settings named based on organ optimized for were tested (liver, intestine, etc). No clear change in fractionation was observed in differential centrifugation of the samples. $n=1$ unless otherwise specified. (i) Flow cytometric analysis of kidney parenchymal cells, depicting the capture of live proximal tubular epithelial cells $\left(\mathrm{CD} 10^{+} \mathrm{CD} 13^{+}\right)$and endothelial cells $\left(\mathrm{CD}^{2} 1^{+} \mathrm{HLA}^{-} \mathrm{DR}^{+/}\right)$. 
bioRxiv preprint doi: https://doi.org/10.1101/2021.12.09.471943; this version posted December 10, 2021. The copyright holder for this preprint (which was not certified by peer review) is the author/funder, who has granted bioRxiv a license to display the preprint in perpetuity. It is made available under aCC-BY-NC-ND 4.0 International license.

$\lfloor 331$
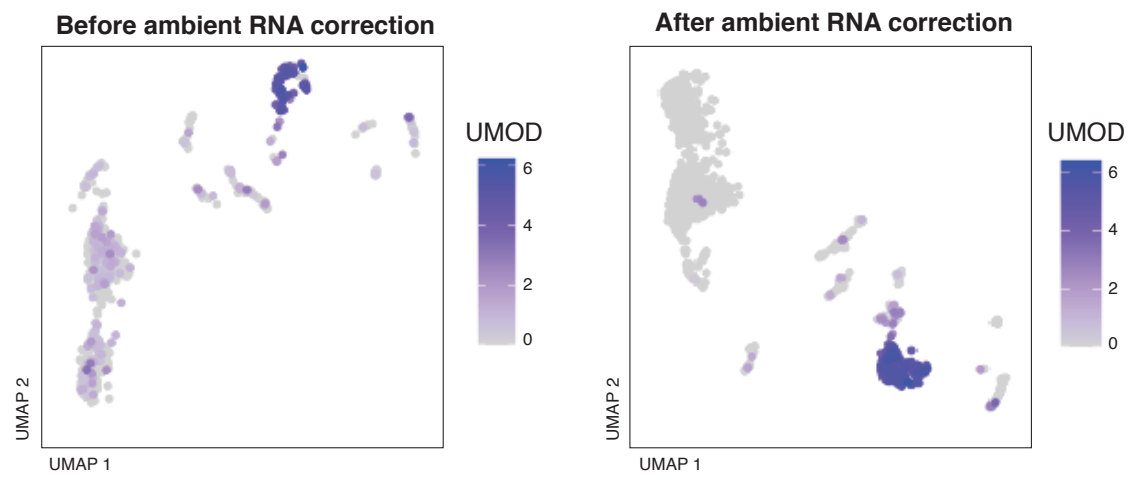

Supplementary Figure 16. Ambient RNA contamination. Feature plots showing the expression of UMOD, a gene specific to cTAL/LOH cells, with widespread low level expression present across all clusters prior to ambient RNA correction and more biologically appropriate expression patterns after ambient RNA correction, demonstrated with a sample dataset (Total9). 